Guilherme Cruz Rossi

\title{
Estudo das Forças de Corte no Processo de Fresamento de Bordas de Chapas Utilizadas para a Fabricação de Tubos de Aço com Costura
}

Dissertação apresentada à Escola Politécnica da Universidade de São Paulo para obtenção do título de Mestre em Engenharia Mecânica 
Guilherme Cruz Rossi

\section{Estudo das Forças de Corte no Processo de Fresamento de Bordas de Chapas Utilizadas para a Fabricação de Tubos de Aço com Costura}

Dissertação apresentada à Escola Politécnica da Universidade de São Paulo para obtenção do título de Mestre em Engenharia Mecânica

Área de Concentração: Engenharia de Projeto de Fabricação

Professor Orientador: Prof. Dr. Gilmar Ferreira Batalha

São Paulo

2008 


\section{FICHA CATALOGRÁFICA}

Rossi, Guilherme Cruz

Estudo das forças de corte no processo de fresamento de bordas de chapas utilizadas para a fabricação de tubos de aço com costura / G.C. Rossi. -- ed.rev. -- São Paulo, 2007.

$129 \mathrm{p}$.

Dissertação (Mestrado) - Escola Politécnica da Universidade de São Paulo. Departamento de Engenharia Mecatrônica e de Sistemas Mecânicos.

1.Fresamento 2.Usinagem 3.Regressão linear múltipla 4.Dinamometria 5.Tubos de aço com costura.Universidade de São Paulo. Escola Politécnica. Departamento de Engenharia Mecatrônica e de Sistemas Mecânicos Il.t. 


\section{AGRADECIMENTOS}

Ao orientador Prof. Dr. Gilmar Batalha Ferreira pelas diretrizes seguras e permanente incentivo.

Ao Prof. Dr. Éd Cláudio Bordinassi pela ajuda imprescindível na realização deste trabalho.

Ao Prof. Dr. Sérgio Delijaicov pelos importantes ensinamentos sobre o assunto e apoio na realização do trabalho.

À TenarisConfab que forneceu o material para a fabricação dos corpos-de-prova além de informações sobre o produto e o processo de fabricação de tubos de aço.

À Sandvik Coromant que forneceu as pastilhas para a realização dos ensaios.

Às equipes das oficinas mecânicas da Poli, da UniFEI e da Mauá que auxiliaram na fabricação do dinamômetro, corpos-de-prova e ensaios.

À minha noiva Lisiane que me apoiou durante todo o período de pesquisa, sempre compreensiva nos momentos de ausência.

Aos meus pais que tornaram tudo isso possível. 


\section{RESUMO}

O propósito deste trabalho é estudar as forças de corte envolvidas no processo de fresamento de bordas de chapas utilizadas para a fabricação de tubos de aço com costura e como estas variam em função dos parâmetros de corte utilizados. O objetivo é correlacionar estas forças à qualidade do acabamento superficial das bordas usinadas, uma vez que esta é fundamental para a qualidade final da solda do tubo. Para isso, foi construído um dinamômetro de mesa para medição das forças, e os dados foram analisados através do Método da Regressão Linear Múltipla. Os resultados obtidos demonstraram que, tanto para a força de corte quanto para a rugosidade da superfície usinada, o parâmetro que mais influencia é o avanço por dente, seguido pela largura de corte, sendo que o que menos influencia é a velocidade de avanço. Estes resultados foram comprovados com êxito no processo industrial foco deste estudo através da medição da corrente elétrica dos motores dos eixos-árvore e da vibração dos mesmos.

Palavras-chave: fresamento, usinagem, regressão linear múltipla, dinamometria, tubos de aço com costura. 


\begin{abstract}
This work aims to study the cutting forces involved in the edge milling process for welded pipes manufacturing and how these forces vary due to the cutting parameters. The objective is to create a relationship between these forces and the surface roughness of the machined edges, once it's fundamental to the pipe weld quality. To do this, it was designed and manufactured a dynamometer, and the data was analyzed statistically by the Linear Multiple Regression Method. The results show that for the cutting forces as well as the surface roughness, the most significant parameter is the feed per tooth, followed by the cutting width and the feed speed. These results were successfully proven on the industrial process that is the focus of this study, through the spindle motors electric current and its vibration.
\end{abstract}

Key-words: milling, machining, linear multiple regression, strain gage, welded pipes. 


\section{SUMÁRIO}

\section{LISTA DE FIGURAS}

\section{LISTA DE TABELAS}

\section{LISTA DE SÍMBOLOS}

1 - INTRODUÇÃO

2 - OBJETIVOS

3 - REVISÃO BIBLIOGRÁFICA

$\begin{array}{lr}3.1-\text { FRESAMENTO } & 18\end{array}$

3.1.1 - Tipos de Fresamento 19

3.1.2 - Movimentos da peça e da ferramenta 21

3.1.3 - Formação de Cavaco $\quad 22$

3.1.4 - Principais falhas e desgaste da ferramenta de corte 24

$\begin{array}{ll}3.2 \text { - MECÂNICA DO PROCESSO DE FRESAMENTO } & 27\end{array}$

3.3 - RUGOSIDADE

3.3.1 - Definições de alguns parâmetros de rugosidade 33

3.3.2 - Rugosidade no Processo de Fresamento 36

3.4 - EXTENSOMMETROS (STRAin GAGES) 38

3.4.1 - Princípios da extensometria elétrica 39

3.4.2 - Análise da resistência do condutor 41

3.4.3 - Características dos extensômetros elétricos 44

3.5 - INSTRUMENTAÇÃO

3.5.1 - Desempenho estático e dinâmico de instrumentos 48

$\begin{array}{ll}3.6-\text { DINAMOMETRIA } & 51\end{array}$

3.7 - MÉTodo da REgRESSÃo LinEAR MÚltipla

4 - PROJETO DO DINAMÔMETRO

5 - CONSTRUÇÃO DO DINAMÔMETRO

5.1 - ANÁLISE PRÉVIA $\quad 64$

$\begin{array}{ll}5.2 \text { - PREPARAÇÃO DAS SUPERFÍCIES } & 65 \\ 5.3 \text { - MARCAÇÃO DAS LINHAS DE ORIENTAÇÃO } & 65\end{array}$

$\begin{array}{ll}5.3 \text { - MARCAÇÃO DAS LiNHAS DE ORIENTAÇÃOO } & 65\end{array}$

$\begin{array}{ll}5.4 \text { - COLAGEM } & 66\end{array}$

$\begin{array}{ll}5.5 \text { - IDA AO FORNO } & 67\end{array}$

6 - CALIBRAÇÃO DO DINAMÔMETRO $\quad 68$

7 - ESTUDO DE CASO $\quad \mathbf{8 0}$

$\begin{array}{lr}7.1 \text { - DELINEAMENTO EXPERIMENTAL } & 81\end{array}$

$\begin{array}{lr}7.2 \text { - CORPOS-DE-PROVA E FERRAMENTAS } & 82\end{array}$

$\begin{array}{ll}7.3 \text { - ENSAIOS } & 84\end{array}$ 
7.4 - ANÁLISE DOS DADOS

7.5 - DisCUSSÃO DOS RESULTADOS

7.6 - APLICAÇÃo PRÁTICA DOS RESULTADOS

8 - CONCLUSÕES

9 - SUGESTÕES PARA TRABALHOS FUTUROS

10 - REFERÊNCIAS BIBLIOGRÁFICAS

11 - ANEXOS

Anexo 1 - Memorial de CÁlculo Células de CARGa 


\section{LISTA DE FIGURAS}

Figura 3.1.2.1 - Movimento de corte - Adaptado de (Araújo e Silveira, 2001) .......................................21

Figura 3.2.1 - Geometria do Processo de Fresamento - adaptado de (Altintas, 2000)............................ 29

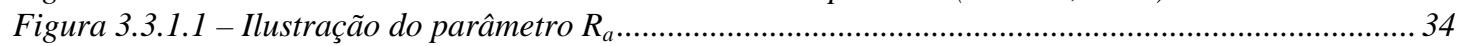

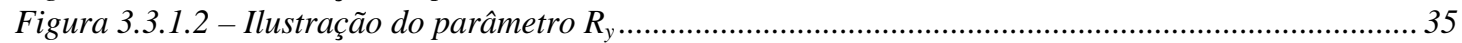

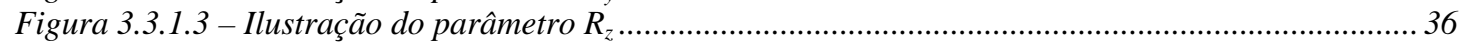

Figura 3.4.1.1 - Deformação específica................................................................................................... 40

Figura 3.4.3.1 - Formas dos Strain Gages: Uniaxial (a); Bi-axial (b); Tri-axial (c) - Adaptado de (Dally,

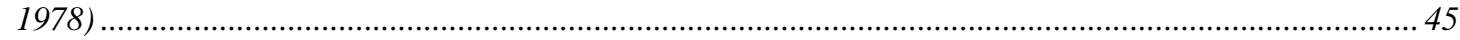

Figura 3.5.1 - Configuração de um instrumento................................................................................. 46

Figura 3.5.2 - Esquema de um medidor eletrônico de deformação .......................................................... 48

Figura 3.7.1 - Modelagem dos Experimentos.......................................................................................... 54

Figura 4.1 - (a) Anel para medição de forças; (b) Elemento anel para análise elástica - adaptado de

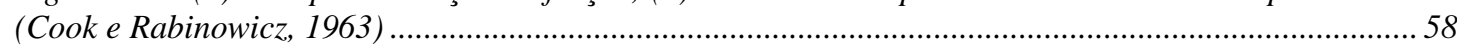

Figura 4.2 - Esquema de Montagem das Células de Carga no Dinamômetro............................................. 61

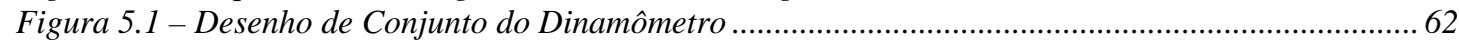

Figura 5.1.1 - Superfícies Selecionadas para a Primeira Etapa ............................................................ 64

Figura 5.1.2 - Superfícies Selecionadas para Primeira Etapa .................................................................6 64

Figura 5.2.1 - Conjunto de Células de Carga com Superfícies Preparadas............................................. 65

Figura 5.5.1 - Célula de Carga Pronta para Ir ao Forno.........................................................................6 67

Figura 6.1 - Posição de aplicação das cargas de calibração ....................................................................6 68

Figura 6.2 - Curvas de Calibração para Carregamento A1 ................................................................ 71

Figura 6.3 - Curvas de Calibração para Carregamento A2 ................................................................... 71

Figura 6.4 - Curvas de Calibração para Carregamento A3 ...................................................................... 72

Figura 6.5 - Curvas de Calibração para Carregamento A4 .................................................................... 72

Figura 6.6 - Curvas de Calibração para Carregamento L1 ................................................................... 75

Figura 6.7 - Curvas de Calibração para Carregamento L2.................................................................. 75

Figura 6.8 - Curvas de Calibração para Carregamento L3................................................................. 76

Figura 6.9 - Curvas de Calibração para Carregamento L4................................................................... 76

Figura 6.10 - Curvas de Calibração para Carregamento L5................................................................. 77

Figura 6.11 - Curvas de Calibração para Carregamento L6........................................................................ 77

Figura 6.12 - Curvas de Calibração para Carregamento Axial .............................................................. 78

Figura 6.13 - Curvas de Calibração para Carregamento Laterial $(Y)$.................................................... 78

Figura 6.14 - Curvas de Calibração para Carregamento Laterial $(X)$.................................................... 79

Figura 7.1.1 - Diagrama das Variáveis de Entrada e Saída do Processo de Fresamento......................... 81

Figura 7.2.1 - Porta-ferramentas e pastilhas ..................................................................................... 83

Figura 7.2.2 - Matéria-prima dos corpos-de-prova - Aço API 5L X80 .................................................. 83

Figura 7.3.1 - Forças de Corte Ensaio v $v_{f}$ Replicação 1 .............................................................................. 85

Figura 7.3.2 - Espectro de freqüências ensaio vf Replicação 1 ................................................................. 85

Figura 7.3.3 - Forças de Corte Ensaio vf Replicação 2 ....................................................................... 86

Figura 7.3.4 - Espectro de freqüências ensaio vf Replicação 2 .................................................................8 86

Figura 7.3.5 - Forças de Corte Ensaio ae.vf Replicação 1 ................................................................. 87

Figura 7.3.6 - Espectro de freqüências ensaio ae.vf Replicação 1 ..........................................................87

Figura 7.3.7 - Forças de Corte Ensaio ae.vf Replicação 2 ..................................................................... 88

Figura 7.3.8 - Espectro de freqüências ensaio ae.vf Replicação 2 ......................................................... 88

Figura 7.3.9 - Forças de Corte Ensaio fz.vf Replicação1 ....................................................................... 89

Figura 7.3.10 - Espectro de freqüências ensaio fz.vf Replicação 1 .......................................................... 89

Figura 7.3.11 - Forças de Corte Ensaio fz.vf Replicação 2 .................................................................... 90

Figura 7.3.12 - Espectro de freqüências ensaio fz.vf Replicação 2 ........................................................... 90

Figura 7.3.13 - Forças de Corte Ensaio fz.ae.vf Replicação 1.............................................................. 91

Figura 7.3.14 - Espectro de freqüências ensaio fz.ae.vf Replicação 1....................................................... 91

Figura 7.3.15 - Forças de Corte Ensaio fz.ae.vf Replicação 2................................................................ 92 
Figura 7.3.16 - Espectro de freqüências ensaio fz.ae.vf Replicação 2................................................... 92

Figura 7.3.17 - Forças de Corte Ensaio (1) Replicação 1 ...................................................................... 93

Figura 7.3.18 - Espectro de freqüências ensaio (1) Replicação 1 ........................................................... 93

Figura 7.3.19 - Forças de Corte Ensaio (1) Replicação 2 ....................................................................... 94

Figura 7.3.20 - Espectro de freqüências ensaio (1) Replicação 2 ........................................................... 94

Figura 7.3.21 - Forças de Corte Ensaio ae Replicação 1 ....................................................................... 95

Figura 7.3.22 - Espectro de freqüências ensaio ae Replicação 1 ................................................................. 95

Figura 7.3.23 - Forças de Corte Ensaio ae Replicação 2 .................................................................... 96

Figura 7.3.24 - Espectro de freqüências ensaio ae Replicação 2 ............................................................ 96

Figura 7.3.25 - Forças de Corte Ensaio fz Replicação 1 ...................................................................... 97

Figura 7.3.26 - Espectro de freqüências ensaio fz Replicação 1 ........................................................... 97

Figura 7.3.27 - Forças de Corte Ensaio fz Replicação 2 ....................................................................... 98

Figura 7.3.28 - Espectro de freqüências ensaio fz Replicação 2 ........................................................... 98

Figura 7.3.29 - Forças de Corte Ensaio fz.ae Replicação 1 ...................................................................... 99

Figura 7.3.30 - Espectro de freqüências ensaio fz.ae Replicação 1 ......................................................... 99

Figura 7.3.31 - Forças de Corte Ensaio fz.ae Replicação 2 ............................................................. 100

Figura 7.3.32 - Espectro de freqüências ensaio fz.ae Replicação 2 ........................................................ 100

Figura 7.3.33 - Detalhe de 2 rotações da ferramenta no Ensaio $f_{z}$ Replicação 1 ................................... 101

Figura 7.4.1 - Efeito dos Parâmetros sobre a Força de Corte .................................................................. 103

Figura 7.4.2 - Efeito dos Parâmetros sobre a rugosidade $\left(R_{a}\right)$......................................................... 104

Figura 7.4.3 - Efeito dos Parâmetros sobre a rugosidade $\left(R_{y}\right)$.......................................................... 104

Figura 7.4.4 - ANOVA da Força $x$ avanço por dente ............................................................................. 105

Figura 7.4.5 - Plotagem dos pontos de Força x avanço por dente.......................................................... 105

Figura 7.4.6 - ANOVA da Força x largura de corte .............................................................................. 106

Figura 7.4.7 - Plotagem dos pontos de Força x largura de corte .......................................................... 106

Figura 7.4.8 - ANOVA da Força x velocidade de avanço ................................................................... 107

Figura 7.4.9 - Plotagem dos pontos de Força x velocidade de avanço.................................................. 107

Figura 7.4.10 - ANOVA de Ra x avanço por dente ............................................................................... 108

Figura 7.4.11 - Plotagem dos pontos de Ra x avanço por dente .......................................................... 108

Figura 7.4.12 - ANOVA de Ra x largura de corte .............................................................................. 109

Figura 7.4.13 - Plotagem dos pontos de Ra x largura de corte ............................................................. 109

Figura 7.4.14 - ANOVA de Ra x velocidade de avanço.......................................................................... 110

Figura 7.4.15 - Plotagem dos pontos de Ra $x$ velocidade de avanço ..................................................... 110

Figura 7.4.16 - ANOVA de Ry x avanço por dente.............................................................................. 111

Figura 7.4.17 - Plotagem dos pontos de Ry x avanço por dente ............................................................ 111

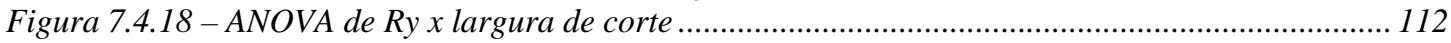

Figura 7.4.19 - Plotagem dos pontos de Ry x largura de corte ............................................................... 112

Figura 7.4.20 - ANOVA de Ry x velocidade de avanço ....................................................................... 113

Figura 7.4.5 - Plotagem dos pontos de Ry x velocidade de avanço ..................................................... 113

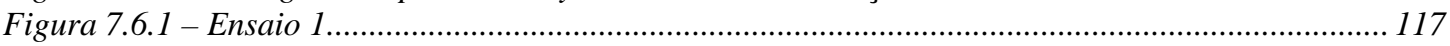

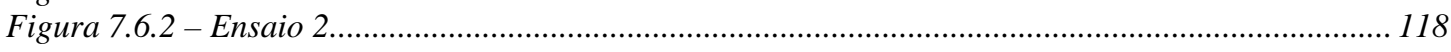

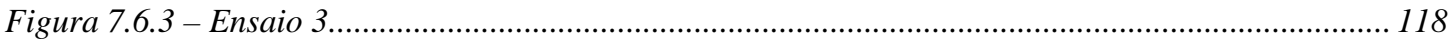

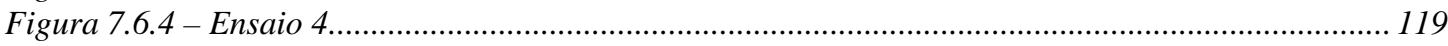

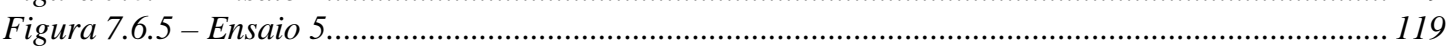

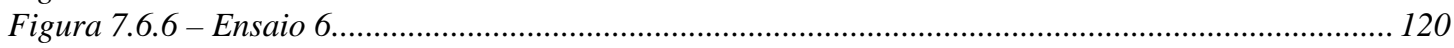

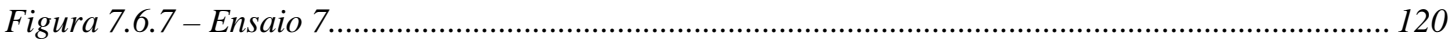

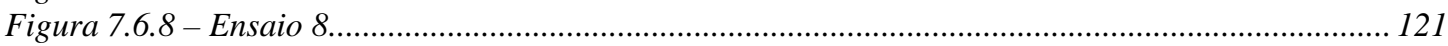

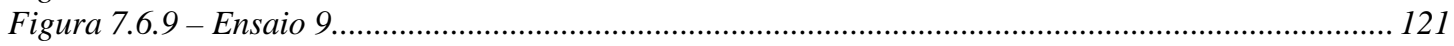

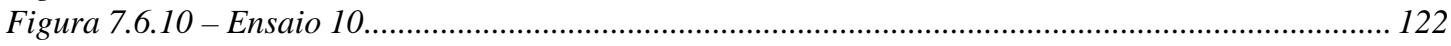

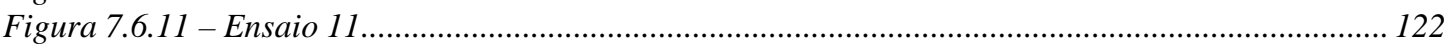

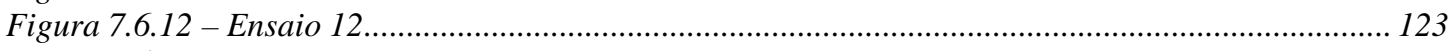

Figura 7.6.13 - Resultados da Análise de Vibração............................................................................. 123

Figura 11.1.1 - Esquema Célula de Carga ....................................................................................... 131 
Figura 11.1.2 - Ligação em Ponte... 


\section{LISTA DE TABELAS}

Tabela 3.1.1 - Comparação entre tipos de fresamento.............................................................................2 21

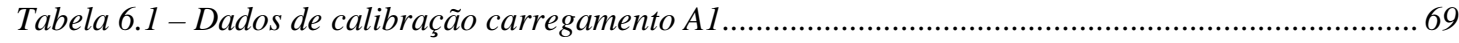

Tabela 6.2 - Dados de calibração carregamento A2 ...................................................................................6 69

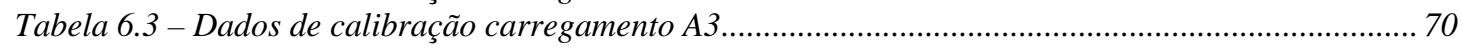

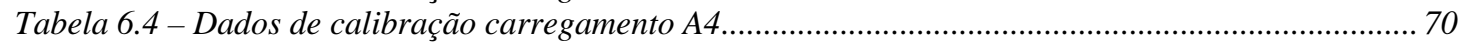

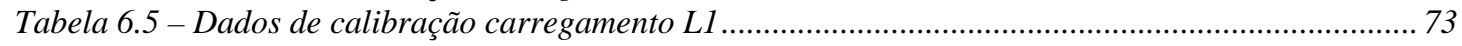

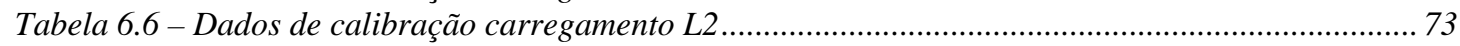

Tabela 6.7 - Dados de calibração carregamento L3 ............................................................................. 73

Tabela 6.8 - Dados de calibração carregamento L4 ............................................................................ 74

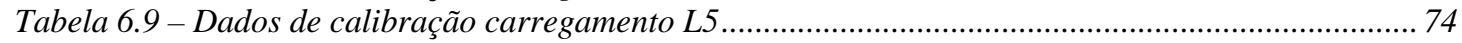

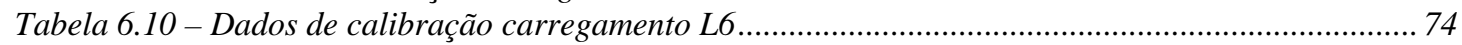

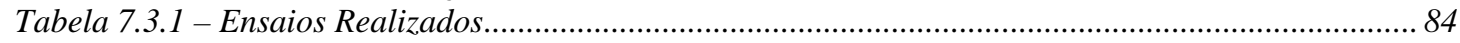

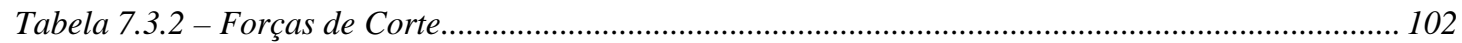

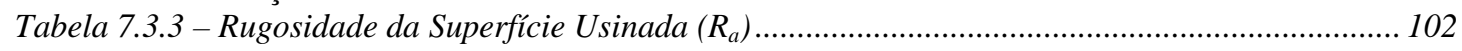

Tabela 7.3.4 - Rugosidade da Superfície Usinada $\left(R_{y}\right)$..................................................................... 102

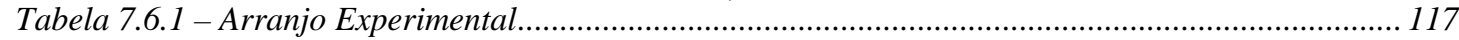

Tabela 7.6.2 - Resultados dos ensaios de comprovação ........................................................................... 124

Tabela 7.6.3 - \% Carga dos Motores dos Cabeçotes .............................................................................. 124

Tabela 7.6.4 - Vibração dos Cabeçotes..................................................................................................... 124

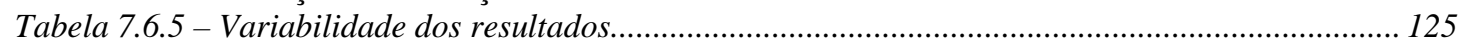




\section{LISTA DE SÍMBOLOS}

$\mathrm{v}_{\mathrm{c}}$ : Velocidade de Corte.................................................................... $[\mathrm{m} / \mathrm{min}]$

$\mathrm{V}_{\mathrm{f}}$ : Velocidade de Avanço.............................................................. $[\mathrm{mm} / \mathrm{min}]$

$\mathrm{v}_{\mathrm{e}}$ : Velocidade Efetiva de Corte........................................................ $[\mathrm{m} / \mathrm{min}]$

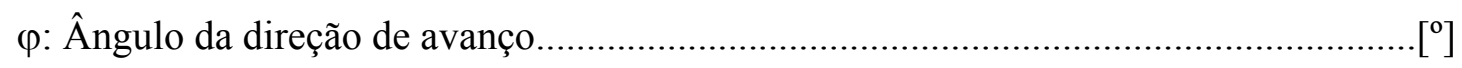

$\eta$ : Ângulo da direção efetiva de corte.......................................................................... $\left.{ }^{0}\right]$

$\Phi:$ Ângulo da parte infinitesimal da ferramenta......................................................... $\left[^{\circ}\right]$

$\mathrm{K}$ : Vetor Força específica de corte......................................................... $\left[\mathrm{N} / \mathrm{mm}^{2}\right]$

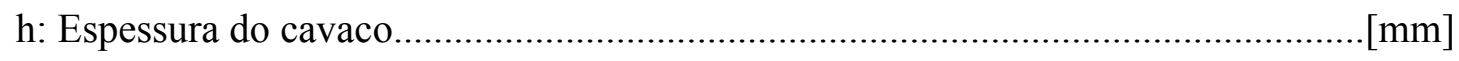

d: Diâmetro da ferramenta..............................................................................mm

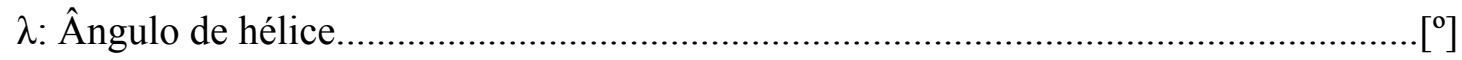

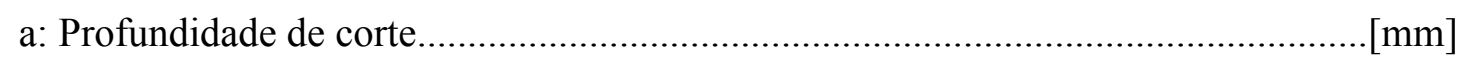

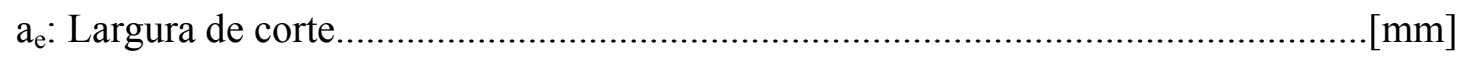

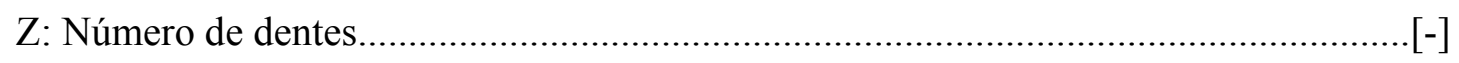

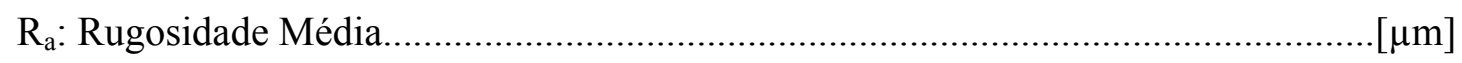

$\mathrm{R}_{\mathrm{y}}$ : Rugosidade medida entre picos e vales................................................. $[\mu \mathrm{m}]$

$\mathrm{f}_{\mathrm{z}}$ : Avanço por dente................................................................

n: Número de replicações..........................................................................................

$\mathrm{F}_{\mathrm{x}}$ : Força de corte na direção perpendicular ao avanço............................................ [N]

$\mathrm{F}_{\mathrm{y}}$ : Força de corte na direção do avanço............................................................... $[\mathrm{N}]$

$\mathrm{F}_{\mathrm{z}}$ : Força de Corte na direção axial da ferramenta.................................................... [N]

$\mathrm{V}_{\mathrm{cmxp}}$ : Velocidade de Máxima Produção........................................................ $[\mathrm{m} / \mathrm{min}]$

$\mathrm{t}_{\mathrm{t}}$ : Tempo Total de Confecção.....................................................................................

$\mathrm{t}_{\mathrm{ft}}$ : Tempo de Troca de Ferramental.....................................................................min] 


\section{1 - INTRODUÇÃO}

Atualmente, a qualidade dos produtos é uma das características mais importantes a se levar em conta nos processos de fabricação. Neste sentido, tanto para projetar estes produtos quanto as máquinas-ferramenta que irão produzi-los, é muito importante conhecer a magnitude das forças envolvidas no processo.

Além disso, é importante conhecer as correlações existentes entre estas forças de corte e os parâmetros de corte, tais como a velocidade de corte, a profundidade de corte e o avanço, para que estes possam ser selecionados da melhor maneira possível para cada tipo de operação. Outra variável de saída destas operações é o acabamento superficial, o qual define muitas vezes a qualidade final da peças usinadas, e a necessidade ou não de operações subseqüentes. Muitas vezes o acabamento superficial também é fator limitante tecnologicamente para um processo, como é o caso do processo que será analisado neste trabalho.

Para se realizar a monitoração da força de corte nos processos de usinagem, existem diversos métodos, sendo que alguns deles estão descritos abaixo:

- Emissão Acústica

- Potência elétrica consumida

- Extensômetros (resistivos, piezo-resistivos, piezoelétricos, etc)

Neste contexto, a redução do tempo de ciclo de um equipamento é importante à medida que proporciona um aumento na produtividade do mesmo. Porém, este aumento de produtividade não pode ser realizado comprometendo os custos ou a qualidade do processo. Assim, sempre que se deseja aumentar a produtividade de um equipamento, deve-se realizar um estudo para identificação dos parâmetros que menos influenciam no custo e na qualidade. 


\section{2 - OBJETIVOS}

Este trabalho tem como objetivo a construção de um dinamômetro de mesa para a medição dos esforços de usinagem numa operação de fresamento. Este dinamômetro tem seu funcionamento baseado em células de carga montadas com sensores do tipo "Strain Gages" (extensômetros), o que torna possível medir os esforços de corte em 3 direções ortogonais (Cook e Rabinowicz, 1963).

De posse do dinamômetro projetado e construído, serão feitos estudos para correlacionar as forças de corte, os parâmetros de corte e a rugosidade da superfície usinada, através de técnicas de Regressão Linear Múltipla. Esta técnica será utilizada devido à sua fácil aplicação. Para tanto, os dados contidos no intervalo de análise devem ser contínuos e monotônicos. A força de corte será analisada em termos da força resultante de corte, enquanto a rugosidade da superfície usinada será analisada em termos de acabamento superficial da peça.

Os dados serão analisados com o objetivo de otimizar o tempo de ciclo de uma fresadora de bordas de chapas utilizadas para a fabricação de tubos de aço com costura da TenarisConfab, em Pindamonhangaba, São Paulo.

Segundo (Diniz, 2006), para se obter a maior produtividade num processo de corte, deve-se utilizar a velocidade de corte de máxima produção $\left(\mathrm{v}_{\mathrm{cmxp}}\right)$, na qual o tempo total de confecção de uma peça $\left(\mathrm{t}_{\mathrm{t}}\right)$ é mínimo. Porém, segundo o mesmo, esta velocidade é dependente da velocidade de troca de ferramental $\left(t_{\mathrm{ft}}\right)$, assim, é importante não deixarmos de nos preocupar com a vida da ferramenta, pois a mesma influencia não somente os custos de produção, mas também a produtividade em si.

Desta forma, o processo de corte será analisado para que sejam identificadas as variáveis que, quando alteradas para ganho de produtividade, aumentem menos as forças de corte, e que indiretamente estarão impactando menos a vida da ferramenta. 
As variáveis analisadas serão a velocidade de avanço $\left(\mathrm{v}_{\mathrm{f}}\right)$, que está diretamente ligada à produtividade do processo, o avanço por dente $\left(\mathrm{f}_{\mathrm{z}}\right)$, que está diretamente ligado à capacidade do equipamento, e a largura de corte $\left(\mathrm{a}_{\mathrm{e}}\right)$, que está diretamente ligada ao produto.

Além de servir como ferramenta para os estudos da força de corte num processo de fresamento, o dinamômetro será utilizado também nas aulas de graduação da Escola Politécnica da USP, que não possui nenhum equipamento semelhante.

O projeto se divide nas seguintes etapas:

\section{Construção do Dinamômetro:}

- Pesquisa bibliográfica para aquisição dos conhecimentos necessários para o desenvolvimento do dinamômetro.

- Projeto do Dinamômetro.

- Construção do dinamômetro.

- Levantamento das Curvas de Calibração do dinamômetro.

\section{Estudo de Caso (TenarisConfab):}

- Delineamento Experimental.

- Realização de ensaios para estudo das forças de corte no processo de fresamento de bordas de chapas utilizadas para fabricação de tubos de aço com costura.

- Análise estatística dos dados de força e acabamento superficial obtidos.

- Resultados e conclusões.

A organização deste trabalho foi elaborada na forma dos seguintes capítulos:

No capítulo 1, procurou-se expor a motivação deste trabalho, do ponto de vista do ganho de produtividade nos processos de usinagem, além de algumas técnicas para a monitoração das variáveis envolvidas neste processo. 
No capítulo 2, foram apresentados os objetivos do trabalho, divididos em duas etapas (Construção do Dinamômetro e Estudo de Caso), além de ser apresentada a metodologia que seria utilizada para se atingir os mesmos.

No capítulo 3, procurou-se fazer uma revisão bibliográfica do processo de fresamento sob o ponto de vista dos tipos de operação, dos movimentos da peça e da ferramenta, da formação de cavaco, das principais falhas e desgastes das ferramentas, da mecânica do processo, da rugosidade da superfície usinada, dos strain gages utilizados para medição das forças de corte, da instrumentação do dinamômetro e do Método da Regressão Linear Múltipla utilizada para analisar os resultados.

Nos capítulos 4 e 5, procurou-se demonstrar os cálculos, procedimentos e critérios envolvidos no projeto e na fabricação do dinamômetro.

No capítulo 6, demonstrou-se o procedimento de calibração estática do dinamômetro, assim como os erros envolvidos provenientes do processo de fabricação do mesmo. Ao final do capítulo, foram apresentadas as equações obtidas para corrigir estes erros.

No capítulo 7, foi apresentado o estudo de caso que motivou os experimentos realizados com o dinamômetro. Foram apresentados os resultados obtidos através da medição das forças de corte e da rugosidade da superfície usinada, assim como a discussão destes resultados. Ao final, foi realizada uma verificação prática destes resultados, no próprio equipamento fruto do estudo, sendo que os mesmos foram comprovados.

Já no capítulo 8, foram apresentadas as conclusões obtidas através da realização das duas etapas do trabalho.

Por fim, no capítulo 9, procurou-se apresentar algumas sugestões de trabalhos que podem ser desenvolvidos no sentido de aumentar a produtividade e a qualidade do processo de fresamento de bordas de chapas, além da redução de seu custo. 


\section{3 - REVISÃO BIBLIOGRÁFICA}

\section{1 - Fresamento}

Segundo (Sandvik, 2005), o fresamento é basicamente o corte de metais com uma ferramenta rotativa de múltiplas arestas de corte que executa movimentos programados sobre uma peça em quase todos os sentidos de direção. Já segundo (Diniz, 2006), o fresamento é a operação de usinagem que tem as seguintes características:

- A ferramenta, chamada fresa, é provida de arestas cortantes dispostas simetricamente em torno de um eixo.

- O movimento de corte é proporcionado pela rotação da fresa ao redor de seu eixo.

- O movimento de avanço é geralmente feito pela própria peça em usinagem, que está fixada na mesa da máquina, o qual obriga a peça a passar sob a ferramenta em rotação, que lhe dá forma e dimensão desejadas.

Dessas definições, pode-se concluir que o movimento de avanço pode ser realizado tanto pela peça quanto pela fresa; o que irá definir é a construção da máquinaferramenta que está sendo utilizada para o processo.

Segundo a disposição dos dentes ativos da fresa, pode-se classificar a operação em:

- Fresamento tangencial: os dentes ativos se encontram na superfície cilíndrica da ferramenta; o eixo da fresa fica paralelo à superfície usinada.

- Fresamento frontal ou de topo: os dentes ativos se encontram na superfície frontal da ferramenta; o eixo da fresa fica perpendicular à superfície usinada. 


\subsection{1 - Tipos de Fresamento}

Segundo o sentido de fresamento, podemos classificar as operações em:

Fresamento concordante ou "para baixo" (down milling): o sentido de avanço da peça é o mesmo da rotação da fresa na área de corte; a espessura do cavado vai diminuindo desde o início do corte (Sandvik, 2005). Ainda segundo (Diniz, 2006), é aquele onde o ângulo entre a linha radial que passa pelo ponto de contato aresta-peça e uma outra linha radial que passa pelo ponto onde a espessura do cavaco formado (h) é zero, ângulo $\varphi$, começa em um valor máximo e decresce até zero.

O fresamento concordante tem as seguintes vantagens:

- Força de corte força a peça contra a mesa (no fresamento discordante a força de corte tende a levantar a peça. Isto faz com que peças delgadas percam seu apoio na mesa ou vibrem).

- Vida mais longa da ferramenta (menor desgaste).

- Melhor acabamento superficial.

- Menor força e potência para o avanço.

Apesar destas vantagens, o fresamento concordante tem as seguintes desvantagens, ou situação onde não poderá ser usado:

- Quando ocorre folga entre o fuso e a castanha de comando do avanço da mesa da fresadora. No fresamento concordante a força de corte puxa a peça para baixo da fresa numa magnitude proporcional à folga, gerando um cavaco mais espesso do que o predito para o avanço programado. Esta força de corte excessiva pode provocar quebra dos dentes ou insertos (pastilhas). No caso do fresamento discordante, as forças de corte se opõem à força de avanço, eliminando a folga em sistemas de avanço menos rígidos. 
- O fresamento concordante não deve ser usado quando a superfície da peça tiver resíduos de areia (desmoldados de fundição em molde de areia), escamas ou grandes irregularidades (carepa de laminação ou cascas ou droses de fundição). Nestes casos, o fresamento discordante é mais vantajoso, por permitir que a aresta de corte da fresa penetre abaixo desta camada superficial indesejável e evitar o seu efeito desfavorável sobre a vida da fresa.

Fresamento discordante ou "para cima" (up milling): o sentido de avanço da peça é oposto ao da rotação da fresa na área de corte; a espessura do cavaco começa em zero e vai aumentando até o final do corte (Sandvik, 2005). Só depois que a espessura de corte atinge certo valor e que se ultrapassa o limite de deformação elástica, entrando no domínio da deformação plástica por cisalhamento, é que se inicia efetivamente o processo de corte do cavaco. Como resultado, a aresta de corte da fresa escorrega sobre a peça, provocando um desgaste abrasivo. O material inicial é mais duro em função do encruamento produzido pelo dente (faca) precedente. Isto determina uma vida menor das arestas no fresamento discordante. Há tendência de caldeamento (solda fria ou desgaste por aderência) dos cavacos sobre a aresta e superfícies de saída (aresta postiça de corte). Ainda segundo (Diniz, 2006), é aquele onde o ângulo $\varphi$ cresce de zero a um valor máximo.

No caso do eixo da fresa interceptar o material da peça, têm-se simultaneamente, fresamento concordante e discordante. Este fresamento combinado ocorre na maioria dos processos de fresamento de topo.

Em resumo, podemos fazer uma comparação entre os tipos de fresamento na tabela a seguir: 
Tabela 3.1.1 - Comparação entre tipos de fresamento

\begin{tabular}{l|cc}
\hline \multicolumn{1}{c|}{ Característica } & Fresamento Concordante & Fresamento Discordante \\
\hline Peças Delgadas (vibração) & Menos & mais \\
Espessura de corte & Positiva & negativa \\
Desgaste da ferramenta & Menor & maior \\
Potência de corte & Menor & maior \\
\hline
\end{tabular}

3.1.2 - Movimentos da peça e da ferramenta

Os movimentos e velocidades de corte podem ser definidos em relação à peça:

- Movimento de corte: segundo (Stemmer, 1989), é produzido com o objetivo de provocar um movimento relativo entre a peça e a face da ferramenta. No caso do fresamento de topo, este movimento corresponde à rotação da fresa. Segundo (Diniz, 2006), sem a ocorrência concomitante do movimento de avanço, provoca remoção de cavaco durante uma única rotação ou curso da ferramenta.

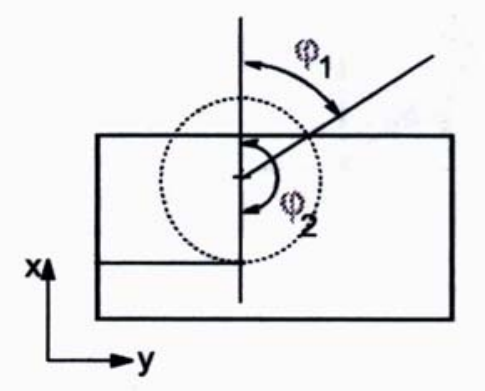

Figura 3.1.2.1 - Movimento de corte - Adaptado de (Araújo e Silveira, 2001)

- Velocidade de corte $\left(\mathrm{v}_{\mathrm{c}}\right)$ : segundo (Stemmer, 1989), é a velocidade instantânea do movimento principal de um ponto selecionado no gume, em relação à peça. Segundo (Diniz, 2006), é a velocidade tangencial instantânea resultante da rotação da ferramenta em torno da peça, em operações onde os movimentos de corte e avanço ocorrem concomitantemente, como é o caso do fresamento. 
- Movimento de avanço: (Stemmer, 1989) e (Diniz, 2006), é causado para provocar um movimento relativo adicional entre a peça e a face da ferramenta, gerando uma remoção contínua de cavaco quando somado ao movimento de corte. No caso do fresamento de topo, geralmente consiste na movimentação da mesa da fresadora.

- Velocidade de avanço $\left(\mathrm{v}_{\mathrm{f}}\right)$ : segundo (Stemmer, 1989), é a velocidade instantânea do movimento de avanço num ponto selecionado no gume, em relação à peça. Ainda segundo (Diniz, 2006), é o produto do avanço (percurso de avanço em cada volta da ferramenta) pela rotação da ferramenta.

- Movimento efetivo de corte: segundo (Stemmer, 1989) e (Diniz, 2006), é a resultante entre os movimentos de corte e de avanço. É ainda o movimento entre a ferramenta e a peça a partir do qual resulta o processo de usinagem.

- Velocidade efetiva de corte $\left(\mathrm{v}_{\mathrm{e}}\right)$ : segundo (Stemmer, 1989) é a resultante entre as velocidades de corte e de avanço.

- Ângulo da direção de avanço $(\varphi)$ : ângulo entre as direções dos movimentos de corte e de avanço, medido a partir da direção do movimento de corte.

- Ângulo da direção efetiva de corte $(\eta)$ : ângulo entre as direções dos movimentos de corte e efetivo, medido a partir da direção do movimento de corte.

\subsection{3 - Formação de Cavaco}

Segundo (Stemmer, 1989), a forma dos cavacos produzidos nos processos de usinagem pode variar devido a uma série de fatores, dentre eles o avanço, a profundidade e a velocidade de corte, geometria da ferramenta, material da peça, etc. 
Segundo (Diniz, 2006), a formação do cavaco influencia diversos fatores ligados à usinagem, tais como o desgaste da ferramenta, os esforços de corte, o calor gerado, a penetração do fluido de corte, etc. Em geral, a formação do cavaco nas condições normais de usinagem, se processa da seguinte forma:

- Uma pequena porção do material (ainda solidária à peça) é recalcada (deformações elástica e plástica) contra a superfície de saída da ferramenta.

- Esta deformação plástica aumenta progressivamente, até que as tensões de cisalhamento se tornem suficientemente grandes, a ponto de se iniciar um deslizamento (sem perda de coesão) entre o material recalcado e a peça.

- Continuando a penetração da ferramenta, haverá uma ruptura (cisalhamento) parcial ou completa do cavaco, acompanhando o plano de cisalhamento já citado anteriormente e dependendo da ductilidade do material e das condições de usinagem.

- Por fim, devido ao movimento relativo entre a ferramenta e a peça, inicia-se um escorregamento da porção do material deformada e cisalhada (cavaco) sobre a superfície de saída da ferramenta. Este fenômeno é contínuo, sendo que neste momento uma nova porção do material está se formando e cisalhando.

Os cavacos podem ser classificados de diversas maneiras. Abaixo segue uma das propostas existetes:

- Cavaco contínuo - segundo (Stemmer, 1989), o material da peça é recalcado pela ferramenta até que escorrega ao longo do plano de cisalhamento sem romper, deslizando pela superfície de saída da ferramenta. Está associado a um baixo coeficiente de atrito entre cavaco e ferramenta. É o que proporciona um melhor acabamento superficial e consume menos energia. Ainda segundo (Diniz, 2006), apresenta-se constituído de lamelas justapostas numa disposição contínua, sendo que a distinção entre as lamelas não é nítida; forma-se na usinagem de materiais dúcteis, onde o ângulo de saída deve assumir valores elevados. 
- Cavaco cisalhado - segundo (Stemmer, 1989), enquanto o cavaco escorrega ao longo do plano de cisalhamento, este fissura no ponto mais solicitado, sendo que devido à pressão e à temperatura, essas fissuras se soldam. A força de corte cresce progressivamente até que o mesmo rompe. Isso gera vibrações prejudiciais à máquina e que levam a um acabamento superficial pior.

- Cavaco arrancado - segundo (Stemmer, 1989), é o que se produz na usinagem de materiais frágeis. São pequenos fragmentos gerados por ruptura. Freqüentemente, o material é arrancado abaixo da superfície usinada, sendo que para evitar essa possibilidade devem-se usar ferramentas muito bem afiadas e avanços pequenos. Ainda segundo (Diniz, 2006), apresenta-se constituído de fragmentos arrancados da peça usinada; a superfície de contato entre cavaco e superfície de saída da ferramenta é reduzida, assim como a ação do atrito; o ângulo de saída deve assumir valores baixos, nulos ou negativos.

3.1.4 - Principais falhas e desgaste da ferramenta de corte

As principais formas de desgaste e avarias da ferramenta são:

- Desgaste de flanco - segundo (Stemmer, 1989), é a faixa desgastada no flanco da ferramenta. Geralmente é usado como critério de fim de vida da ferramenta. Ainda segundo (Diniz, 2006), ocorre na superfície de folga da ferramenta, causado pelo contato entre ferramenta e peça. É incentivado pelo aumento da velocidade de corte.

- Desgaste de Cratera ou Crateramento - segundo (Stemmer, 1989), concavidade que se forma na superfície de saída da ferramenta, devido ao atrito do cavaco com a ferramenta. Pode levar à quebra da ferramenta. Ainda segundo (Diniz, 2006), pode não ocorrer em alguns processos de usinagem, principalmente 
quando se utiliza ferramentas de metal duro recobertas, ferramentas cerâmicas e quando o material da peça é frágil.

- Deformação plástica - segundo (Diniz, 2006), é um tipo de avaria da ferramenta, na qual a pressão aplicada à ponta da ferramenta, somada à alta temperatura, gera deformação plástica da aresta de corte, que com o tempo pode levar à quebra da ferramenta. É evitada pelo emprego de uma ferramenta com maior dureza à quente e maior resistência à deformação plástica, ou pela mudança das condições de usinagem e/ou geometria da ferramenta, visando à diminuição dos esforços e temperatura de corte.

- Lascamento da aresta de corte - segundo (Stemmer, 1989), é um tipo de avaria devido a solicitações mecânicas ou térmicas da aresta de corte que causam a quebra de pedaços da aresta. Produz superfícies ásperas e irregulares. Ainda segundo (Diniz, 2006), ocorrem principalmente em ferramentas com material frágil e/ou quando a aresta de corte é pouco reforçada.

- Trincas de origem térmica - segundo (Diniz, 2006), é um tipo de avaria que surge devido ao grande gradiente de temperaturas existente na zona de corte (ocorrem perpendicularmente à aresta de corte) e/ou pela variação dos esforços mecânicos (ocorrem paralelamente à aresta de corte). Os fatores que geram estes gradientes são: corte interrompido, acesso irregular do fluido de corte, variação da espessura de corte e solda da pastilha no porta-ferramentas. Podem ser evitadas escolhendo-se uma ferramenta mais tenaz, diminuindo o avanço por dente e posicionando a fresa corretamente em relação à peça.

- Aresta postiça de corte - segundo (Stemmer, 1989), é formada por adesão de material do cavaco na superfície de saída, mudando a geometria de corte. Pode, no momento em que se descola da ferramenta, riscar a peça e/ou a ferramenta. 
Os mecanismos que levam a estes tipos de desgaste e avarias são os seguintes:

- Abrasão - é a remoção de material via mecanismos de trincamento, sulcamento, micro-corte ou outros de finas partículas de material. Aumenta com o aumento do número de inclusões na peça.

- Aderência - entre o material da peça e as asperezas superficiais da ferramenta sob altas temperaturas e pressões presentes na zona de corte.

- Difusão - processo de desgaste envolvendo difusão de átomos na interface entre peça e ferramenta. É ativado em temperaturas elevadas que aumentam a mobilidade dos átomos nesta interface.

- Oxidação - devido ao aquecimento de peças a altas temperaturas com a formação camadas oxidadas. 


\section{2 - Mecânica do processo de Fresamento}

Segundo (Altintas, 2000), no processo de fresamento, a espessura instantânea do cavaco $\mathrm{h}$ varia periodicamente como função da imersão da ferramenta variável com o tempo. A variação da espessura do cavaco pode ser aproximada por:

$$
h(\phi)=f_{z} \operatorname{sen} \phi
$$

Onde $\mathrm{f}_{\mathrm{z}}$ é o avanço por dente ( $\mathrm{mm} /$ volta-dente) e Ø é o ângulo instantâneo de imersão. O ângulo de hélice será considerado igual a zero, que é o caso de operações de fresamento de topo com insertos. As forças de corte tangencial $\left(\mathrm{F}_{\mathrm{t}}(\varnothing)\right)$, radial $\left(\mathrm{F}_{\mathrm{r}}(\varnothing)\right)$ e axial $\left(\mathrm{F}_{\mathrm{a}}(\varnothing)\right)$ são expressas como função da área variável do cavaco $(\operatorname{ah}(\varnothing))$ a do comprimento da borda de contato (a):

$$
\left\{\begin{array}{l}
F_{t}(\phi)=K_{t c} a h(\phi)+K_{t e} a \\
F_{r}(\phi)=K_{r c} a h(\phi)+K_{r e} a \\
F_{a}(\phi)=K_{a c} a h(\phi)+K_{a e} a
\end{array}\right\}
$$

Onde $\mathrm{K}_{\mathrm{tc}}, \mathrm{K}_{\mathrm{rc}}$ e $\mathrm{K}_{\mathrm{ac}}$ são os coeficientes de força de corte devido à ação de corte nas direções tangencial, radial e axial, respectivamente, e $\mathrm{K}_{\mathrm{te}}, \mathrm{K}_{\mathrm{re}}$ e $\mathrm{K}_{\mathrm{ae}}$ são as constantes de borda. Assumindo como zero o raio de ponta e o ângulo de aproximação nos insertos, as componentes axiais da força de corte se tornam zero $\left(\mathrm{F}_{\mathrm{a}}=0\right)$. Os coeficientes de corte são admitidos constantes para um par ferramenta - peça, e podem ser estimados tanto mecanisticamente a partir de 
ensaios de fresamento quanto utilizando transformações de corte oblíquo clássicas, dadas pelas equações encontradas em (Altintas, 2000).

A espessura média do cavaco por volta é calculada a partir da zona usinada como:

$$
h_{a}=\frac{\int_{\phi_{s t}}^{\phi_{e x}} f_{z} \operatorname{sen} \phi \cdot d \phi}{\phi_{e x}-\phi_{s t}}=-f_{z} \frac{\cos \phi_{e x}-\cos \phi_{s t}}{\phi_{e x}-\phi_{s t}}
$$

O torque de corte instantâneo $\left(T_{c}\right)$ no eixo-árvore é:

$$
T_{c}=F_{t} \frac{D}{2}
$$

Onde D é o diâmetro da fresa. As componentes da força de corte horizontal (isto é, de avanço), normal e axial atuantes na ferramenta são derivadas do diagrama de equilíbrio mostrado na figura a seguir: 


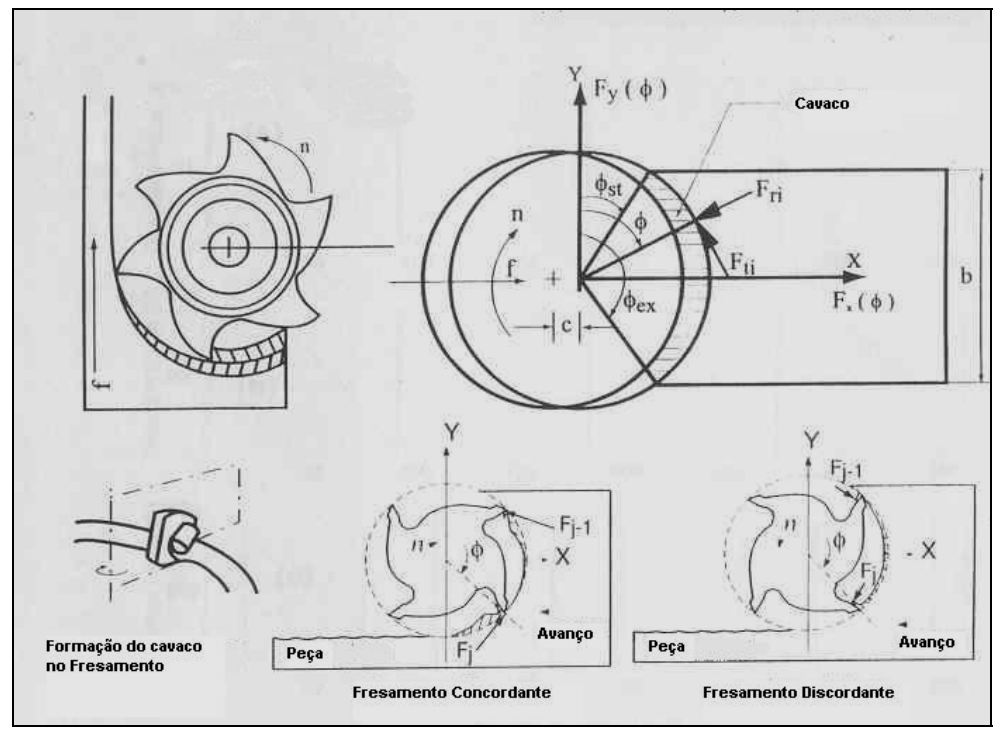

Figura 3.2.1 - Geometria do Processo de Fresamento - adaptado de (Altintas, 2000)

$$
\left\{\begin{array}{l}
F_{x}(\phi)=-F_{t} \cos \phi-F_{r} \operatorname{sen} \phi \\
F_{y}(\phi)=+F_{t} \operatorname{sen} \phi-F_{r} \cos \phi \\
F_{z}(\phi)=F_{a}
\end{array}\right\}
$$

Deve ser notado que as forças de corte somente são produzidas quando a ferramenta está na zona de corte, o que significa:

$$
F_{x}(\phi), F_{y}(\phi), F_{z}(\phi)>0 \stackrel{\text { quando }}{\longrightarrow} \phi_{s t} \leq \phi \leq \phi_{e x}
$$

Onde $\varnothing_{\text {st }}$ e $\varnothing_{\text {ex }}$ são os ângulos de entrada e saída da ferramenta, respectivamente. Outro ponto importante é que pode existir mais de um dente cortando o material simultaneamente, dependendo do número de dentes da ferramenta e da profundidade radial do corte. O ângulo de espaçamento entre dentes $\varnothing_{\mathrm{p}}$ (ou ângulo de passo da ferramenta), é dado por: 


$$
\phi_{p}=\frac{2 \pi}{N}
$$

Onde $\mathrm{N}$ é o número de dentes da ferramenta. Haverá mais de um dente cortando simultaneamente quando o ângulo de varredura $\left(\varnothing_{\mathrm{s}}=\varnothing_{\mathrm{ex}}-\varnothing_{\mathrm{st}}\right)$ é maior do que o ângulo de passo da ferramenta (isto é, $\varnothing_{\mathrm{s}}>\varnothing_{\mathrm{p}}$ ). Quando mais de um dente corta simultaneamente, a contribuição de cada dente para a força total de avanço e normal deve ser considerada. Deve ser notado também que desde que cada dente está afastado de seus vizinhos pelo ângulo de passo, a espessura do cavaco removido por cada aresta de corte será diferente dada uma posição instantânea da ferramenta. Podem-se formular as forças totais de avanço, normal e axial como:

$$
F_{x}=\sum_{j=1}^{N} F_{x j}\left(\phi_{j}\right), F_{y}=\sum_{j=1}^{N} F_{y j}\left(\phi_{j}\right), F_{z}=\sum_{j=1}^{N} F_{z j}\left(\phi_{j}\right)
$$

Sempre que $\emptyset_{\mathrm{st}}<=\varnothing_{\mathrm{j}}<=\emptyset_{\mathrm{ex}}$. Cada termo na somatória representa a contribuição de cada dente na força de corte. Se o dente j está fora da zona de imersão, não irá contribuir para a força total de corte. A força de corte resultante na ferramenta (ou na peça) é dada por:

$$
F=\sqrt{F_{x}^{2}+F_{y}^{2}+F_{z}^{2}}
$$


O torque instantâneo de corte no eixo-árvore é:

$$
T_{c}=\frac{D}{2} \sum_{j=1}^{N} F_{t j}\left(\phi_{j}\right) \longrightarrow \phi_{s t} \leq \phi_{j} \leq \phi_{e x}
$$

Onde D é o diâmetro da ferramenta. A potência de corte $\left(\mathrm{P}_{\mathrm{t}}\right)$ requerida do motor é:

$$
P_{t}=V \sum_{j=1}^{N} F_{t j}\left(\phi_{j}\right) \longrightarrow \phi_{s t} \leq \phi_{j} \leq \phi_{e x}
$$

Onde $\mathrm{V}=\pi \mathrm{Dn}$ é a velocidade de corte e $\mathrm{n}$ é a rotação do eixo. 


\section{3 - Rugosidade}

A medição da rugosidade merece um cuidado especial que muitas vezes não é despendido em detrimento de outras grandezas envolvidas (Teses.USP, 2005). Os parâmetros de rugosidade escolhidos muitas vezes são uma caracterização incompleta do perfil ou superfície que se deseja estudar. Por se tratarem de valores numéricos provenientes de integrações ou de operações matemáticas simples de perfis amostrais destas superfícies, estão sujeitos a diversos erros de medição e interpretação. No entanto, são valores extremamente úteis na comparação entre superfícies.

A rugosidade, ou o perfil linear de uma superfície que é designado por este nome, é normalmente representado em escalas (de ampliação ou redução) distintas para as direções vertical e horizontal. Isso para evidenciar a mudança de perfil de maior interesse para a análise de uma superfície, já que as escalas de variação para as direções perpendiculares a superfície analisada são, em geral, menores que as para direções paralelas à superfície.

Desta forma, como em grande parte das vezes deseja-se saber mais sobre a variação do perfil perpendicular à superfície, é comum ampliar as variações de um perfil de rugosidade nesta direção, e em uma escala menor de ampliação as variações na direção paralela à superfície.

Assim sendo, muitas das representações referentes à rugosidade de um perfil podem levar a uma interpretação incorreta, caso não se considere este fato ao analisá-las. Além deste possível erro de compreensão, outros erros de distorção da informação de rugosidade podem ocorrer, geralmente, ligados ao instrumento de medição. No caso dos apalpadores, podem ocorrer erros ligados à carga aplicada e ao raio de ponta do mesmo.

Para evitar este tipo de erro, podem ser utilizados equipamentos ópticos, sendo que estes não necessitam de contato com a superfície analisada. Porém, por sua vez, este tipo de equipamento tem praticidade reduzida, uma vez que geralmente devem ser 
utilizados em laboratório, além de possuírem limitações ligadas à sua distância focal, principalmente no caso das superfícies mais irregulares.

3.3.1 - Definições de alguns parâmetros de rugosidade

A rugosidade média, denominada $\mathrm{R}_{\mathrm{a}}$, é possivelmente o conceito mais antigo de rugosidade ainda em uso. Sua disseminação pode ser atribuída à sua facilidade de cálculo, mesmo com aparelhos analógicos simples. Sua definição pode ser expressa como o desvio médio de um perfil de sua linha média. Outra boa definição seria a distância média de um perfil desde sua linha média, sobre um comprimento medido. Matematicamente, a expressão é a seguinte:

$R_{a}=\frac{l}{l_{m}} \int_{0}^{l m}|y(x)| d x$

Um exemplo gráfico deste parâmetro pode ser visto na figura a seguir: 


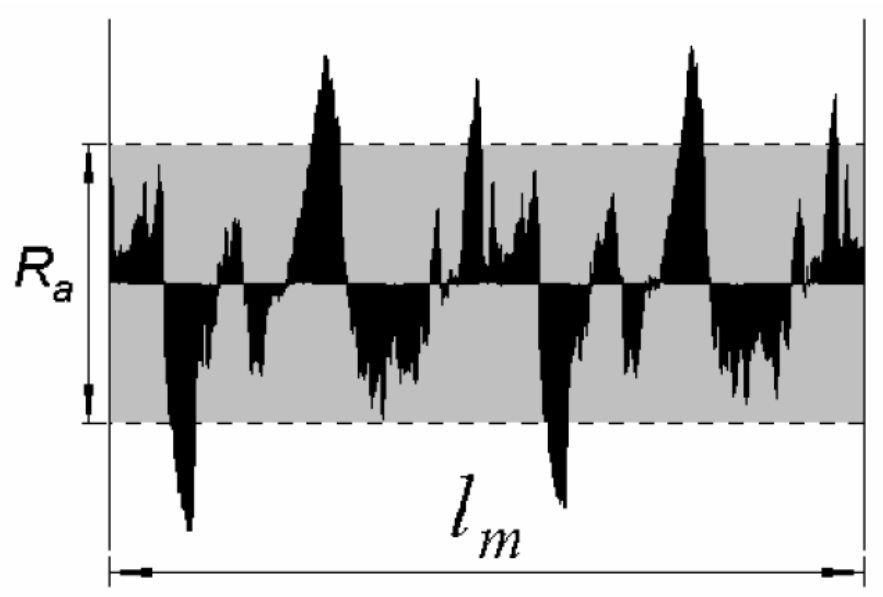

Figura 3.3.1.1 - Ilustração do parâmetro $\mathbf{R}_{\mathrm{a}}$

Este parâmetro de rugosidade tem a desvantagem de não esclarecer ou caracterizar a variabilidade dos diferentes valores locais da rugosidade sobre o perfil analisado.

Outro conceito amplamente difundido é o espaçamento médio entre picos $\left(\mathrm{S}_{\mathrm{m}}\right)$. Sua definição é aceita como o comprimento medido sobre a quantidade de picos contados (D). A definição de pico é como o maior ponto registrado entre dois cruzamentos da linha média do perfil. Pode ser definido matematicamente da seguinte maneira:

$S_{m}=\frac{l_{m}}{D}$

Este parâmetro é utilizado amplamente em indústrias de chapas metálicas, por designar uma condição que afeta diretamente a aparência, a função e a conformabilidade deste produto acabado. 
Já o parâmetro $\mathrm{R}_{\mathrm{y}}$, ou profundidade de polimento, é definido como sendo a distância entre o pico mais alto e o vale mais baixo, dentro de um comprimento medido de um perfil de rugosidade. A figura a seguir ilustra um exemplo deste parâmetro:

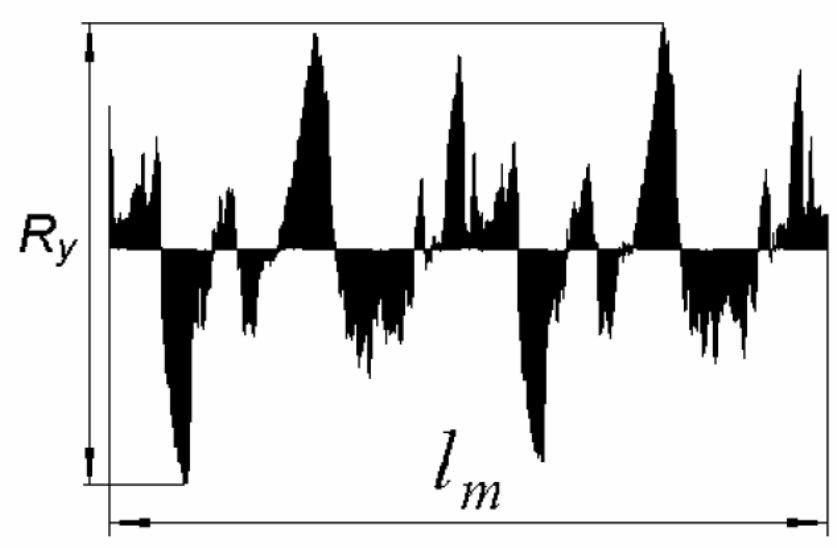

Figura 3.3.1.2 - Ilustração do parâmetro $\mathbf{R}_{\mathrm{y}}$

$\mathrm{O}$ parâmetro $\mathrm{R}_{\mathrm{y}}$ tem vantagens e desvantagens: é um verdadeiro indicador da distância máxima de picos e vales de um comprimento medido. Contudo, o pico mais alto pode estar no início do perfil analisado, enquanto o vale mais profundo pode estar no final deste perfil. Assim, estas duas ocorrências estão muito pouco correlacionadas, e o parâmetro $\mathrm{R}_{\mathrm{y}}$ registrado pode transmitir uma idéia incorreta sobre a superfície. Para evitar tais situações, há outro parâmetro de rugosidade semelhante ao $R_{y}, o R_{z}$. De acordo com a norma ISO 4287, o parâmetro $\mathrm{R}_{\mathrm{z}}$ é a distância média entre os 5 picos mais altos e os 5 vales mais profundos, dentro de um comprimento medido, ou:

$$
R_{z}=\frac{1}{5}\left(\sum_{i=1}^{5} p_{i}+\sum_{i=1}^{5} v_{i}\right)
$$


Graficamente, $\mathrm{o} \mathrm{R}_{\mathrm{z}}$ pode ser representado como a seguir:

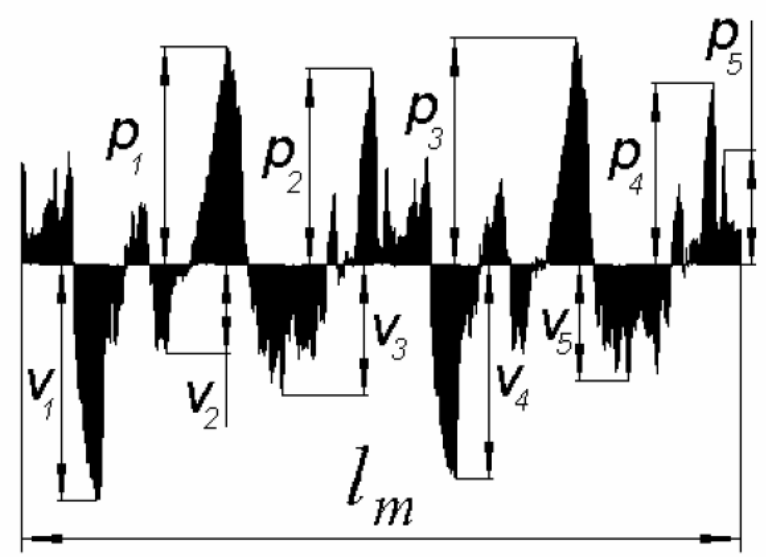

Figura 3.3.1.3 - Ilustração do parâmetro $\mathbf{R}_{\mathrm{z}}$

Juntos, os parâmetros $\mathrm{R}_{\mathrm{y}}$ e $\mathrm{R}_{\mathrm{z}}$ fornecem uma idéia mais clara para a monitoração da variação do acabamento superficial em um processo de fabricação. Valores similares de $R_{y}$ e $R_{z}$ indicam um acabamento superficial consistente de um processo de fabricação, enquanto que diferenças significativas destes dois indicam defeitos superficiais quando se deseja uma superfície consistente.

$\mathrm{R}_{\mathrm{z}}$ isoladamente pode ser considerado mais sensível a mudanças no acabamento superficial que $\mathrm{R}_{\mathrm{a}}$, por exemplo. Isso porque somente alturas máximas de perfis, e não suas médias, são comparadas e analisadas.

\subsection{2 - Rugosidade no Processo de Fresamento}

Segundo (Diniz, 2006), o fresamento tangencial produz uma superfície ondulada, sendo que a desta ondulação define a rugosidade máxima teórica. Esta rugosidade é calculada a partir da seguinte fórmula: 
$R_{\max t e o r}=\frac{f_{Z}{ }^{2}}{4 D}$

onde:

$\mathrm{f}_{\mathrm{z}}=$ avanço por dente $(\mathrm{mm})$

$\mathrm{D}=$ diâmetro da fresa $(\mathrm{mm})$

No entanto, a rugosidade real é sempre maior ou igual à teórica, devido aos seguintes fatores:

- Posicionamento irregular das pastilhas no sentido radial (deformação no encosto das pastilhas, tolerância dimensional das pastilhas).

- Desgaste não-uniforme das arestas de corte.

- Fluxo de saída de cavacos irregular.

- Excentricidade do eixo-árvore.

- Vibrações geradas pela falta de fixação e/ou rigidez da peça.

Pode-se comparar este valor de rugosidade máxima com o valor de Ry, que é a distância entre o pico mais alto e o vale mais baixo de um perfil, conforme visto anteriormente nesta seção. 


\section{4 - Extensômetros (Strain Gages)}

$\mathrm{Na}$ sua forma mais completa, extensômetro elétrico é um resistor composto de uma finíssima camada de material condutor, depositado então sobre uma base isolante. Este é então colado sobre a estrutura em teste com auxílio de adesivos como epóxi ou cianoacrilatos. Pequenas variações de dimensões da estrutura são então transmitidas mecanicamente ao strain gage, que transforma essas variações em outras equivalentes de sua resistência elétrica (por esta razão, os strain gages são definidos como transdutores).

Segundo (Dally, 1978), algumas das características comumente usadas para julgar a adequação de um strain gage para uma aplicação em particular são as seguintes:

- A constante de calibração para o extensômetro deve ser estável; não deve variar com o tempo ou temperatura.

- O extensômetro deve ser capaz de medir deformações com uma precisão de $\pm 1 \mu \mathrm{m} / \mathrm{m}$ em um range de deformação de $10 \%$.

- O tamanho do extensômetro (comprimento e largura) deve ser pequeno para que se possa fazer uma aproximação adequada da deformação em um ponto.

- A resposta do extensômetro, controlada principalmente por sua inércia, deve ser suficiente para permitir a gravação de deformações dinâmicas.

- O sistema do extensômetro deve permitir leitura de dados local ou remota.

- A saída do extensômetro durante a leitura de dados deve ser independente da temperatura ou outros parâmetros ambientais.

- A aquisição do extensômetro e de seus equipamentos auxiliares deve ser economicamente viável. 
- O sistema do extensômetro não deve envolver instalações e técnicas operacionais muito complexas.

- O extensômetro deve exibir uma resposta linear com a deformação.

- O extensômetro deve servir como elemento sensor primário em outros transdutores onde grandezas desconhecidas, assim como a pressão, são medidas em função da deformação.

Os extensômetros elétricos apresentam algumas características que o diferenciam no momento da escolha, sendo que as que mais se destacam são: a boa precisão e linearidade, fácil instalação, ampla faixa de temperatura, pequeno, leve, barato, possibilita realizar medidas à distância, excelente resposta estática e dinâmica além de ser aplicável mesmo sob condições severas.

A seleção do strain gage apropriado para determinada aplicação é influenciada pelas seguintes características: objetivo (tipo) da medição, o material aonde será colado, dimensões do strain gage, precisão, potência que o strain gage pode dissipar, material da grade metálica e sua construção, material do suporte isolante, material do adesivo, tratamento e proteção do medidor e configuração.

Os extensômetros possuem um baixo e previsível efeito térmico, onde uma simples compensação e métodos de correção permitem uma operação de precisão em altas taxas de temperatura.

\subsection{1 - Princípios da extensometria elétrica}

Ao analisar o comportamento elétrico dos fios metálicos energizados, submetidos a esforços mecânicos de tração, Kelvin, em 1856, obteve as seguintes conclusões (Almeida, 1996): 
A resistência elétrica do fio muda em função da deformação (alongamento ou encurtamento):

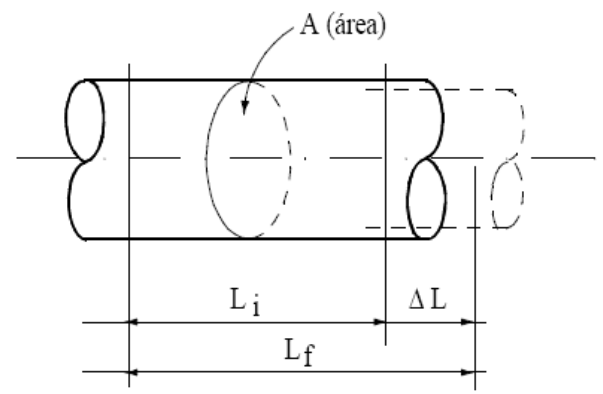

Figura 3.4.1.1 - Deformação específica

$\varepsilon=\frac{\Delta L}{L}=\frac{L_{f}-L_{i}}{L_{i}}$

e

$\frac{\Delta R}{R} \alpha \frac{\Delta L}{L}$

ou seja,

$\frac{\Delta R}{R}=K \frac{\Delta L}{L}$

$\mathrm{ou}$

$\frac{\Delta R}{R}=K \varepsilon$ 
Os materiais têm sensibilidades diferentes (K)

- $\quad$ Níquel/Cobre $\mathrm{K} \sim=2,1$

- Tungstênio/Platina $\mathrm{K} \sim=4,0$

É necessário utilizar um circuito elétrico com boa amplificação para determinar a variação de resistência elétrica do fio. Neste caso foi recomendado o circuito da ponte de Wheatstone. Este circuito foi publicado em 1848, por Charles Wheatstone.

\subsection{2 - Análise da resistência do condutor}

- Resistência do condutor (Kelvin)

$$
R=\rho \frac{L}{A}
$$

ou

$$
R=\rho\left(\frac{4}{\pi D^{2}}\right) L
$$

onde:

$\mathrm{R}=$ resistência elétrica do condutor $(\Omega)$;

$\rho=$ resistividade, em $\Omega . m$;

$\mathrm{A}=$ área, em m2;

$\mathrm{L}=$ comprimento, em $\mathrm{m}$. 
A mudança de resistência é encontrada pela diferencial da função $R$, considerando $\rho, \mathrm{L}$ e D como variáveis. Além disso, todas as variáveis são consideradas lineares:

$$
\begin{aligned}
& d R=\frac{\partial R}{\partial \rho} d \rho+\frac{\partial R}{\partial D} d D+\frac{\partial R}{\partial L} d L \\
& \frac{\partial R}{\partial \rho}=\left(\frac{4}{\pi D^{2}}\right) L \\
& \frac{\partial R}{\partial L}=\rho\left(\frac{4}{\pi D^{2}}\right) \\
& \frac{\partial R}{\partial D}=\frac{4}{\pi} \rho L \frac{\partial}{\partial D}\left(\frac{1}{D^{2}}\right)=\rho L \frac{4}{\pi} \frac{-2 D}{D^{4}}=-\rho L \frac{8}{\pi} \frac{1}{D^{3}}
\end{aligned}
$$

Desse modo:

$$
d R=\left(\frac{4}{\pi D^{2}}\right) L d \rho-\rho L \frac{8}{\pi} \frac{1}{D^{3}} d D+\rho\left(\frac{4}{\pi D^{2}}\right) d L
$$

e dividindo-se por $\mathrm{R}$, resulta em:

$$
\frac{d R}{R}=\frac{d \rho}{\rho}-\frac{2 d D}{D}+\frac{d L}{L}
$$


Considerando-se que:

$\frac{d D}{D}=-v \frac{d L}{L}$

Por definição:

$\varepsilon=\frac{d L}{L}$

Então:

$\frac{d R}{R}=\varepsilon\left(1+2 v+\frac{d \rho}{\rho} \frac{1}{\varepsilon}\right)$

$\frac{d R}{R}=\varepsilon K$

$K=1+2 v+\frac{d \rho}{\rho} \frac{1}{\varepsilon}$

No caso da deformação do extensômetro não afetar a resistividade, o valor de $\mathrm{K}$ para $v=0,3$ será, aplicando a equação 18 :

$$
K=1+2(0,3)=1,6+\frac{d \rho}{\rho} \frac{1}{\varepsilon}
$$


Pela Equação de Bridgman, obtida através de ensaios com diversos tipos de materiais:

$$
\frac{d \rho}{\rho}=c \frac{d v}{v}
$$

onde $\mathrm{c}=$ constante.

$$
\begin{aligned}
& \frac{d v}{v}=\varepsilon_{x}+\varepsilon_{y}+\varepsilon_{z} \\
& \frac{d v}{v}=\varepsilon_{x}-2 v \varepsilon_{x} \\
& \frac{d v}{v}=\varepsilon(1-2 v)
\end{aligned}
$$

Assim, substituindo, considerando $\mathrm{c}=1$ como uma média geral de diversos materiais ensaiados:

$$
\begin{aligned}
& k=1+2 v+\frac{c \varepsilon(1-2 v)}{\varepsilon} \\
& k=1+2 v+c(1-2 v) \\
& c=1 \Rightarrow k=2
\end{aligned}
$$

Os valores de $\mathrm{K}$ para as aplicações usuais variam de 1,70 a 2,20.

\subsection{3 - Características dos extensômetros elétricos}

Partindo da relação fundamental da extensometria (equação 19), para a medida das deformações na superfície da maioria dos materiais estruturais, normalmente, são utilizados extensômetros elétricos de resistência com as seguintes características: 
- Resistência elétrica: $60 \Omega$ a $1000 \Omega$. Geralmente utilizam-se extensômetros de $120 \Omega$ e $350 \Omega$;

- Constante do extensômetro (gage factor) K. Neste caso utiliza-se um valor em torno de 2;

- O comprimento da grade de medida, normalmente, corresponde a 3, 5, 10, 15 e 20 milímetros.

Os extensômetros elétricos têm uma forma específica para cada aplicação. No caso de medidas de deformação, considerando um estado plano de tensões, na superfície de peças tem-se:

- Uniaxial;

- Bi-axial - rosetas de duas direções;

- Tri-axial - rosetas de três direções, conhecidas como rosetas delta.

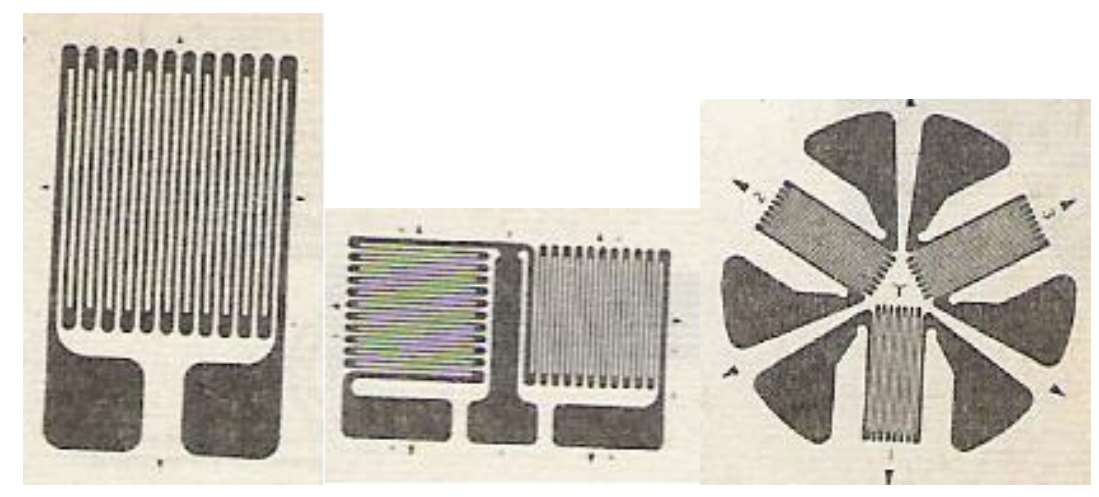

(a)

(b)

(c)

Figura 3.4.3.1 - Formas dos Strain Gages: Uniaxial (a); Bi-axial (b); Tri-axial (c) - Adaptado de (Dally, 1978) 


\section{5 - Instrumentação}

O método experimental requer uso intensivo de instrumentos. Assim, é necessário que se conheçam as técnicas de medição, os instrumentos, a forma adequada de aplicá-los em seus aparatos experimentais e técnicas de processamento dos dados obtidos. Para entender o funcionamento de instrumentos de medição, ou mesmo projetar um instrumento, é necessário saber como eles são configurados a partir de elementos funcionais.

O diagrama abaixo mostra as funções básicas necessárias para a constituição de qualquer instrumento (FEM.UNICAMP, 2005):

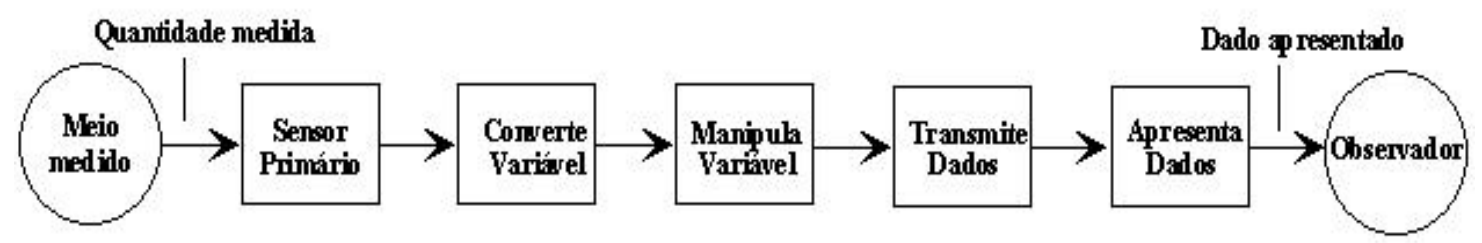

Figura 3.5.1 - Configuração de um instrumento

- Elemento sensor primário - aquele que primeiro recebe a informação do meio físico medido e gera um sinal de saída que depende de algum modo da quantidade medida.

- Elemento conversor de variável - aquele que converte o sinal de saída do elemento sensor primário em um outro sinal mais apropriado para a medição, sem, entretanto, alterar a informação contida no sinal original.

- Elemento manipulador de variável - aquele que opera uma mudança no valor numérico associado ao sinal de saída do elemento conversor de variável segundo uma regra precisamente definida, mantendo, entretanto, a natureza física do sinal. 
- Elemento transmissor de dados - aquele que transmite dados entre os elementos funcionais do sistema de medição quando estes se encontram fisicamente separados.

- Elemento apresentador de dados - aquele que coloca os dados em uma forma reconhecida por um dos sentidos humanos (pelo observador) para efeito de monitoramento, controle ou análise.

- Elemento armazenador/reprodutor de dados - aquele que armazena os dados de maneira não necessariamente reconhecida pelos sentidos humanos e que os apresenta (reproduz) a partir de um comando qualquer.

A Figura 3.5.1 apresenta os elementos funcionais de um sistema de medição, isto é, do instrumento, e não seus elementos físicos. Um instrumento específico pode apresentar várias combinações das funções básicas, em seqüências distintas daquela da Figura 3.5.1, sendo que um mesmo componente físico pode desempenhar várias destas funções. Uma outra configuração menos detalhada considera os sistemas de medição como contendo três partes:

- Estágio sensor/transdutor - realiza a detecção da variável física e a converte em um sinal mais apropriado para medição, normalmente mecânico ou elétrico. $\mathrm{O}$ sensor deveria ser, idealmente, insensível a cada uma das outras possíveis entradas interferentes não desejadas: 1) ruído, por definição um sinal nãodesejável que varia (flutua) muito rapidamente; 2) deslocamento (drift), um sinal não-desejável que varia lentamente.

- Estágio intermediário - realiza uma modificação do sinal oriundo do estágio anterior através de amplificação, filtragem, etc. Isto é, o estágio intermediário deve realizar a transdução da informação para torná-la aceitável: realiza a 1) filtragem do sinal para remover ruídos, e 2) amplifica o sinal, isto é aumenta sua potência.

- Estágio final - realiza a apresentação final dos dados, o seu armazenamento e, se necessário, o controle da variável medida. Isto é, no estágio final está o 
mostrador (ou display), o banco de memória onde dados são armazenados, o computador que fará o controle do processo, etc.

Podemos descrever o esquema de um medidor eletrônico de deformação da seguinte maneira:

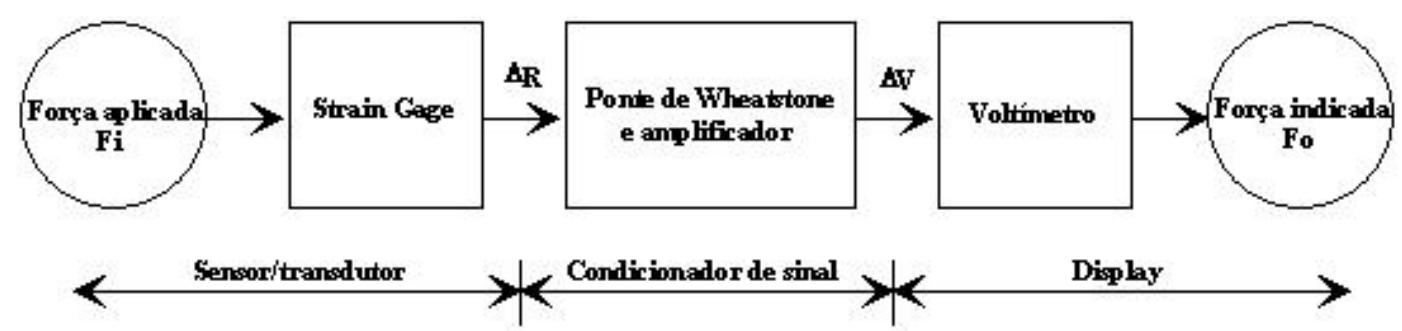

Figura 3.5.2 - Esquema de um medidor eletrônico de deformação

3.5.1 - Desempenho estático e dinâmico de instrumentos

O estudo das características de desempenho de um instrumento de medida e de sistemas de medição em geral é normalmente feito em termos da análise de suas características estáticas e características dinâmicas. As razões que explicam são:

- Algumas aplicações envolvem a medida de quantidades que permanecem constantes ou que variam apenas muito lentamente (grandezas estáticas ou semiestáticas, como, por exemplo, a pressão e a temperatura ambientes).

- Outras aplicações requerem a medida de quantidades que variam rapidamente, sendo, portanto, necessário examinar-se as relações dinâmicas entre a entrada e a saída do instrumento de medida (por exemplo, a flutuação de velocidade típica da turbulência de um escoamento de fluido). 
As características estáticas de um instrumento influenciam a qualidade das medidas realizadas em condições dinâmicas, mas o tratamento simultâneo de ambas é inviável matematicamente.

Percebe-se, portanto, que embora a separação do comportamento de um instrumento em características estáticas e dinâmicas seja muitas vezes acadêmica, tratase de uma abordagem aproximada necessária para a solução de problemas práticos.

Todas as características de desempenho estático de um instrumento são obtidas através de um procedimento denominado calibração estática. Este termo refere-se a uma situação onde todas as entradas (desejadas, interferentes e modificadoras) são mantidas constantes durante certo intervalo de tempo, exceto uma. Ou seja, a entrada sendo investigada é variada dentro de uma faixa de valores constantes, o que faz com que a saída varie dentro de uma outra faixa de valores constantes. A relação entrada-saída obtida representa uma calibração estática do instrumento válida para as condições de valores constantes de todas as outras entradas.

Normalmente, há muitas entradas interferentes e/ou modificadoras para um dado instrumento, cada qual causando apenas um efeito muito pequeno sobre a entrada desejada. Dada a inviabilidade prática de controlá-las todas, a afirmação "todas as entradas exceto uma são mantidas constantes" refere-se a uma situação ideal que pode ser aproximada, mas nunca atingida na prática. O termo "método de medida" descreve esta situação ideal enquanto o termo "processo de medida" descreve a realização prática (imperfeita) do método de medida.

As entradas mantidas constantes requerem a sua medida independentemente do instrumento sendo calibrado. Para entradas interferentes ou modificadoras (cujos efeitos sobre a saída devem ser relativamente pequenos em um instrumento de boa qualidade), não é necessária uma grande precisão nas medidas. Entretanto, ao se calibrar a resposta do instrumento às entradas desejadas, estas devem ser medidas com uma precisão maior do que aquela do instrumento sendo calibrado. Como regra geral, o padrão de 
calibração (entrada desejada) deve ser no mínimo dez vezes mais preciso do que o instrumento sendo calibrado.

Em geral, o procedimento de calibração estática pode ser realizado seguindo-se as etapas abaixo:

- Identificar e relacionar todas as possíveis entradas para um dado instrumento.

- Decidir, com base na aplicação em questão, quais entradas são relevantes.

- Obter os equipamentos que possibilitarão a variação das entradas relevantes em todas as faixas consideradas necessárias.

- Obter as relações entrada-saída variando alternadamente cada entrada considerada relevante e mantendo todas as outras constantes.

- Realizar uma superposição adequada das várias relações entrada-saída de forma a descrever o comportamento global estático do instrumento.

Ao medirmos uma quantidade física qualquer com um dado instrumento, perguntamo-nos o quão próximo o valor numérico obtido está do valor "verdadeiro".

Obviamente, o assim chamado valor verdadeiro geralmente não é conhecido já que medidas perfeitas ou mesmo definições exatas das quantidades físicas são impossíveis. Portanto, o termo valor "verdadeiro" refere-se ao valor que seria obtido se a quantidade física em questão fosse medida por um método exemplar de medição, isto é, um método suficientemente preciso em vista da utilização final dos dados. 


\section{6 - Dinamometria}

Para que se possa realizar uma análise quantitativa dos processos de corte de metais, algumas observações devem ser realizadas antes, durante e depois do corte. $\mathrm{O}$ número de observações que podem ser feitas durante o corte são limitadas; uma das medições mais importantes deste tipo tem sido a determinação das componentes das forças de corte. Esta seção irá discutir os aspectos mais importantes no projeto dos dinamômetros para a medição destas forças.

Os requerimentos mais importantes no projeto de dinamômetros são:

Rigidez: um dinamômetro deve ser rígido o suficiente para que a operação de corte não seja influenciada por suas deflexões. Para tanto, a freqüência natural do dinamômetro deve ser pelo menos 4 vezes maior que a freqüência do sinal de excitação. Para fins de análise, qualquer dinamômetro pode ser modelado como uma massa apoiada por uma mola (Shaw, 2005). Assim, a freqüência natural de um sistema como este é igual a:

$$
f_{n}=\frac{1}{2 \pi} \sqrt{\frac{K}{m}}
$$

Em geral, a rigidez estática de um dinamômetro deve estar em torno de $10^{8} \mathrm{~N} / \mathrm{m}$.

Sensibilidade: um dinamômetro deve ser capaz de ler medições de pelo menos $1 \%$ de seu fundo de escala facilmente. Por exemplo, um extensômetro é capaz de ler deformações de $1 \mu \mathrm{m} / \mathrm{m}$ (Dally, 1978).

Precisão: um dinamômetro deve realizar medições com precisão de pelo menos $\pm 1 \%$.

Frequentemente, existem vários outros requerimentos especiais que devem ser atingidos, tais como tamanho, acabamento superficial e aplicabilidade a diversos 
trabalhos. Cada um destes requerimentos especiais assume diferente grau de importância em diferentes aplicações.

Abaixo, alguns dos dispositivos que vêm sendo utilizados para medir pequenas deflexões nos dinamômetros são (Shaw, 2005):

- Células de pressão hidráulica;

- Dispositivos pneumáticos;

- Dispositivos ópticos de diversos tipos - métodos de interferometria podem ser utilizados para medições muito precisas usando o comprimento de onda da luz como unidade de medida. Deflexões angulares muito pequenas podem ser medidas através da reflexão de um feixe de luz da superfície móvel;

- Cristais piezelétricos - são amplamente utilizados como unidade de medida em dinamômetros de corte de metais. Os mesmos podem ser projetados para ter maiores freqüências naturais de vibração do que outros tipos de dinamômetros. 


\section{7 - Método da Regressão Linear Múltipla}

A técnica de regressão múltipla é uma metodologia para o estudo das relações entre variáveis. É implementada visando à determinação de relações entre variáveis dependentes e independentes, podendo ser usada para analisar dados e gerar um modelo. A partir de um modelo de regressão múltipla, podem-se obter as variáveis preditivas e determinar a relação entre as variáveis do critério e as variáveis preditivas (Jennrich, 1995). Neste sentido, a técnica de regressão múltipla seria útil na predição da variável dependente tal como a máxima rugosidade da superfície usinada ou a força de corte em cada rotação via variáveis independentes tais como a velocidade de avanço, largura de corte e avanço por dente.

É desejável que um modelo forneça uma equação matemática para as suas relações físicas funcionais. Entretanto, isso geralmente é muito difícil ou impossível para o processo de fresamento de topo, devido à grande quantidade de fatores envolvidos. Daí, modelos físicos só podem ser criados nos casos mais simples.

Assim, o modelo deve conter vários fatores experimentais. Para fazer isso, os fatores devem variar e assumir dois níveis, um máximo e um mínimo, e os resultados devem ser guardados. Depois disso, funções matemáticas devem ser procuradas para aproximar os valores encontrados experimentalmente, dentro de certa precisão.

Porém, isso só é válido se a variação dos fatores entre os níveis máximo e mínimo puder descrever o comportamento do mesmo neste intervalo. Para isso, deve-se constatar que o comportamento deste fator é contínuo e monotônico, o que é bem razoável em se tratando de processos de corte tecnológicos, como é o caso do fresamento de topo.

Delineamentos fatoriais são freqüentemente usados em experimentos envolvendo muitos fatores onde é necessário estudar o efeito dos fatores sobre uma resposta (Montgomery, 2001). Destes, o caso mais importante é o $\mathrm{k}$ fatorial com dois níveis, um alto e um baixo. Um ensaio completo requer $2^{\mathrm{k}}$ observações. Pelo fato de só existirem 
dois níveis para cada fator, deve-se assumir que o comportamento da resposta provocada pelos mesmos é aproximadamente linear dentro da faixa de valores compreendidos entre os dois níveis.

É utilizada uma notação especial para representar as possíveis combinações entre os fatores. Em geral, uma combinação de fatores é representada por uma série de letras minúsculas. Se uma letra está presente, então o fator correspondente a ela está no nível alto naquela combinação; se estiver ausente, o fator está no nível baixo. Por exemplo, num experimento $2^{3}$ fatorial, uma combinação com $\mathrm{A}$ e $\mathrm{C}$ no nível alto e $\mathrm{B}$ no nível baixo é representada por ac. Combinações onde todos os fatores estão no nível baixo são representadas por (1). Cada uma dessas representações indica a soma de todas as observações com a mesma combinação de níveis de fatores.

Geometricamente, essa modelagem é um cubo como o da figura 3.7.1, com as oito combinações formando os seus cantos. Com este, é possível estimar 3 efeitos principais $(\mathrm{a}, \mathrm{b}, \mathrm{c})$, considerando como fatores o avanço, a velocidade de corte e a profundidade de corte, respectivamente, três efeitos de interação de fatores dois a dois e um efeito da interação dos três fatores juntos.

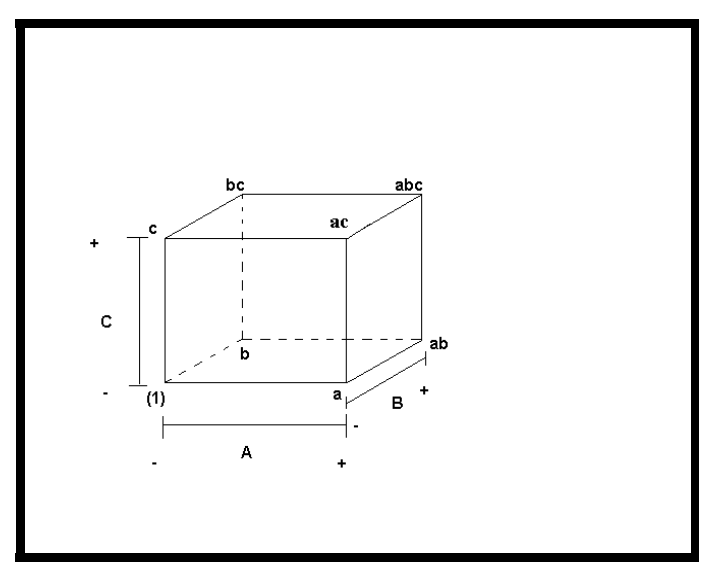

Figura 3.7.1 - Modelagem dos Experimentos

Utilizando-se a figura 3.7.1, os efeitos podem ser facilmente estimados. Considerando as seguintes relações: 
- $\mathrm{a}=\mathrm{f}_{\mathrm{z}}$

- $b=v_{f}$

- $c=a_{e}$

$\mathrm{O}$ efeito principal $\mathrm{f}_{\mathrm{z}}$ pode ser estimado somando-se os valores obtidos das quatro combinações do lado direto do cubo, onde $\mathrm{f}_{\mathrm{z}}$ está no nível mais alto, subtraindo deste total a soma dos valores obtidos das quatro combinações do lado esquerdo do cubo, onde $\mathrm{f}_{\mathrm{z}}$ está no nível mais baixo, e dividindo-se este total por $4 \times \mathrm{n}$, onde $\mathrm{n}=4$ replicações. Isto resulta em:

Efeito $_{z}=\frac{1}{4 n} \cdot\left[f_{z}+f_{z} \cdot v_{f}+f_{z} \cdot a_{e}+f_{z} \cdot v_{f} \cdot a_{e}-(1)-v_{f}-a_{e}-v_{f} \cdot a_{e}\right]$

Da mesma maneira, os outros efeitos principais podem ser estimados, sendo que para o efeito de $\mathrm{v}_{\mathrm{f}}$ devem-se usar os lados da frente e de trás do cubo, e para $\mathrm{a}_{\mathrm{e}}$ devem-se usar os lados de cima e de baixo do cubo, resultando em:

$$
\begin{aligned}
& \text { Efeitov }_{f}=\frac{1}{4 n} \cdot\left[v_{f}+f_{z} \cdot v_{f}+v_{f} \cdot a_{e}+f_{z} \cdot v_{f} \cdot a_{e}-(1)-f_{z}-a_{e}-f_{z} \cdot a_{e}\right] \\
& \text { Efeitoa }_{e}=\frac{1}{4 n} \cdot\left[a_{e}+f_{z} \cdot a_{e}+v_{f} \cdot a_{e}+f_{z} \cdot v_{f} \cdot a_{e}-(1)-f_{z}-v_{f}-f_{z} \cdot v_{f}\right]
\end{aligned}
$$

Os efeitos das interações dos fatores dois a dois são estimados, no caso da interação $f_{z}-v_{f}$, pela diferença entre a soma dos efeitos de $f_{z}$ nos dois níveis de $v_{f}$. Por convenção, metade desta diferença é chamada de interação $f_{z}-v_{f}$. Simbolicamente, as três interações entre os fatores são: 
Efeito $_{z}-v_{f}=\frac{1}{4 n} \cdot\left[f_{z} \cdot v_{f} \cdot a_{e}-v_{f} \cdot a_{e}+f_{z} \cdot v_{f}-v_{f}-f_{z} \cdot a_{e}+a_{e}-f_{z}+(1)\right]$

Efeito $_{z}-a_{e}=\frac{1}{4 n} \cdot\left[(1)-f_{z}+v_{f}-f_{z} \cdot v_{f}-a_{e}+f_{z} \cdot a_{e}-v_{f} \cdot a_{e}+f_{z} \cdot v_{f} \cdot a_{e}\right]$

Efeitov $_{f}-a_{e}=\frac{1}{4 n} \cdot\left[(1)+f_{z}-v_{f}-f_{z} \cdot v_{f}-a_{e}-f_{z} \cdot a_{e}+v_{f} \cdot a_{e}+f_{z} \cdot v_{f} \cdot a_{e}\right]$

A interação $f_{z}-v_{f}-a_{e}$ é definida como a soma das diferenças entre a interação $\mathrm{f}_{\mathrm{z}}-\mathrm{v}_{\mathrm{f}}$ para os dois diferentes níveis de $\mathrm{a}_{\mathrm{e}}$, sendo assim:

Efeito $_{z}-v_{f}-a_{e}=\frac{1}{4 n} \cdot\left[f_{z} \cdot v_{f} \cdot a_{e}-v_{f} \cdot a_{e}-f_{z} \cdot a_{e}+a_{e}-f_{z} \cdot v_{f}+v_{f}+f_{z}-(1)\right]$ 


\section{4 - PROJETO DO DINAMÔMETRO}

O projeto do dinamômetro em questão, baseou-se no trabalho de (Saglam e Unuvar, 2001). Este é constituído basicamente de uma mesa, instrumentada com 4 células de carga, distribuídas duas a duas em duas direções ortogonais, sendo que cada uma das células de carga está instrumentada para medir deformações nas direções axial e transversal, fazendo assim com que o dinamômetro seja capaz de medir forças nas três direções ortogonais.

A medição de força é expressa através da deformação do material submetido à mesma, por meio de elementos de calibração (células de carga), sendo estes feitos de materiais elásticos. Quando o material e a geometria são selecionados corretamente de acordo com a força a ser medida, a deformação permanece na região elástica, e a variação desta com a força é linear. Esta deformação pode ser captada por meio de transdutores mecânicos, pneumáticos, ópticos, elétricos, etc. Neste trabalho foram utilizados strain gages, que convertem a deformação em sinais elétricos, devido às vantagens já descritas anteriormente neste trabalho.

Os dois critérios mais importantes no projeto de um dinamômetro são a rigidez e a sensibilidade. O critério de rigidez é a freqüência natural do dinamômetro. Todas as máquinas-ferramenta estão submetidas a vibrações, forçadas e auto-excitadas. Para que os dados de medição de força não sejam influenciados por alguma vibração do dinamômetro durante o corte, a sua freqüência natural deve ser maior que a freqüência de vibração (4 vezes ou mais).

Nos dinamômetros, para correta distribuição de tensões na área dos strain gages, estes são posicionados na região de máxima deformação da célula de carga. A célula de carga é projetada e posicionada de forma que seja deformada pela componente a ser medida da força. Assim, os efeitos das outras componentes serão reduzidos.

As células de carga devem ser usinadas idêntica e simetricamente para evitar efeitos cruzados de uma componente de força sobre as outras. A simetria da célula de 
carga gera caminhos paralelos para a transferência de calor, o que, teoricamente, faz com que dois pontos em lados opostos da célula estejam sempre à mesma temperatura.

O comportamento elástico do material deve ser coerente com a freqüência e intensidade do carregamento. Para aumentar a vida à fadiga em casos de cargas vibratórias e/ou variáveis, materiais com alta tenacidade devem ser selecionados. Para reduzir os efeitos da temperatura na medição, o material da célula de carga deve ter baixo coeficiente de expansão e alta condutibilidade térmica.

A célula de carga foi dimensionada como um anel. Considerando uma das metades do anel, como mostrado na figura 4.1, e considerando o caso em que as partes superior e inferior não possuem o grau de liberdade de rotação. $\mathrm{M}_{0}$ é o momento requerido para satisfazer esta condição.

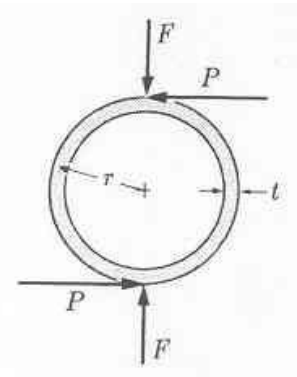

(a)

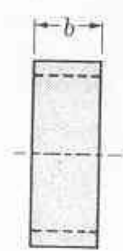

(b)

Figura 4.1 - (a) Anel para medição de forças; (b) Elemento anel para análise elástica - adaptado de (Cook e Rabinowicz, 1963)

O momento fletor $\mathrm{M}_{\theta}$ em qualquer ponto do anel é:

$$
M_{\theta}=M_{0}+\frac{F . r}{2} \operatorname{sen} \theta+\frac{P . r}{2}(1-\cos \theta)
$$

A energia elástica total no anel é: 
$U=\frac{1}{2 E I} \int_{0}^{\pi} M_{\theta}{ }^{2} r . d \theta$

A rotação angular $\varnothing$ do anel em $\theta=0$ é 0 , então:

$\left(\frac{\partial U}{\partial M_{0}}\right)_{\theta=0}=0=\frac{1}{E I} \int_{0}^{\pi} M_{\theta} \frac{\partial M_{\theta}}{\partial M_{0}} r \cdot d \theta$

$\mathrm{Ou}$

$0=\int_{0}^{\pi}\left[M_{0}+\frac{F \cdot r \operatorname{sen} \theta}{2}+\frac{P \cdot r}{2}(1-\cos \theta)\right] d \theta$

Integrando, temos:

$M_{0} \pi+F . r+\frac{P . r . \pi}{2}=0$

Substituindo na equação 49, temos:

$$
M_{\theta}=\frac{F \cdot r}{2}\left(\operatorname{sen} \theta-\frac{2}{\pi}\right)-\frac{P \cdot r}{2} \cos \theta
$$

Pode-se notar que o momento devido a $\mathrm{F} / 2$ é zero quando: 
$\operatorname{sen} \theta=\frac{2}{\pi} \longrightarrow \theta=39,6^{\circ}$

E o momento devido a $\mathrm{P} / 2$ é zero quando:

$\cos \theta=0 \longrightarrow \theta=90^{\circ}$

As duas posições, $\theta=39,6^{\circ}$ e $\theta=90^{\circ}$ são cada uma um nó de deformação para uma das forças. Assim, pode-se escrever:

$$
\begin{aligned}
& M_{39,6^{\circ}}=-\frac{P \cdot r}{2} \cos 39,6^{\circ}=-0,385 P \cdot r \\
& M_{90^{\circ}}=\frac{F \cdot r}{2}\left(\operatorname{sen} 90^{\circ}-\frac{2}{\pi}\right)=0,181 F \cdot r
\end{aligned}
$$

A deformação $\varepsilon$ em um anel estreito é:

$$
\varepsilon=\frac{6 M}{E b t^{2}}
$$

Assim:

$$
\varepsilon_{39,6^{\circ}}=2,31 \frac{P . r}{E b t^{2}}
$$




$$
\varepsilon_{90^{\circ}}=1,09 \frac{F \cdot r}{E b t^{2}}
$$

Podem-se mostrar por simetria que as equações 60 e 61 se mantêm suficientemente constantes para todo o anel da figura 4.1, desde que suas partes superior e inferior estejam com os graus de liberdade de rotação restringidos.

Desta maneira surge então uma unidade capaz de medir independentemente duas componentes de força $\mathrm{F}$ e P. Vide anexo o memorial de cálculo das células de carga.

$\mathrm{O}$ esquema de montagem do mesmo pode ser visto na figura abaixo:

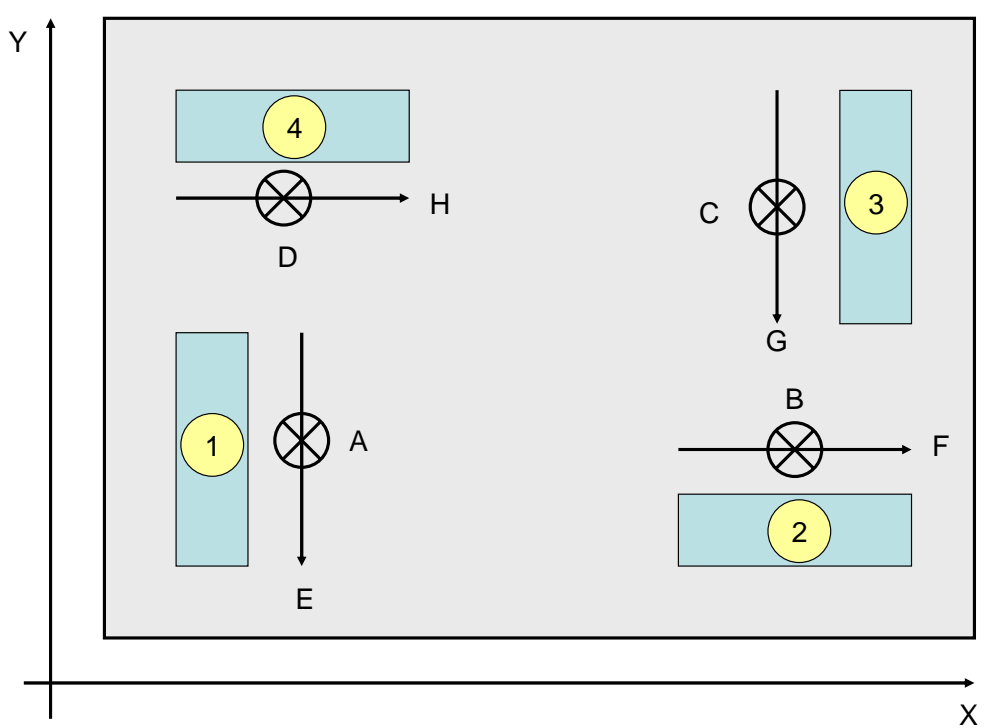

Figura 4.2 - Esquema de Montagem das Células de Carga no Dinamômetro 


\section{5 - CONSTRUÇÃO DO DINAMÔMETRO}

O dinamômetro foi projetado para ter a rigidez necessária para que as vibrações do processo não influenciem as leituras de força (freqüência natural do dinamômetro igual a 4 vezes ou mais a freqüência do sinal de força). O material selecionado, tanto para as células de carga (conforme memorial de cálculo, Anexo 1) quanto para a base e mesa foi o aço ABNT 4340, sendo que a fixação das células de carga à base foi feita por meio de parafusos M10x20 mm, DIN 912 - Classe 12,9.

O desenho de conjunto do dinamômetro pode ser visto na figura abaixo:

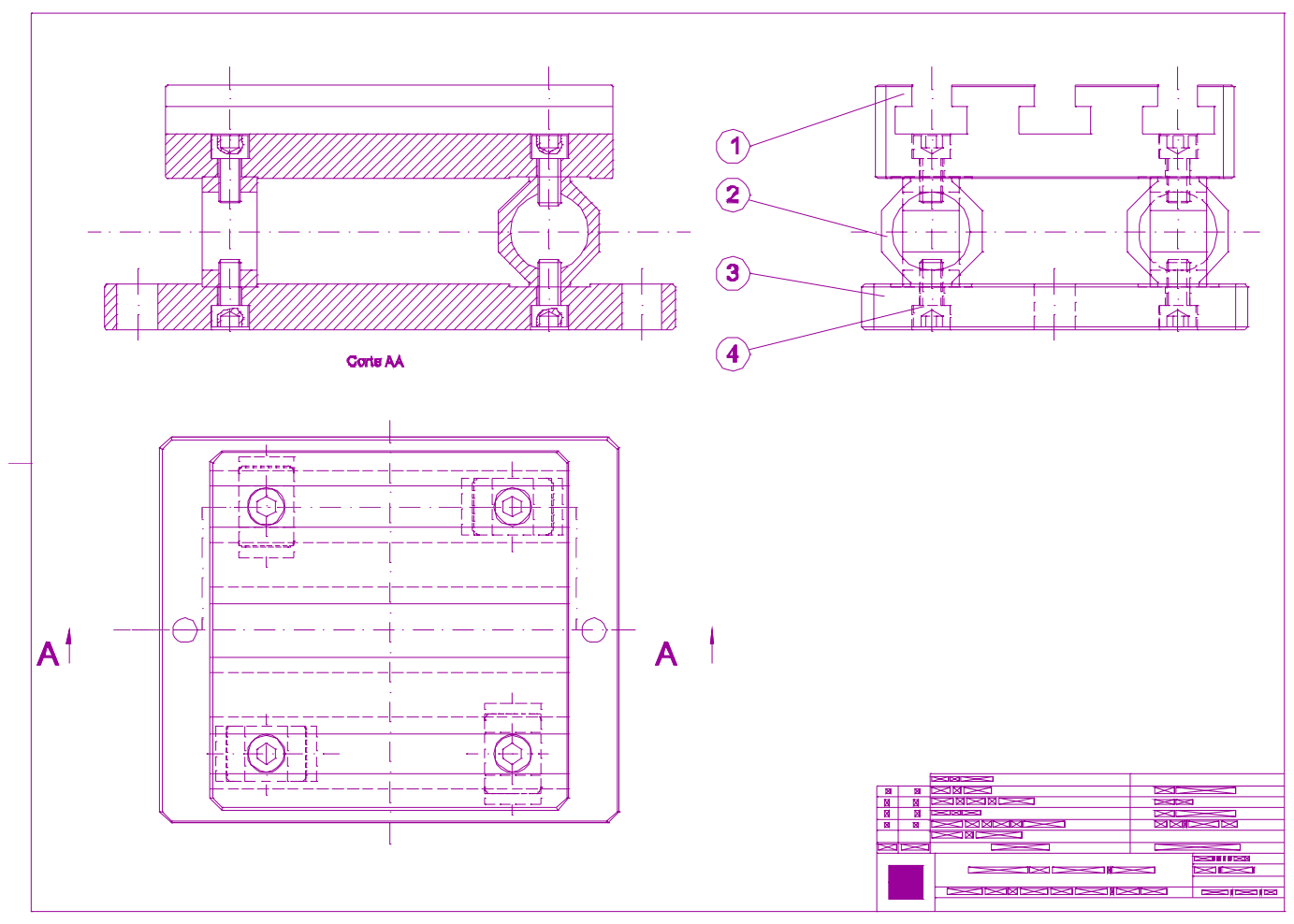

Figura 5.1 - Desenho de Conjunto do Dinamômetro

Os desenhos de fabricação dos componentes estão no Anexo 2. 
As células de carga foram fabricadas num centro de usinagem $\mathrm{CNC}$, de maneira a tentar minimizar as diferenças entre elas. O ângulo real de colagem dos strain gages é de $45^{\circ}$, pois embora as células de carga tenham sido dimensionadas como anéis, as mesmas foram fabricadas como octógonos. Isso porque existe um problema prático na fixação e restrição do grau de liberdade de rotação das superfícies superior e inferior de um anel. Além disso, esta é uma boa aproximação de um anel no que diz respeito à distribuição de tensões.

O procedimento de colagem dos strain gages nas células de carga, seguiu o procedimento padrão, sendo que o mesmo está descrito a seguir: 


\section{1 - Análise Prévia}

A análise prévia consistiu em determinar em quais seriam as superfícies nas quais os strain-gages deveriam ser instalados primeiro, devido às limitações de tamanho da própria célula de carga. Os procedimentos para as outras superfícies são semelhantes. Dois grupos de células de carga foram criados para a primeira colagem, devido ao tamanho e quantidade de pinças disponíveis, figuras 5.1.1 e 5.1.2.

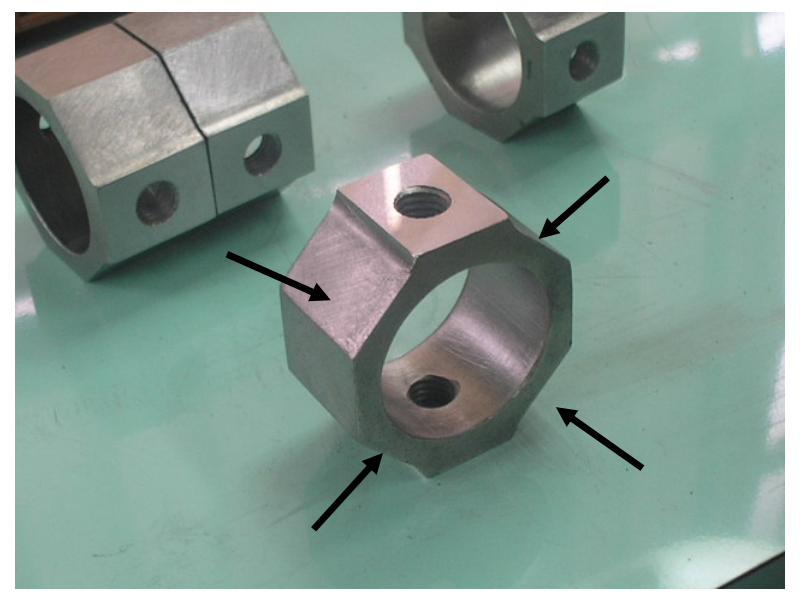

Figura 5.1.1 - Superfícies Selecionadas para a Primeira Etapa

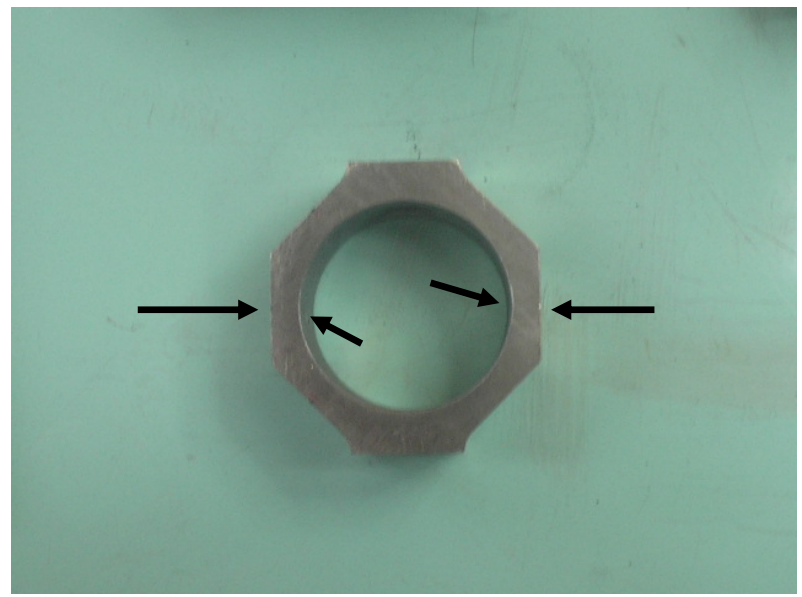

Figura 5.1.2 - Superfícies Selecionadas para Primeira Etapa 


\section{2 - Preparação das Superfícies}

A superfície da célula de carga precisou ser preparada adequadamente antes de proceder à colagem do strain-gage. Inicialmente foi utilizada uma lixa fina $\mathrm{n}^{\mathrm{o}} 200$ e 300 no local de instalação para criar uma rugosidade superficial adequada, permitindo a melhor aderência da cola. Gazes umedecidas foram utilizadas para limpar a superfície da célula de carga.

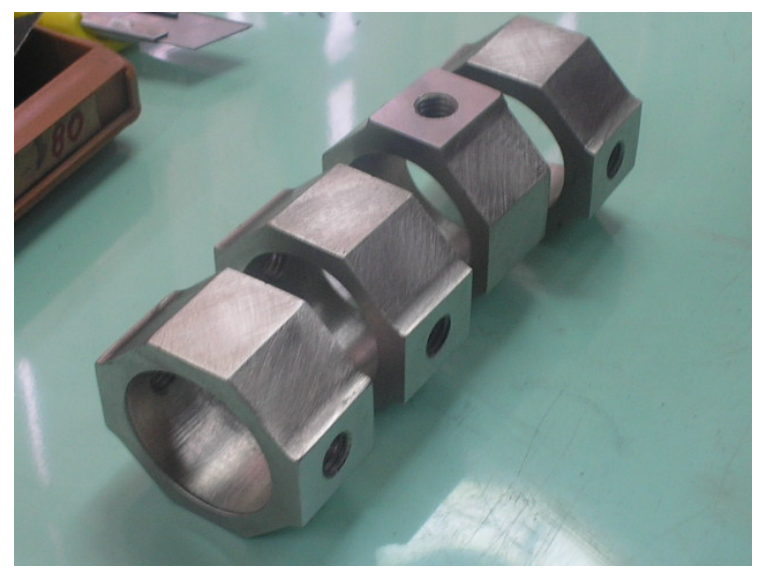

Figura 5.2.1 - Conjunto de Células de Carga com Superfícies Preparadas

\section{3 - Marcação das Linhas de Orientação}

Os strain-gages apresentam linhas de orientação perpendiculares entre si para correta instalação e mensuração. A marcação se deu com estilete, régua e esquadro, nas superfícies anteriormente escolhidas, sendo que as mesmas não atingiram as áreas de colagem dos strain gages. Novamente gazes umedecidas com Acetona foram utilizadas para limpar as superfícies das células de carga. 


\section{4 - Colagem}

Para esta aplicação, foi selecionado o adesivo tipo Epóxi M-610 da Micro Measurement Group, por apresentar grande estabilidade ao longo de sua vida útil, além de sua facilidade de uso. $O$ adesivo foi passado na superfície da célula de carga e o strain-gage, segundo as linhas de orientação marcadas anteriormente. Uma nova camada de cola é então aplicada em cima do strain-gage para aumentar a aderência e protegê-lo do ambiente. O strain-gage foi mantido em sua posição por fita adesiva resistente ao calor da etapa de cura seguinte.

O ciclo de cura é feito a uma temperatura entre 120 e $175^{\circ} \mathrm{C}$, por duas horas, com o extensômetro sob pressão de grampos de 1 a $5 \mathrm{~kg} / \mathrm{mm}^{2}$. Após a colagem, o adesivo resiste a temperaturas ambientes entre $-200^{\circ} \mathrm{C} \mathrm{a}+300^{\circ} \mathrm{C}$.

Depois de colados, os strain-gages devem sofrer um tratamento térmico de póscura, com temperatura de pelo menos $10^{\circ} \mathrm{C}$ acima da de cura por duas horas, para relaxamento das tensões introduzidas devido à ação das pinças e dos gradientes térmicos sobre a sua grade.

Os extensômetros utilizados são do fabricante Excelsensor, sendo que o extensômetro é um modelo unidirecional simples (Excelsensor, 2005). 


\section{5 - Ida ao Forno}

Uma película de Teflon, colocada sobre o extensômetro no processo de colagem, serve para isolar o contato do adesivo com o que não deve ser colado, no momento em que o adesivo se espalhar pela pressão exercida. Suporta, sem alteração, as temperaturas de cura dos adesivos.

Almofadas de silicones foram postas sobre a película de Teflon para distribuir melhor a pressão aplicada pela pinça sem danificar o extensômetro. Por último, uma placa de alumínio também foi colocada para distribuir melhor as pressões.

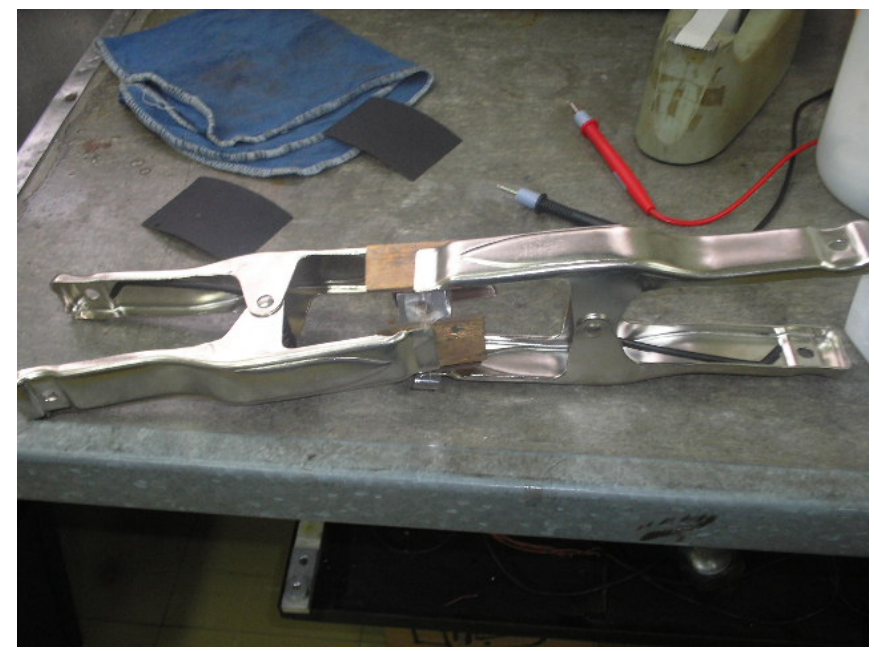

Figura 5.5.1 - Célula de Carga Pronta para Ir ao Forno 


\section{6 - CALIBRAÇÃO DO DINAMÔMETRO}

A calibração do dinamômetro foi feita estaticamente, sendo que foram aplicadas cargas conhecidas em diversos pontos e em diversas direções sobre o mesmo. Foram aplicados carregamentos axiais numerados de 1 a 4 e carregamentos laterais, numerados de 1 a 6. Convencionou-se que os carregamentos axiais serão A1, A2, A3 e A4 e os carregamentos laterais são L1, L2, L3, L4, L5 e L6.

$\mathrm{Na}$ figura abaixo, são mostrados os pontos de aplicação da cada um dos carregamentos:

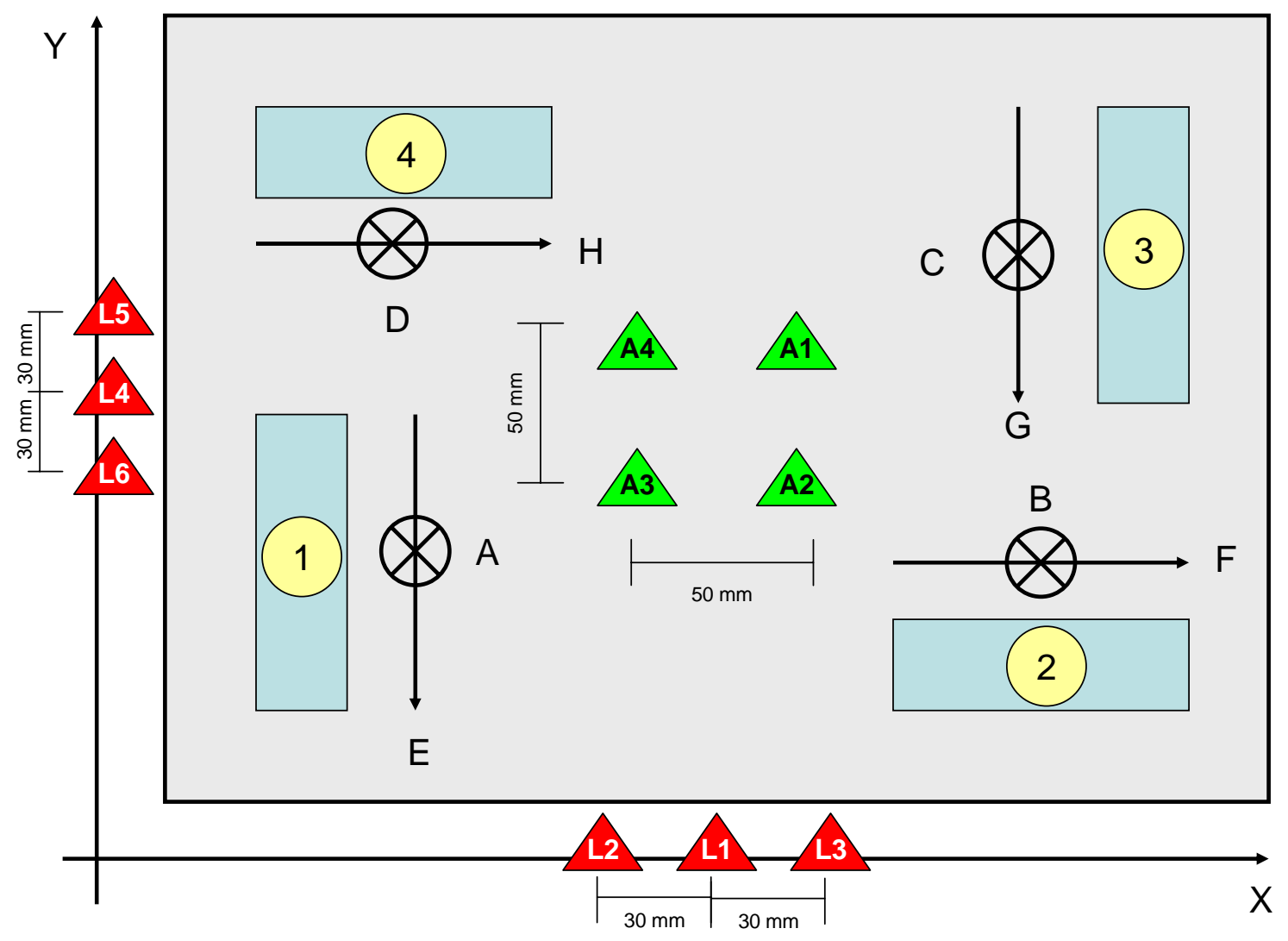

Figura 6.1 - Posição de aplicação das cargas de calibração 
Foram então aplicadas cargas que variaram de 500 a 2000 N, com intervalo de 500 N. Para cada uma das cargas, foram anotados os valores indicados por todas as células de carga em todas as direções. Para comparação dos valores, foi utilizada uma célula de carga comercial tipo "S".

Para os carregamentos axiais, os dados obtidos foram os seguintes:

Tabela 6.1 - Dados de calibração carregamento A1

\begin{tabular}{c|cccc}
\hline \multirow{2}{*}{ Direção } & \multicolumn{4}{|c}{ Carga Aplicada $(N)$} \\
A & 500 & 1000 & 1500 & 2000 \\
\cline { 2 - 5 } B & 80 & 160 & 230 & 310 \\
C & 230 & 460 & 700 & 930 \\
D & 120 & 240 & 350 & 460 \\
E & 70 & 140 & 200 & 270 \\
F & -20 & -50 & -70 & -100 \\
G & 40 & 80 & 130 & 180 \\
H & 60 & 110 & 170 & 230 \\
& -30 & -60 & -90 & -110 \\
\hline
\end{tabular}

Tabela 6.2 - Dados de calibração carregamento A2

\begin{tabular}{c|cccc}
\hline \multirow{2}{*}{ Direção } & \multicolumn{4}{|c}{ Carga Aplicada $(N)$} \\
A & 500 & 1000 & 1500 & 2000 \\
\cline { 2 - 5 } B & 210 & 420 & 640 & 860 \\
C & 130 & 240 & 340 & 450 \\
D & 30 & 50 & 80 & 100 \\
E & 140 & 290 & 440 & 590 \\
F & -50 & -110 & -170 & -230 \\
G & 60 & 100 & 140 & 180 \\
H & 50 & 60 & 80 & 90 \\
& -50 & -80 & -120 & -140 \\
\hline
\end{tabular}


Tabela 6.3 - Dados de calibração carregamento A3

\begin{tabular}{c|cccc}
\hline \multirow{2}{*}{ Direção } & \multicolumn{4}{|c}{ Carga Aplicada $(\mathrm{N})$} \\
$\mathrm{A}$ & 500 & 1000 & 1500 & 2000 \\
\cline { 2 - 5 } $\mathrm{B}$ & 70 & 150 & 230 & 310 \\
$\mathrm{C}$ & 30 & 40 & 50 & 70 \\
$\mathrm{D}$ & 110 & 220 & 330 & 450 \\
$\mathrm{E}$ & 300 & 600 & 890 & 1180 \\
$\mathrm{~F}$ & -30 & -50 & -60 & -70 \\
$\mathrm{G}$ & 50 & 60 & 80 & 110 \\
$\mathrm{H}$ & 70 & 110 & 160 & 210 \\
\hline
\end{tabular}

Tabela 6.4 - Dados de calibração carregamento A4

\begin{tabular}{c|cccc}
\hline \multirow{2}{*}{ Direção } & \multicolumn{4}{|c}{ Carga Aplicada $(N)$} \\
A & 500 & 1000 & 1500 & 2000 \\
\cline { 2 - 5 } B & -20 & -40 & -50 & -70 \\
C & 110 & 220 & 330 & 440 \\
D & 260 & 520 & 770 & 1020 \\
E & 140 & 290 & 450 & 600 \\
F & 10 & 10 & 10 & 10 \\
G & 50 & 100 & 140 & 190 \\
H & 120 & 230 & 350 & 500 \\
& -20 & -50 & -80 & -110 \\
\hline
\end{tabular}


Estes dados foram plotados, dando origem às seguintes curvas:

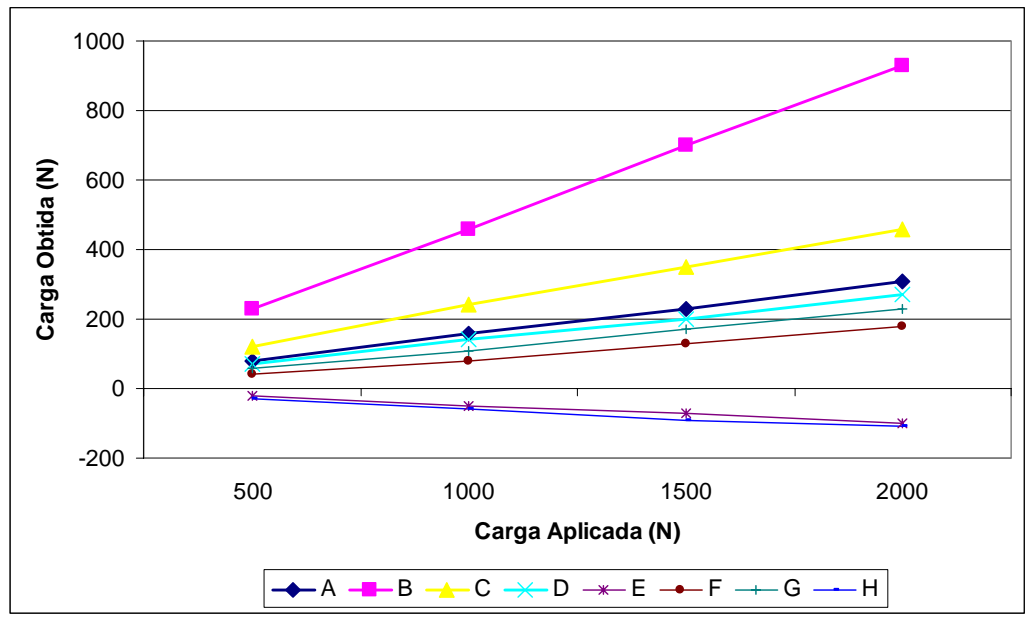

Figura 6.2 - Curvas de Calibração para Carregamento A1

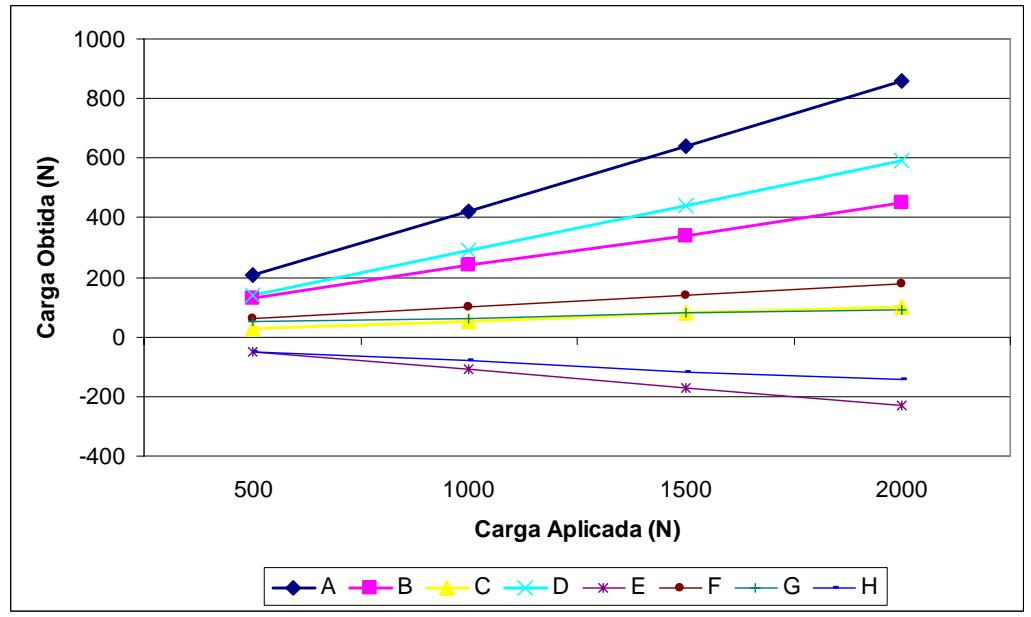

Figura 6.3 - Curvas de Calibração para Carregamento A2 


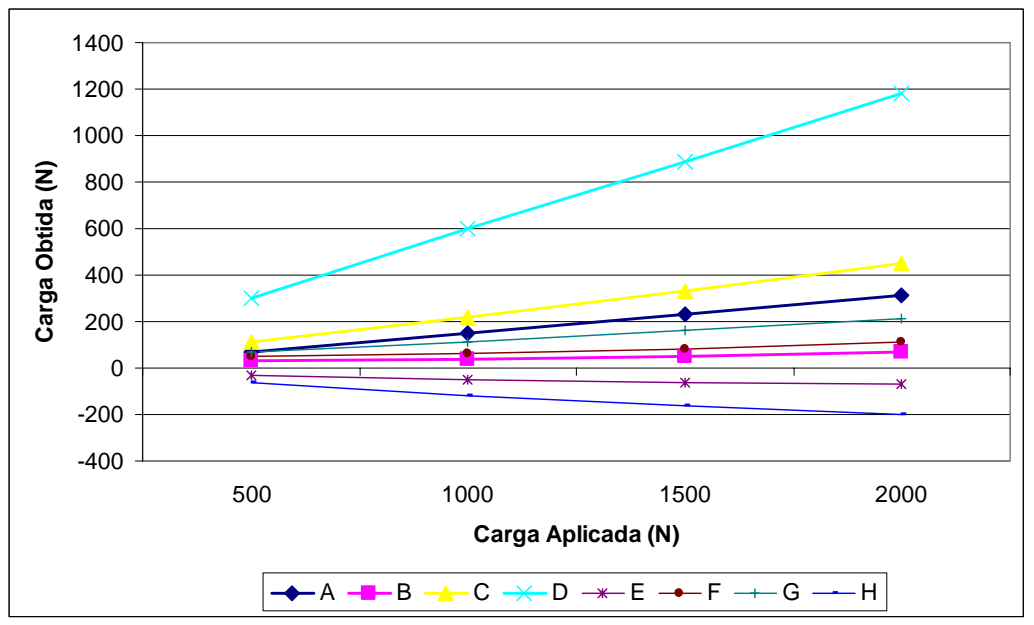

Figura 6.4 - Curvas de Calibração para Carregamento A3

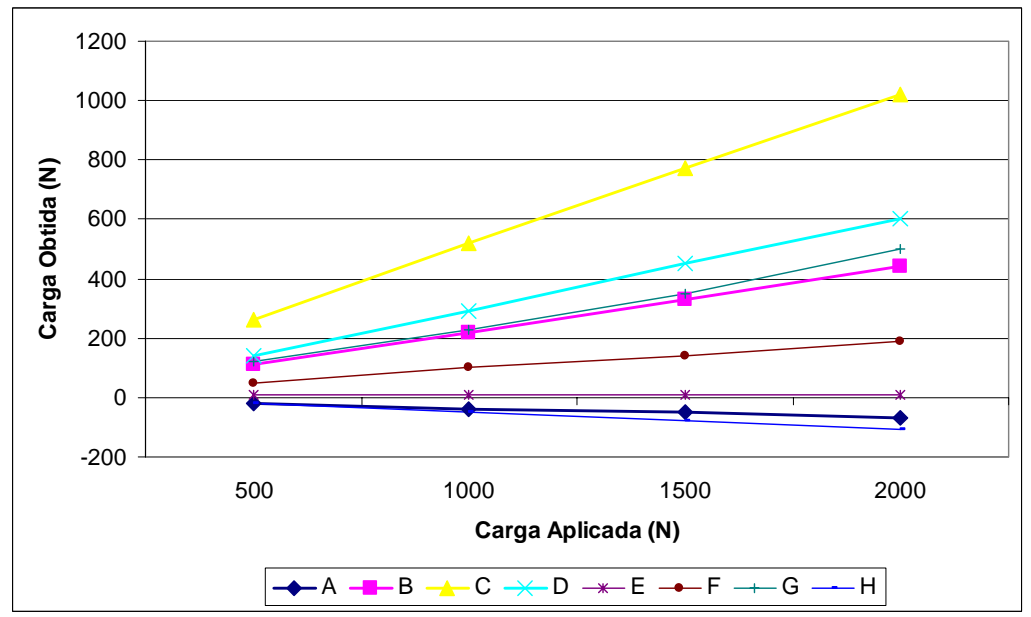

Figura 6.5 - Curvas de Calibração para Carregamento A4

A partir destes gráficos, é possível visualizar as influências cruzadas de um canal sobre os outros.

Para os carregamentos laterais, o procedimento foi repetido, sendo que as tabelas e os gráficos obtidos podem ser vistos a seguir: 
Tabela 6.5 - Dados de calibração carregamento L1

\begin{tabular}{c|cccc}
\hline \multirow{2}{*}{ Direção } & \multicolumn{4}{|c}{ Carga Aplicada $(\mathrm{N})$} \\
$\mathrm{A}$ & 500 & 1000 & 1500 & 2000 \\
\cline { 2 - 5 } $\mathrm{B}$ & -60 & -110 & -160 & -200 \\
$\mathrm{C}$ & 60 & 130 & 180 & 240 \\
$\mathrm{D}$ & 70 & 130 & 190 & 260 \\
$\mathrm{E}$ & -70 & -140 & -210 & -280 \\
$\mathrm{~F}$ & 70 & 170 & 290 & 400 \\
$\mathrm{G}$ & 280 & 580 & 890 & 1210 \\
$\mathrm{H}$ & 80 & 150 & 200 & 260 \\
\hline
\end{tabular}

Tabela 6.6 - Dados de calibração carregamento L2

\begin{tabular}{c|cccc}
\hline \multirow{2}{*}{ Direção } & \multicolumn{4}{|c}{ Carga Aplicada $(N)$} \\
A & 500 & 1000 & 1500 & 2000 \\
\cline { 2 - 5 } B & -60 & -110 & -160 & -200 \\
C & 60 & 120 & 180 & 230 \\
D & 70 & 140 & 210 & 280 \\
E & -90 & -170 & -250 & -320 \\
F & 30 & 70 & 110 & 150 \\
G & 230 & 470 & 700 & 950 \\
H & 160 & 300 & 420 & 530 \\
\hline
\end{tabular}

Tabela 6.7 - Dados de calibração carregamento L3

\begin{tabular}{c|cccc}
\hline \multirow{2}{*}{ Direção } & 500 & \multicolumn{4}{c}{ Carga Aplicada $(N)$} \\
A & -60 & -110 & -160 & 2000 \\
\cline { 2 - 5 } B & 60 & 130 & 190 & -190 \\
C & 70 & 120 & 170 & 250 \\
D & -70 & -130 & -180 & 230 \\
E & 140 & 310 & 490 & -250 \\
F & 340 & 710 & 1080 & 670 \\
G & 0 & -10 & -20 & 1470 \\
H & 120 & 250 & 390 & -40 \\
\hline
\end{tabular}


Tabela 6.8 - Dados de calibração carregamento L4

\begin{tabular}{c|cccc}
\hline \multirow{2}{*}{ Direção } & \multicolumn{4}{|c}{ Carga Aplicada $(\mathrm{N})$} \\
$\mathrm{A}$ & 500 & 1000 & 1500 & 2000 \\
\cline { 2 - 5 } B & 100 & 190 & 290 & 390 \\
$\mathrm{C}$ & 20 & 30 & 50 & 60 \\
$\mathrm{D}$ & -40 & -80 & -120 & -150 \\
$\mathrm{E}$ & -90 & -170 & -250 & -340 \\
$\mathrm{~F}$ & 270 & 540 & 820 & 1110 \\
$\mathrm{G}$ & -20 & -30 & -50 & -60 \\
$\mathrm{H}$ & 210 & 410 & 610 & 800 \\
\hline
\end{tabular}

Tabela 6.9 - Dados de calibração carregamento L5

\begin{tabular}{c|cccc}
\hline \multirow{2}{*}{ Direção } & \multicolumn{4}{|c}{ Carga Aplicada $(N)$} \\
A & 500 & 1000 & 1500 & 2000 \\
\cline { 2 - 5 } B & 100 & 200 & 300 & 410 \\
C & 10 & 20 & 30 & 10 \\
D & -30 & -70 & -100 & -130 \\
E & -80 & -170 & -250 & -340 \\
F & 200 & 410 & 630 & 850 \\
G & -80 & -160 & -230 & -300 \\
H & 270 & 540 & 800 & 1050 \\
\hline
\end{tabular}

Tabela 6.10 - Dados de calibração carregamento L6

\begin{tabular}{c|cccc}
\hline \multirow{2}{*}{ Direção } & 500 & \multicolumn{4}{|c}{ Carga Aplicada (N) } \\
A & 100 & 200 & 1500 & 2000 \\
\cline { 2 - 5 } B & 20 & 50 & 300 & 390 \\
C & -40 & -80 & -130 & 100 \\
D & -100 & -180 & -270 & -170 \\
E & 320 & 660 & 1020 & -350 \\
F & 30 & 80 & 120 & 1370 \\
G & 150 & 280 & 410 & 160 \\
H & -100 & -190 & -290 & -400 \\
\hline
\end{tabular}




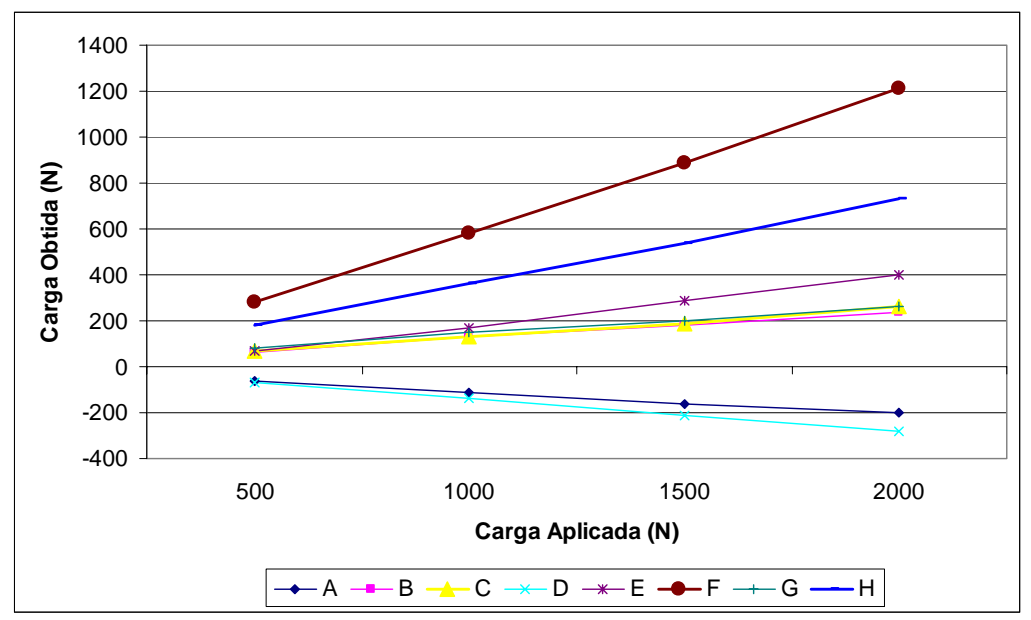

Figura 6.6 - Curvas de Calibração para Carregamento L1

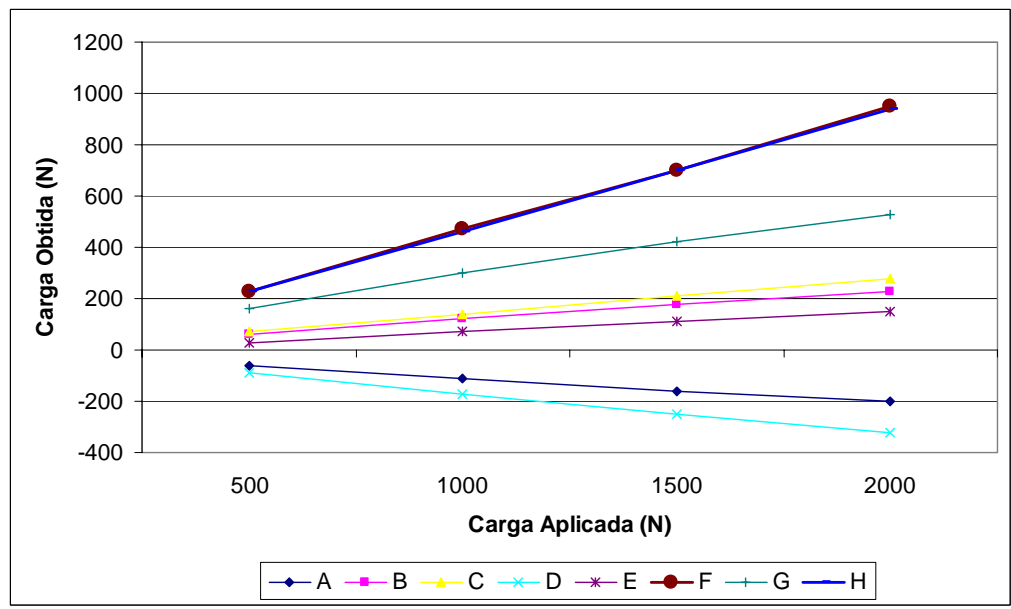

Figura 6.7 - Curvas de Calibração para Carregamento L2 


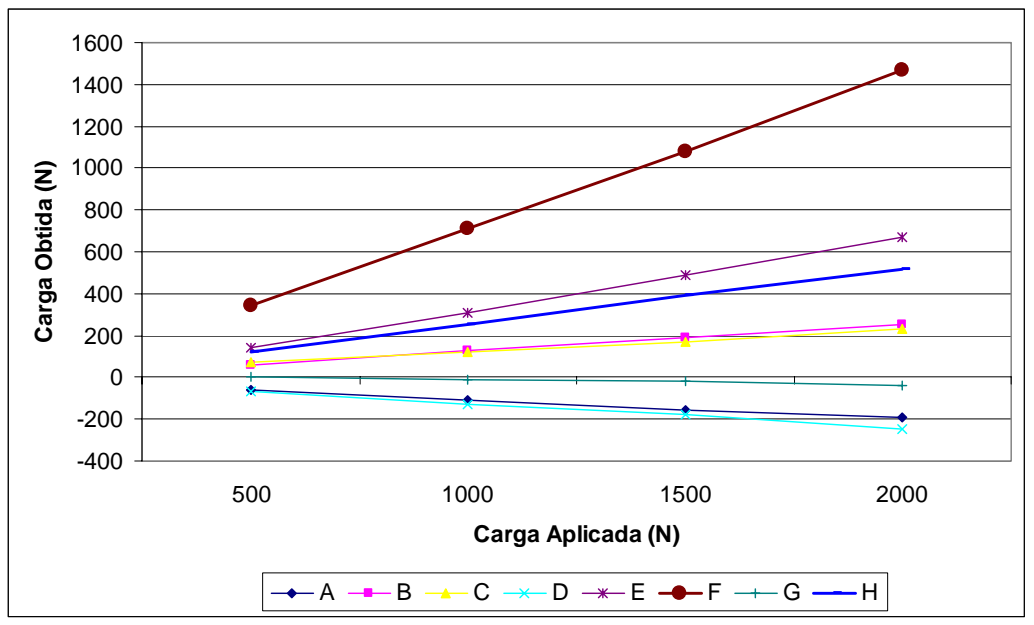

Figura 6.8 - Curvas de Calibração para Carregamento L3

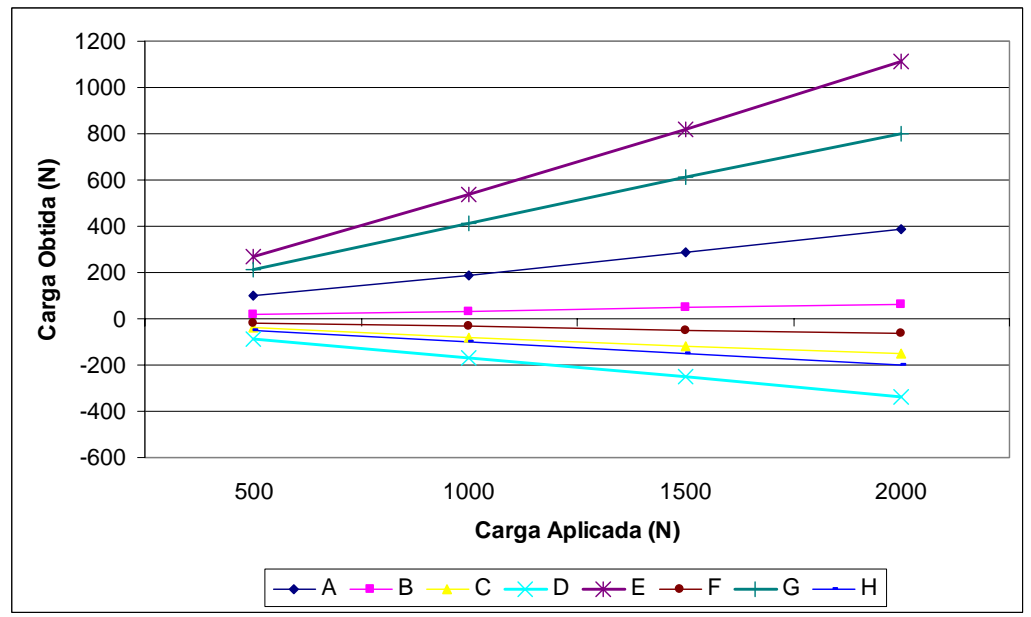

Figura 6.9 - Curvas de Calibração para Carregamento L4 


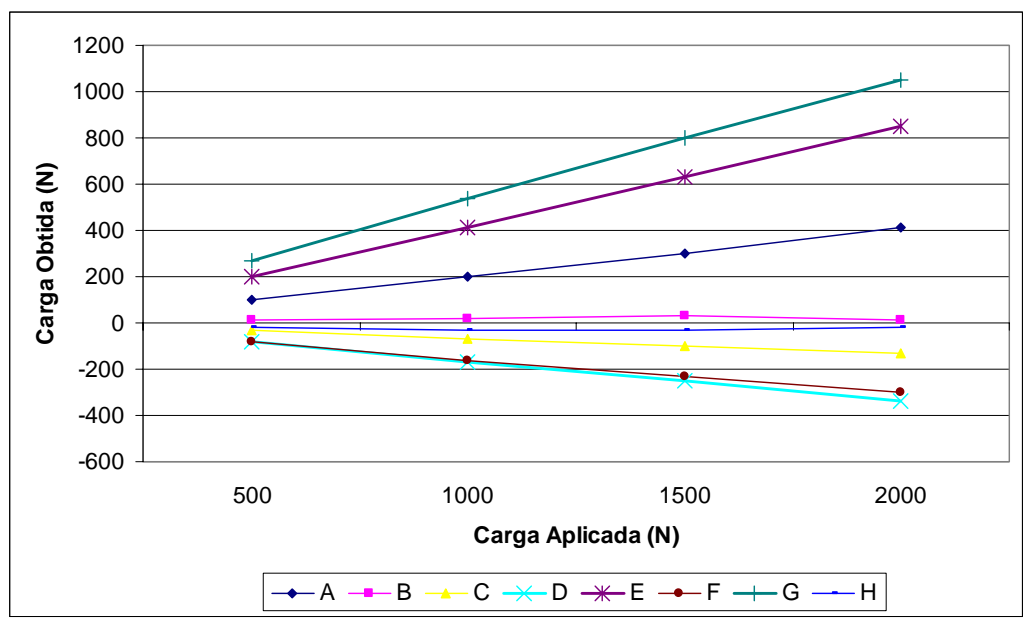

Figura 6.10 - Curvas de Calibração para Carregamento L5

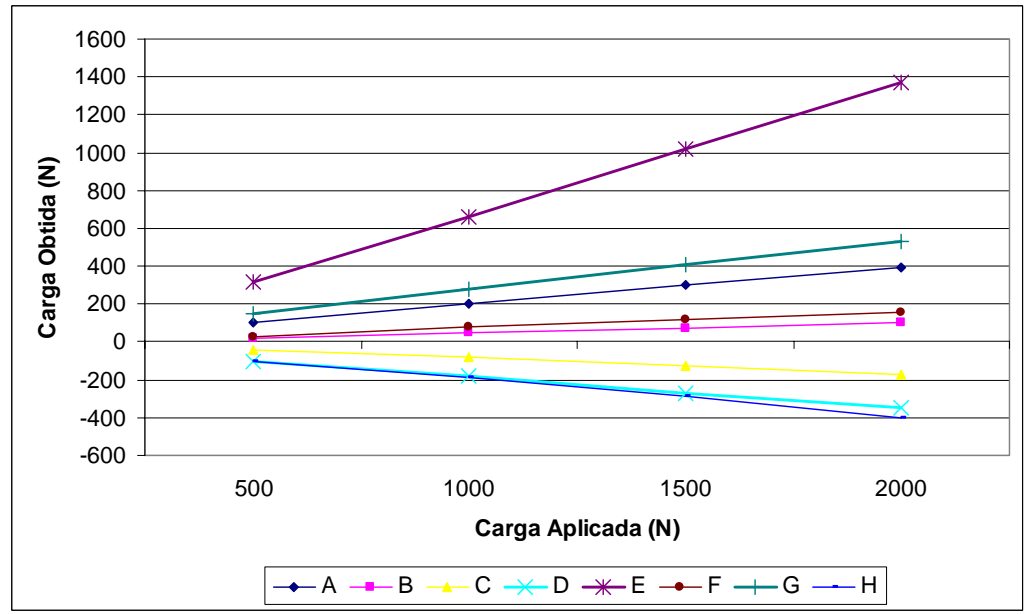

Figura 6.11 - Curvas de Calibração para Carregamento L6

Novamente é possível visualizar os efeitos cruzados entre os canais. Estes efeitos podem ser atribuídos às diferenças dimensionais entre as células de carga e às diferenças nas posições onde foram colados os strain gages, que embora pequenas, acabam sendo amplificadas pelo sistema de medição.

Para análise final dos dados de calibração, foram montados os gráficos abaixo, com a somatória das cargas axiais e laterais: 


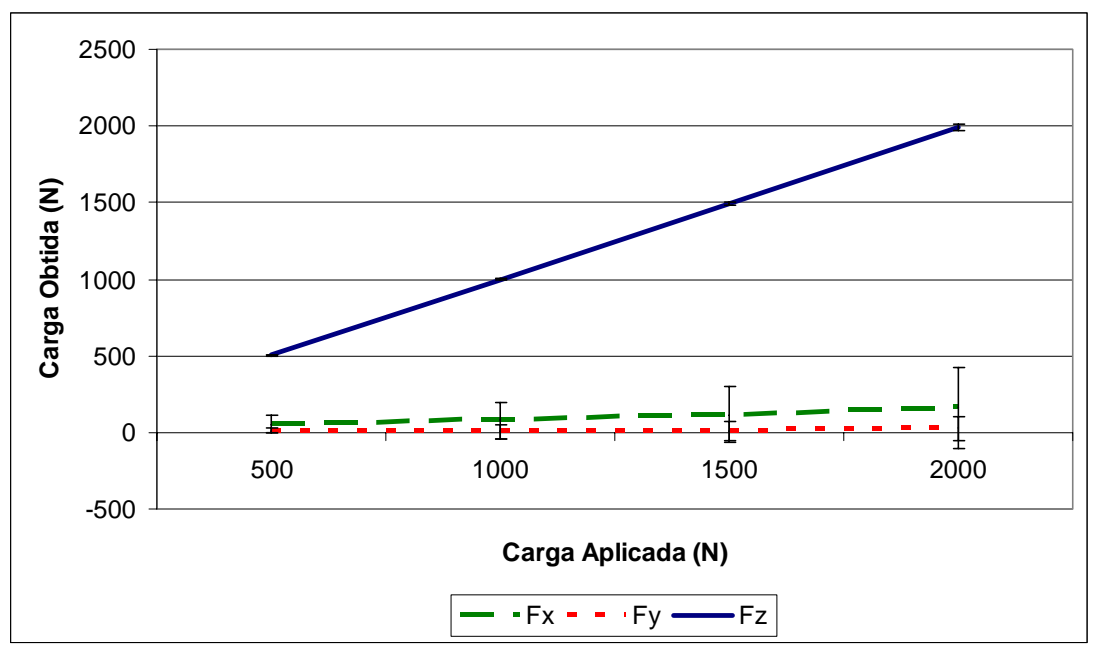

Figura 6.12 - Curvas de Calibração para Carregamento Axial

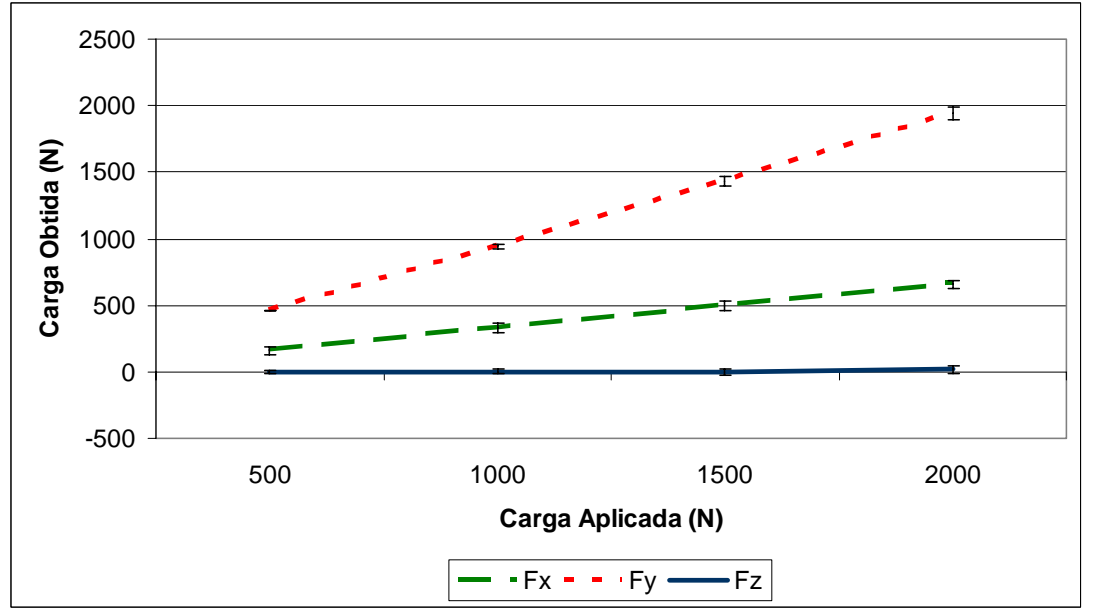

Figura 6.13 - Curvas de Calibração para Carregamento Laterial (Y) 


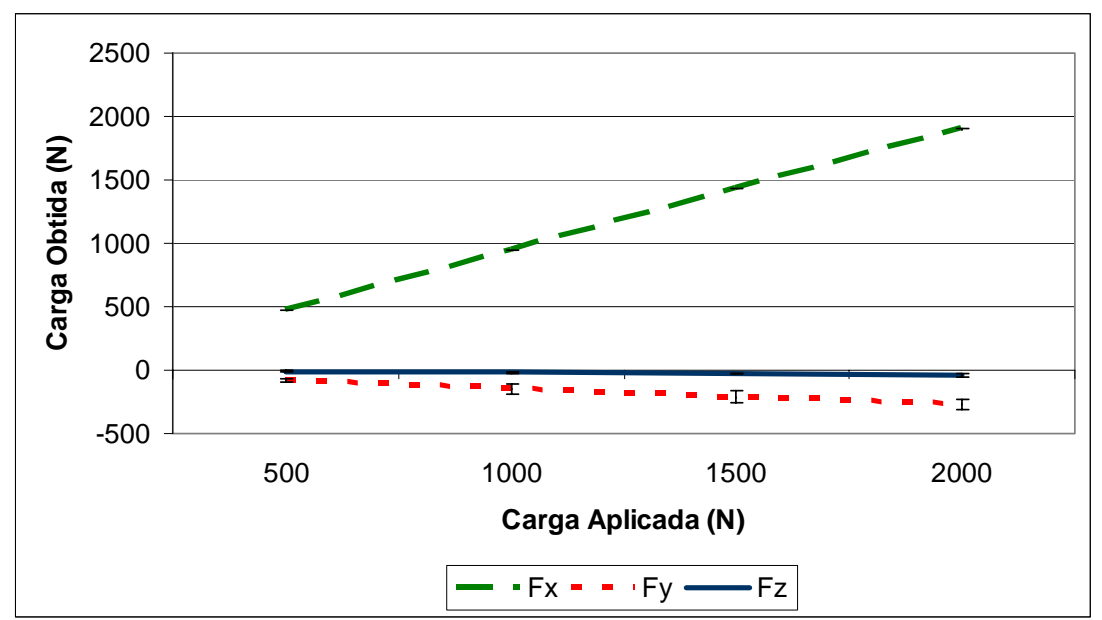

Figura 6.14 - Curvas de Calibração para Carregamento Laterial (X)

Para a disponibilização final dos dados, é necessário eliminar estes efeitos cruzados. Assim, foi desenvolvido uma rotina que implementa equações obtidas através do método da regressão linear múltipla, que agem como filtros para os dados do dinamômetro.

As equações obtidas foram as seguintes:

$$
\begin{aligned}
& \left\{\begin{array}{l}
X=E+G \\
Y=F+H \\
Z=A+B+C+D
\end{array}\right\} \\
& \left\{\begin{array}{l}
F_{X}=1,05 X-0,3291 Y-0,1 Z-1 \\
F_{Y}=0,1338 X+1,0395 Y-0,042 Z \\
F_{Z}=0,0228 X-0,04 Y+0,9524 Z
\end{array}\right\} \\
& \left\{\begin{array}{l}
F_{X} \\
F_{Y} \\
F_{Z}
\end{array}\right\}=\left\{\begin{array}{ccc}
1,05 & -0,3291 & -0,1 \\
0,1338 & 1,0395 & -0,042 \\
0,0228 & -0,04 & 0,9524
\end{array}\right\} \times\left\{\begin{array}{l}
X \\
Y \\
Z
\end{array}\right\}+\left\{\begin{array}{l}
-1 \\
0 \\
0
\end{array}\right\}
\end{aligned}
$$




\section{7 - ESTUDO DE CASO}

Com o auxílio do Dinamômetro construído, conforme a primeira parte deste trabalho, foi realizado um estudo de caso na TenarisConfab, fabricante de tubos de aço com costura para exploração e transporte de óleo e gás, dentre outros, situada na cidade de Pindamonhangaba, São Paulo, SP.

Em uma das fábricas da TenarisConfab são fabricados tubos pelo processo UO SAW, ou seja, a conformação é realizada em duas etapas, a partir da chapa plana; a primeira etapa faz com que a chapa assuma o formato "U", e a segunda etapa completa a conformação, fechando o tubo no formato "O". O processo de soldagem utilizado é o de Solda por Arco Submerso (SAW) (Tenaris, 2007).

As chapas, que servem de matéria-prima para fabricação dos tubos nesta fábrica, têm suas bordas fresadas no início do processo para a correta definição da largura da chapa e para a criação dos chanfros, que serão preenchidos com o material de adição no processo de soldagem.

O objetivo deste estudo é a redução do tempo de ciclo do equipamento denominado Fresadora de Bordas, através da otimização dos parâmetros de corte: velocidade de avanço $\left(v_{f}\right)$, avanço por dente $\left(f_{z}\right)$ e largura de corte $\left(a_{e}\right)$.

Segundo (Diniz, 2006), para se obter a maior produtividade num processo de corte, deve-se utilizar a velocidade de corte de máxima produção $\left(\mathrm{v}_{\mathrm{cmxp}}\right)$, na qual o tempo total de confecção de uma peça $\left(\mathrm{t}_{\mathrm{t}}\right)$ é mínimo. Porém, segundo o mesmo, esta velocidade é dependente da velocidade de troca de ferramental $\left(\mathrm{t}_{\mathrm{ft}}\right)$. Assim, é importante não deixarmos de nos preocupar com a vida da ferramenta, pois a mesma influencia não somente os custos de produção, mas também a produtividade em si.

Desta forma, o processo de corte foi analisado para que fossem identificadas as variáveis que, quando alteradas para ganho de produtividade, aumentam menos as forças de corte, e que indiretamente estarão impactando menos a vida da ferramenta. 


\section{1 - Delineamento Experimental}

Basicamente, foi feito um estudo estatístico do processo, sendo realizado um delineamento fatorial de ensaios, utilizando a ferramenta do Método da Regressão Linear Múltipla para o estudo dos resultados. Os parâmetros de corte são as variáveis de entrada do processo, enquanto as forças resultantes de corte, daqui em diante referenciadas apenas como forças de corte, e as rugosidades média e profundidade de polimento da superfície são as variáveis de saída.

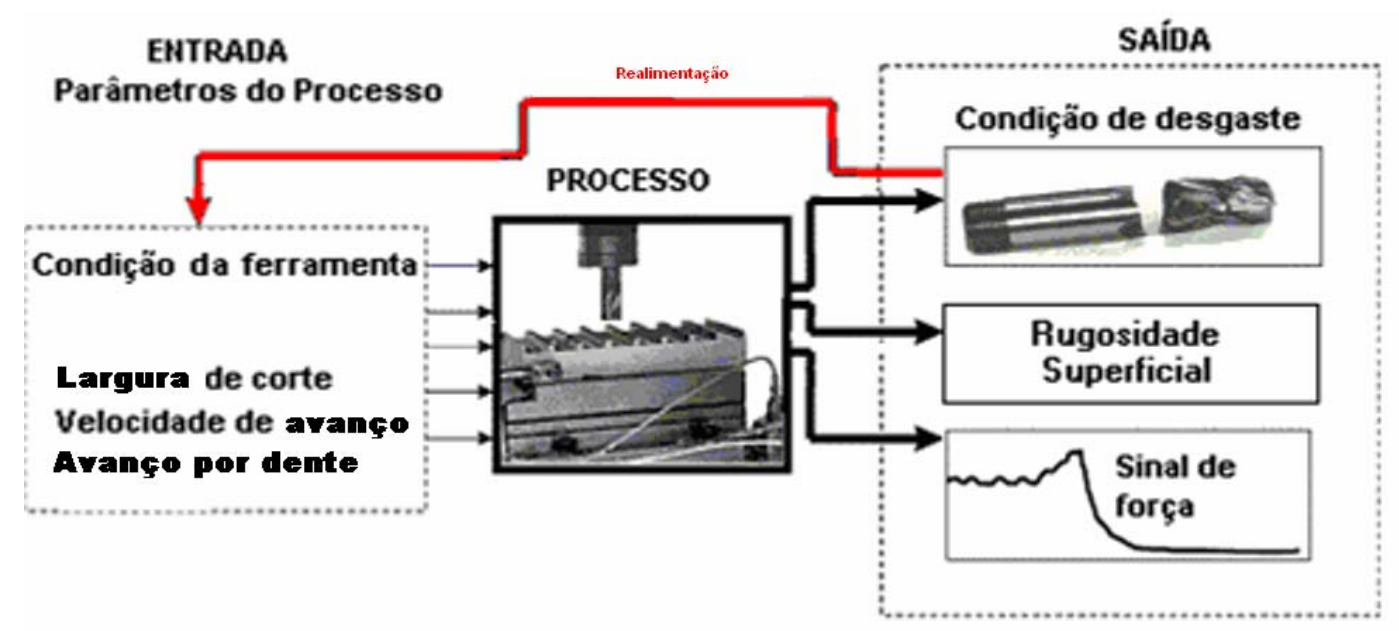

Figura 7.1.1 - Diagrama das Variáveis de Entrada e Saída do Processo de Fresamento

As variáveis de entrada foram alteradas durante os ensaios, sendo que as variáveis de saída foram medidas e relacionadas às primeiras. Os parâmetros de corte foram variados através dos comandos da própria máquina. A rugosidade da superfície usinada foi medida na superfície usinada, sendo que para isso foi utilizado um rugosímetro Taylor-Hobson Surtronic 3+. Já as forças de corte foram medidas utilizando o dinamômetro projetado e construído na primeira parte do trabalho. $\mathrm{O}$ desgaste da ferramenta não foi analisado neste trabalho. 
Foi realizado um delineamento $2^{\mathrm{k}}$ fatorial do experimento, com 2 replicações para cada combinação, que está descrito em (Montgomery, 2001).

Para este experimento, foi usado um delineamento fatorial $2^{3}$, que possui 8 combinações possíveis de níveis de fatores. Porém, foram feitas duas replicações para cada combinação, resultando em um total de 16 ensaios. Em cada um deles foi medida a rugosidade e as forças de corte.

Para a definição dos níveis altos e baixos de cada um dos parâmetros, foram utilizados os seguintes critérios:

- $\mathrm{v}_{\mathrm{f}}$ - limitação da fresadora utilizada para a realização dos ensaios

- $\mathrm{f}_{\mathrm{z}}$ - recomendação do fabricante das pastilhas

- $\mathrm{a}_{\mathrm{e}}$ - teste do limite do conjunto máquina - peça - ferramenta.

\section{2 - Corpos-de-Prova e Ferramentas}

Para a realização dos ensaios, foram fabricados corpos-de-prova a partir de uma chapa fornecida pela TenarisConfab, de aço API 5L X80, utilizado na fabricação de tubos de aço. Os corpos-de-prova foram cortados na medida de 100 x $200 \mathrm{~mm}$, sendo que as superfícies de $200 \mathrm{~mm}$ foram as utilizadas nos ensaios, e estavam no sentido de laminação da chapa, para garantir as mesmas condições do processo.

A máquina utilizada foi uma fresadora com rotação máxima do eixo árvore de $5000 \mathrm{rpm}$ e velocidade máxima de avanço de $1250 \mathrm{~mm} / \mathrm{min}$.

A ferramenta utilizada foi um cabeçote fresador Coromil 290, R290-080027$12 \mathrm{M} 268539$, com ângulo de posição de $90^{\circ}$ e diâmetro de $80 \mathrm{~mm}$, com 6 pastilhas de metal duro da Sanvik Coromant R290-12T308M-PM. 


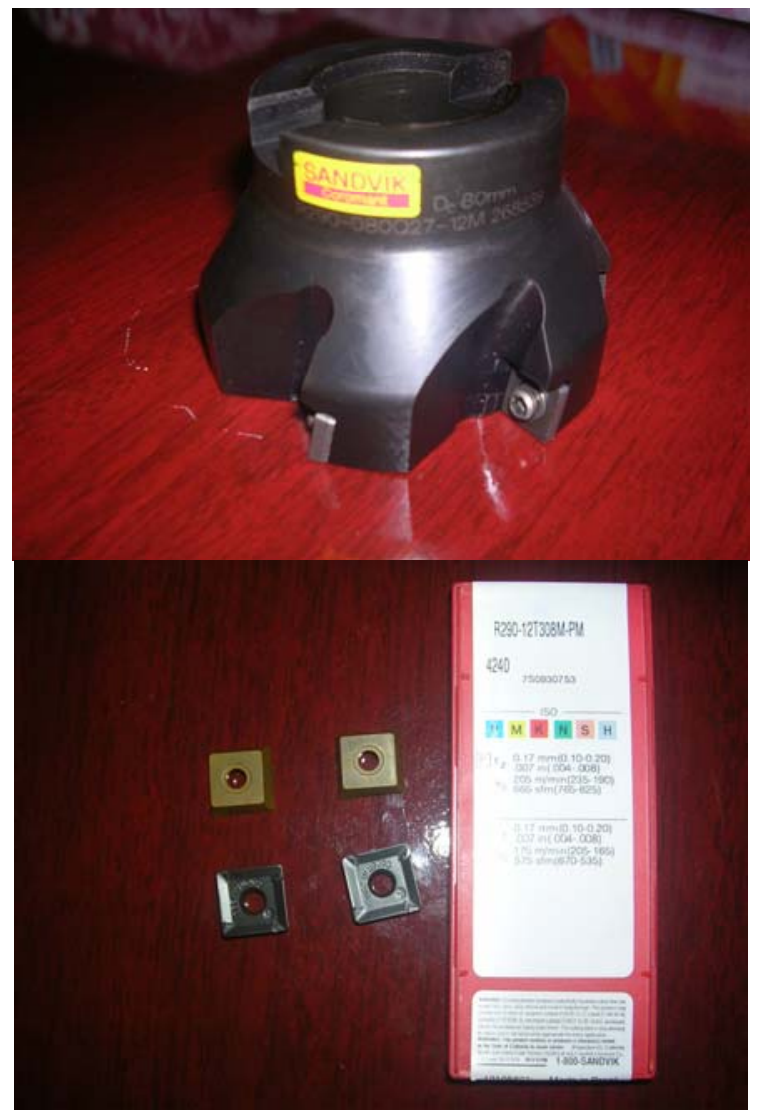

Figura 7.2.1 - Porta-ferramentas e pastilhas

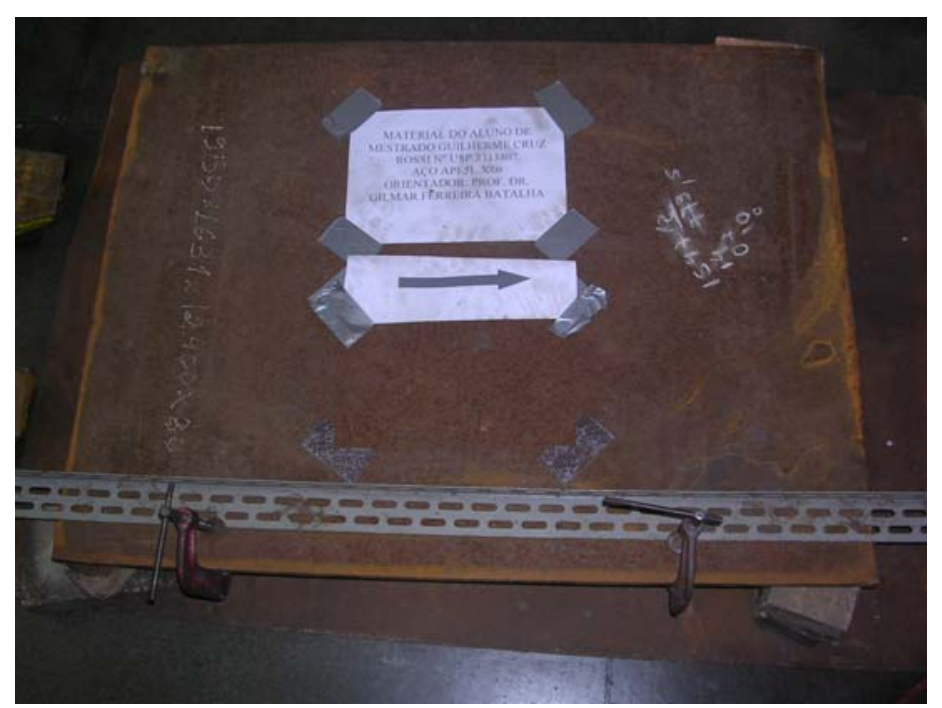

Figura 7.2.2 - Matéria-prima dos corpos-de-prova - Aço API 5L X80 


\section{3 - Ensaios}

Em conjunto com o Dinamômetro projetado e construído, foi utilizado um sistema de aquisição de dados Spider8 da Hottinger Baldwin Messtechnik (HBM), com Catman HBM Software (catman V4.0). A freqüência de amostragem utilizada foi de $600 \mathrm{~Hz}$.

De acordo com o delineamento experimental exposto no item 7.1, foram realizados 16 ensaios, 2 replicações de cada uma das 8 combinações a seguir (seguindo a notação do Método da Regressão Linear Múltipla abordado anteriormente):

Tabela 7.3.1 - Ensaios Realizados

\begin{tabular}{c|cccccccc}
\hline $\begin{array}{c}\text { Combinação / } \\
\text { Parâmetros }\end{array}$ & $\boldsymbol{v}_{\mathbf{f}}$ & $\boldsymbol{a}_{\boldsymbol{e}} \cdot \boldsymbol{v}_{\boldsymbol{f}}$ & $\boldsymbol{f}_{\mathbf{z} \cdot \boldsymbol{v}_{\boldsymbol{f}}}$ & $\boldsymbol{f}_{\mathbf{z} \cdot \boldsymbol{a}_{\mathrm{e}} \cdot \boldsymbol{v}_{\boldsymbol{f}}}$ & $\mathbf{1}$ & $\boldsymbol{a}_{\boldsymbol{e}}$ & $\boldsymbol{f}_{\boldsymbol{z}}$ & $\boldsymbol{f}_{\mathbf{z} \cdot \boldsymbol{a}_{\boldsymbol{e}}}$ \\
\hline $\mathbf{f}_{\mathbf{z}}(\mathbf{m m})$ & 0,05 & 0,05 & 0,17 & 0,17 & 0,05 & 0,05 & 0,17 & 0,17 \\
$\mathbf{a}_{\mathbf{e}}(\mathbf{m m})$ & 1 & 3 & 1 & 3 & 1 & 3 & 1 & 3 \\
$\mathbf{v}_{\mathbf{f}}(\mathbf{m m} / \mathbf{m i n})$ & 1250 & 1250 & 1250 & 1250 & 400 & 400 & 400 & 400 \\
$\mathbf{n}(\mathbf{r p m})$ & 4167 & 4167 & 1225 & 1225 & 1333 & 1333 & 392 & 392 \\
$\mathbf{v}_{\mathbf{c}}(\mathbf{m} / \mathbf{m i n})$ & 1047 & 1047 & 308 & 308 & 335 & 335 & 99 & 99 \\
\hline
\end{tabular}

A seguir, pode-se observar o gráfico de força de corte e o espectro de freqüências para cada um dos ensaios: 


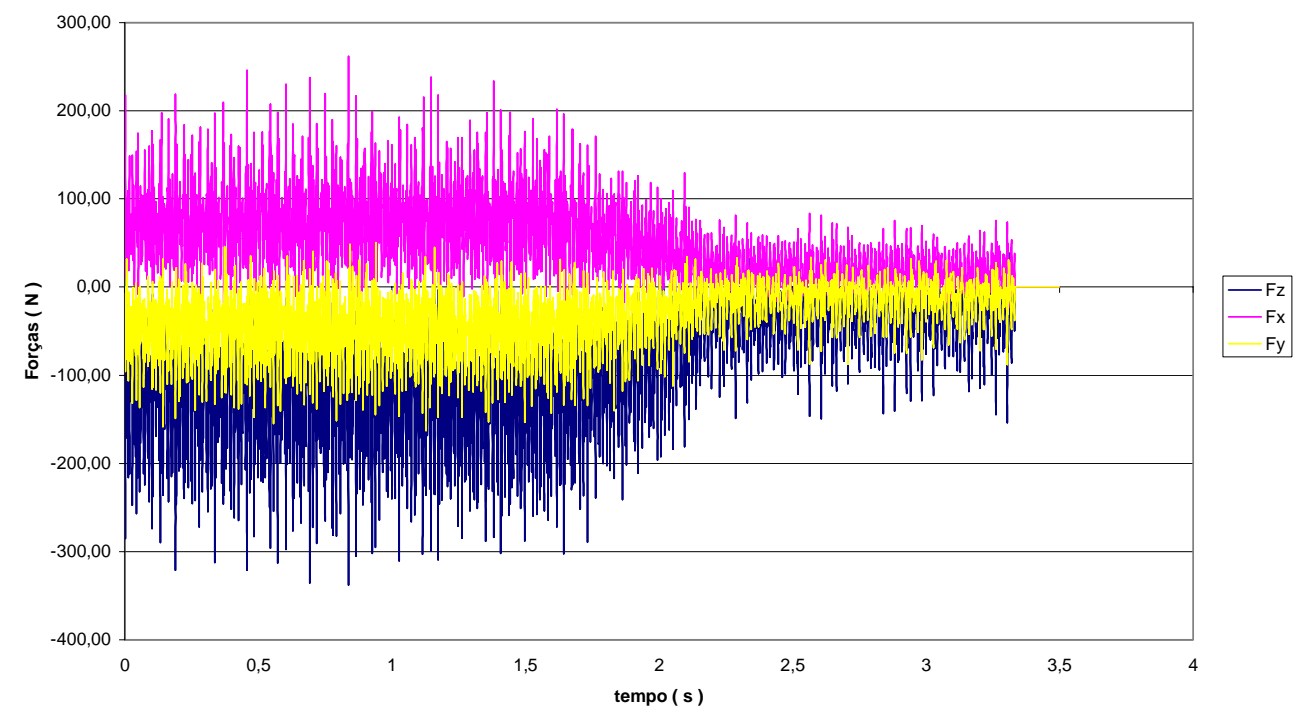

Figura 7.3.1 - Forças de Corte Ensaio v veplicação 1

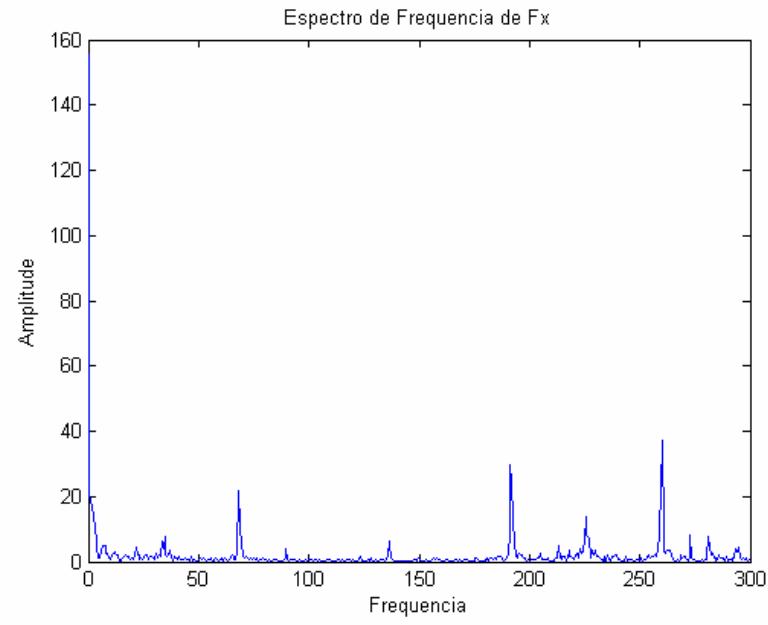

Figura 7.3.2 - Espectro de freqüências ensaio vf Replicação 1 


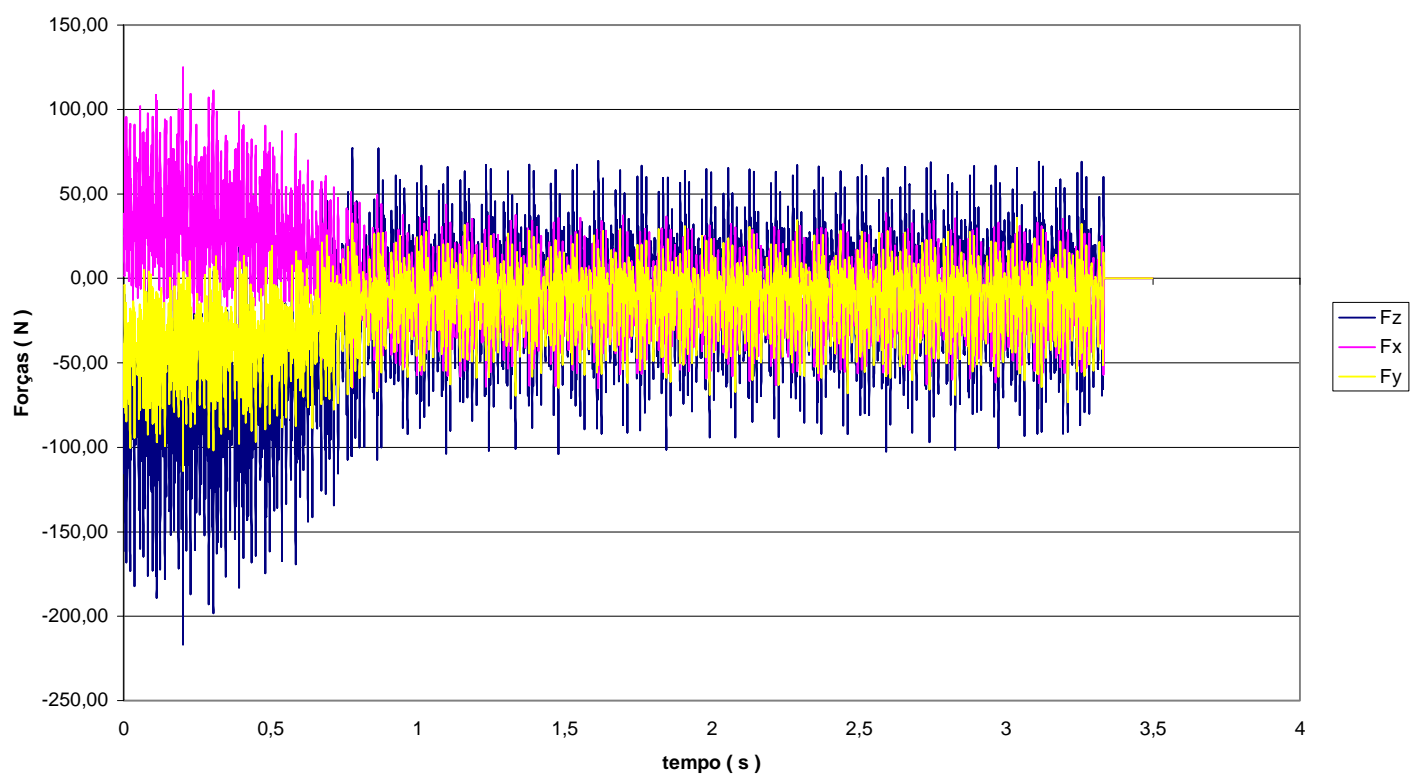

Figura 7.3.3 - Forças de Corte Ensaio vf Replicação 2

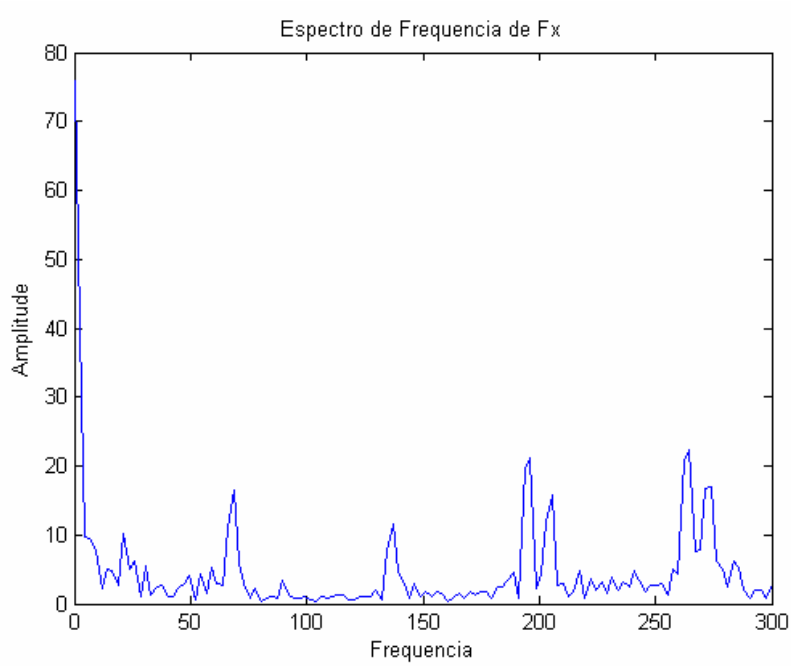

Figura 7.3.4 - Espectro de freqüiências ensaio vf Replicação 2 


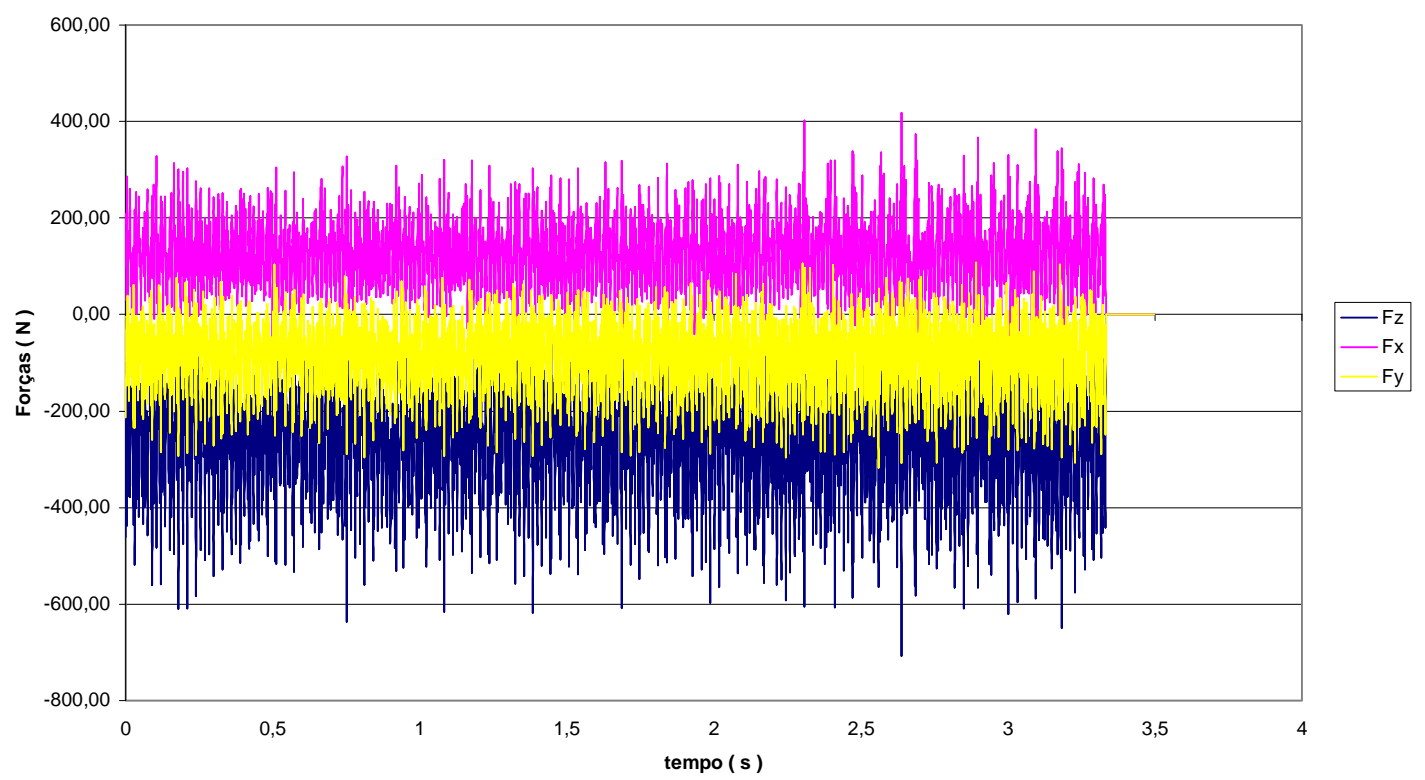

Figura 7.3.5 - Forças de Corte Ensaio ae.vf Replicação 1

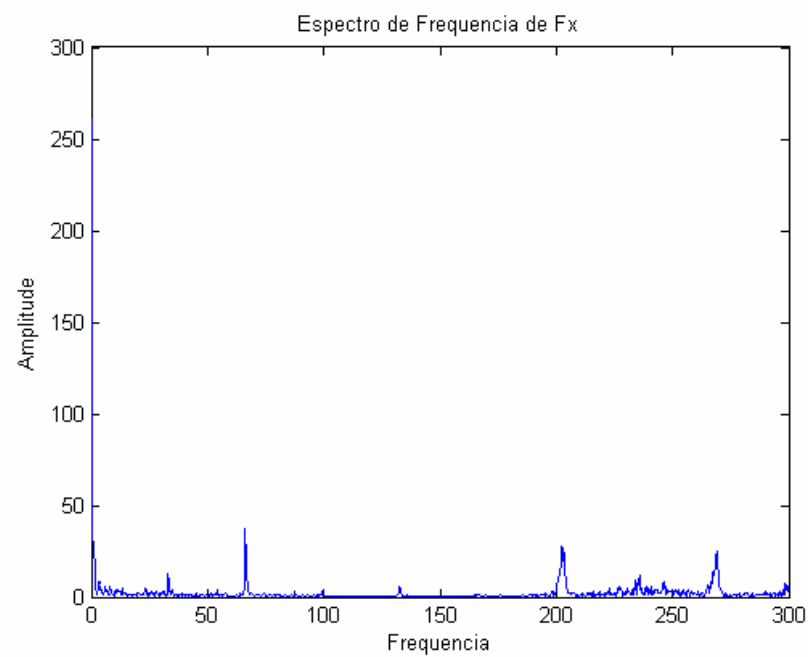

Figura 7.3.6 - Espectro de freqüências ensaio ae.vf Replicação 1 


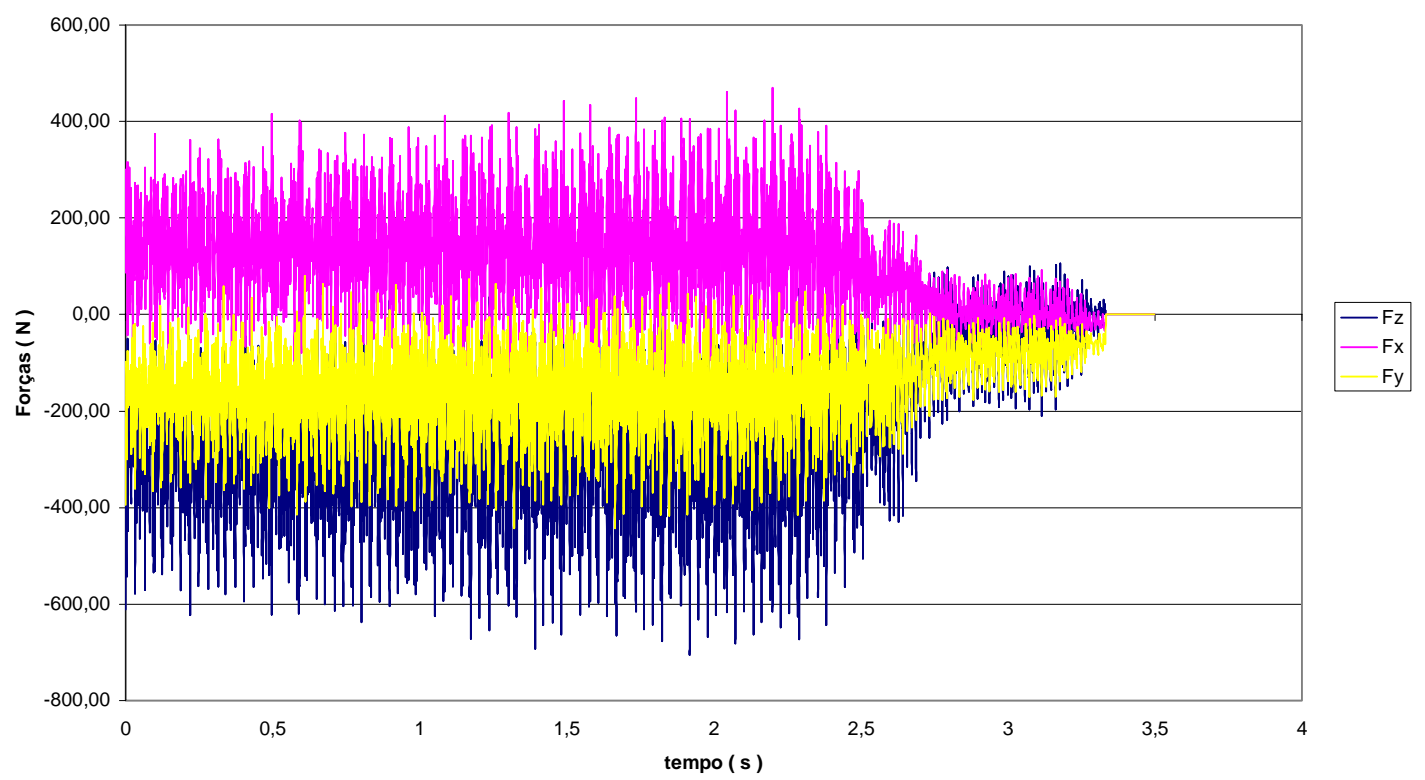

Figura 7.3.7 - Forças de Corte Ensaio ae.vf Replicação 2

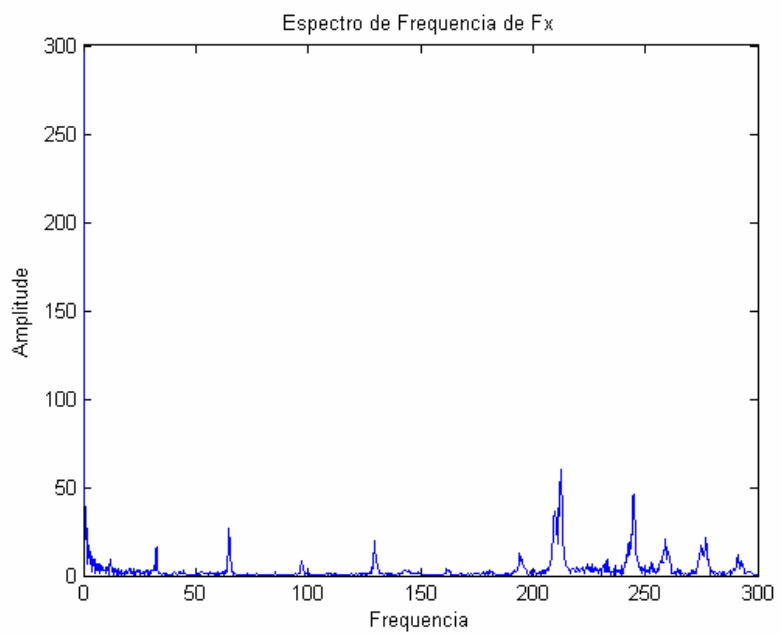

Figura 7.3.8 - Espectro de freqüências ensaio ae.vf Replicação 2 


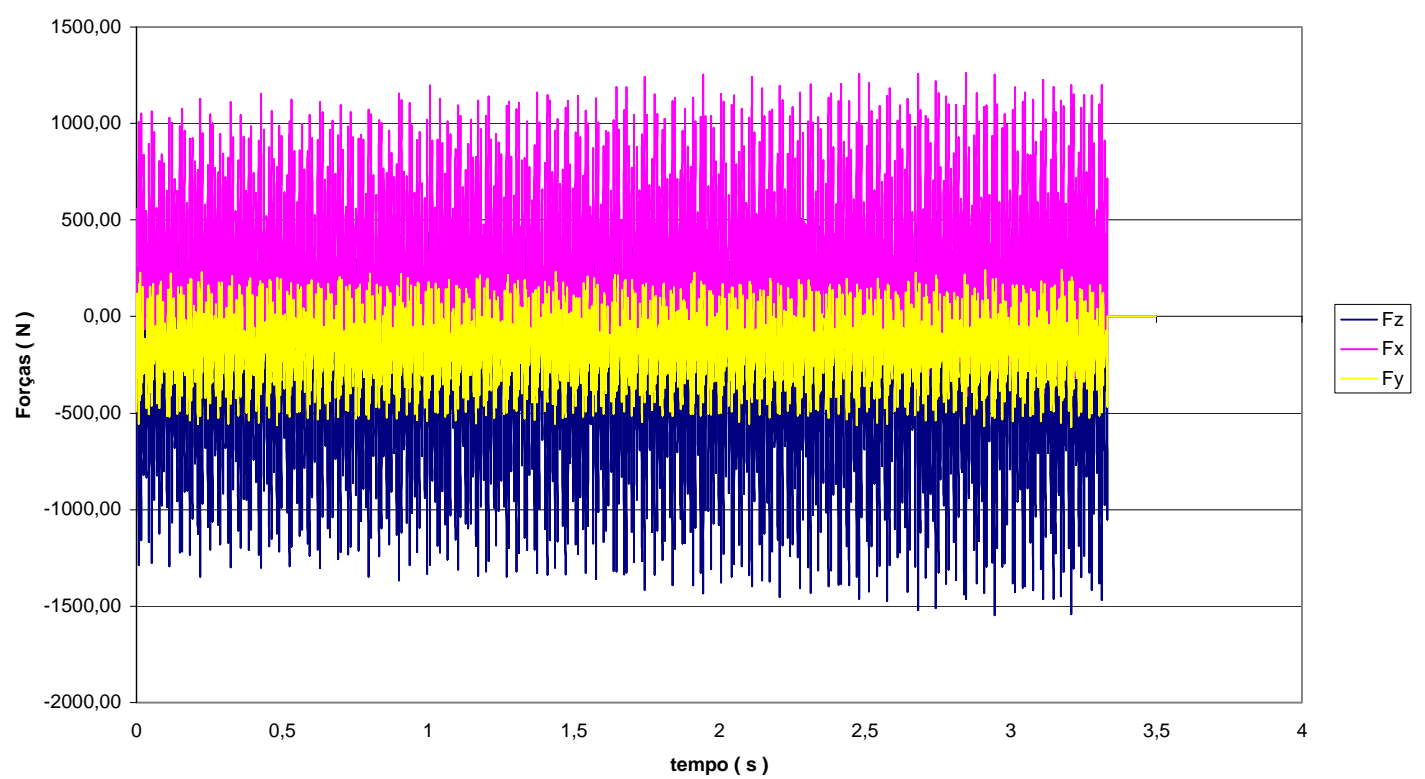

Figura 7.3.9 - Forças de Corte Ensaio fz.vf Replicação1

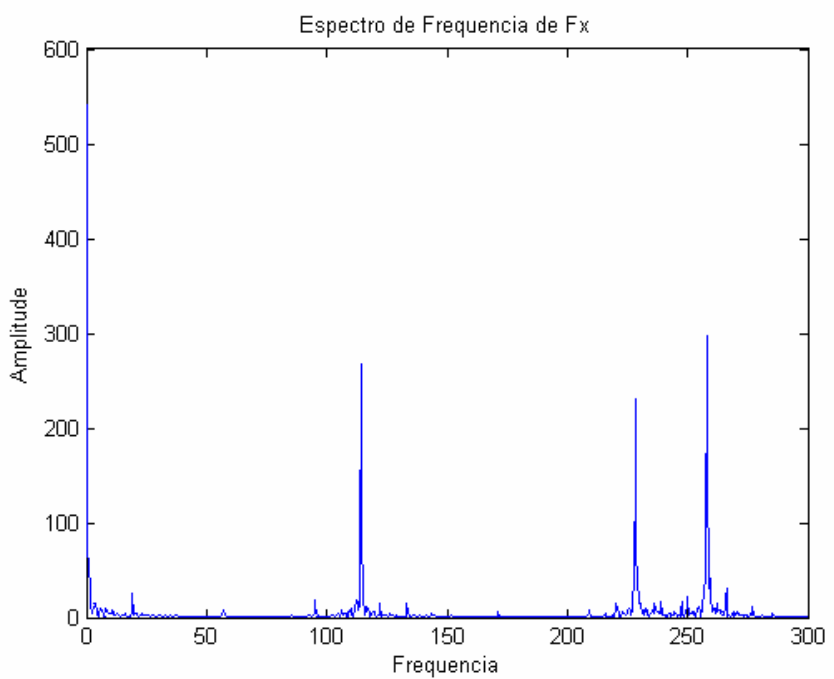

Figura 7.3.10 - Espectro de freqüências ensaio fz.vf Replicação 1 


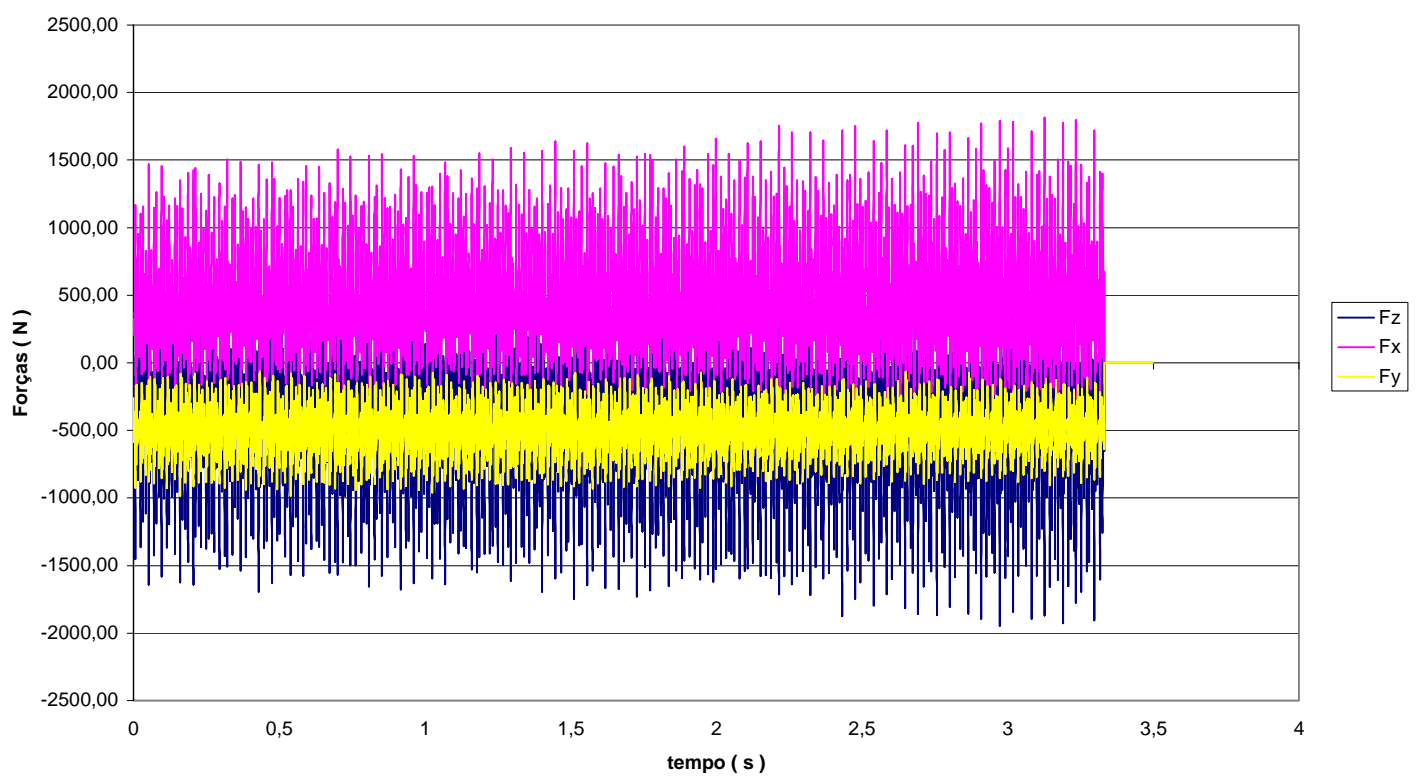

Figura 7.3.11 - Forças de Corte Ensaio fz.vf Replicação 2

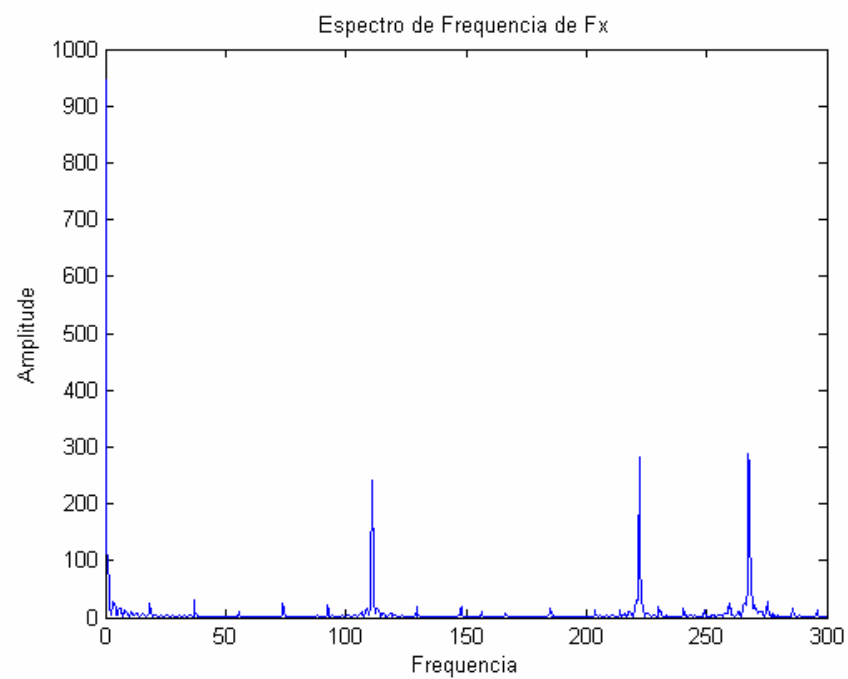

Figura 7.3.12 - Espectro de freqüências ensaio fz.vf Replicação 2 


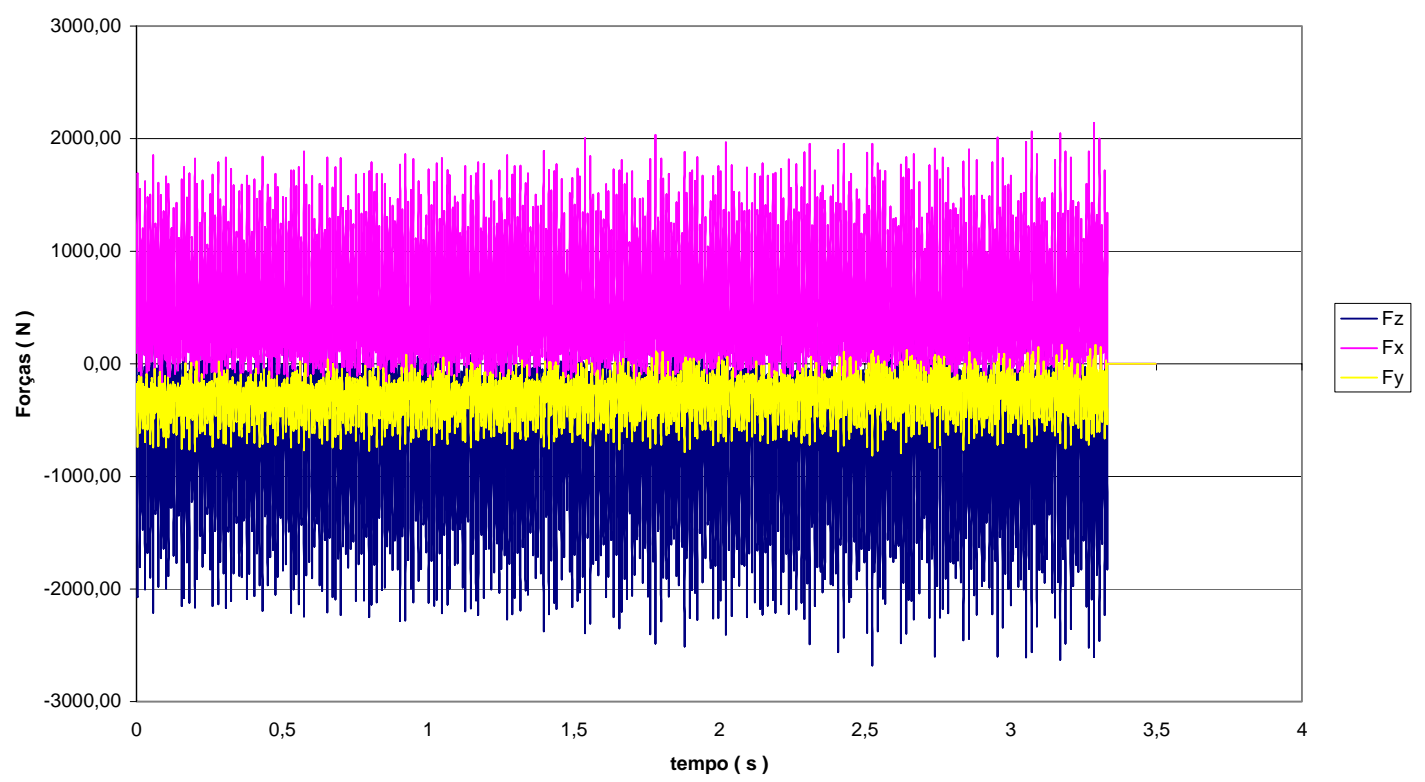

Figura 7.3.13 - Forças de Corte Ensaio fz.ae.vf Replicação 1

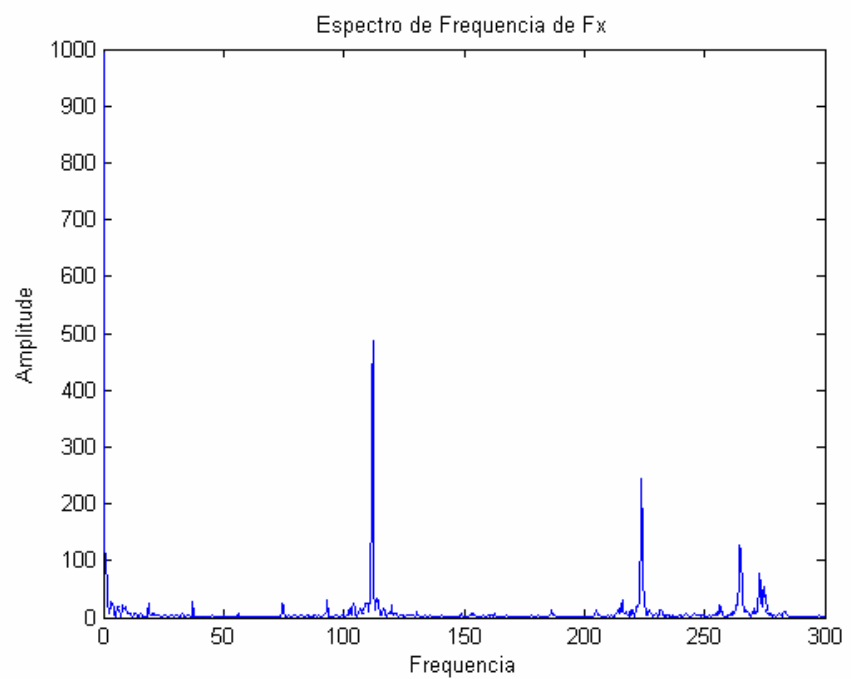

Figura 7.3.14 - Espectro de freqüências ensaio fz.ae.vf Replicação 1 


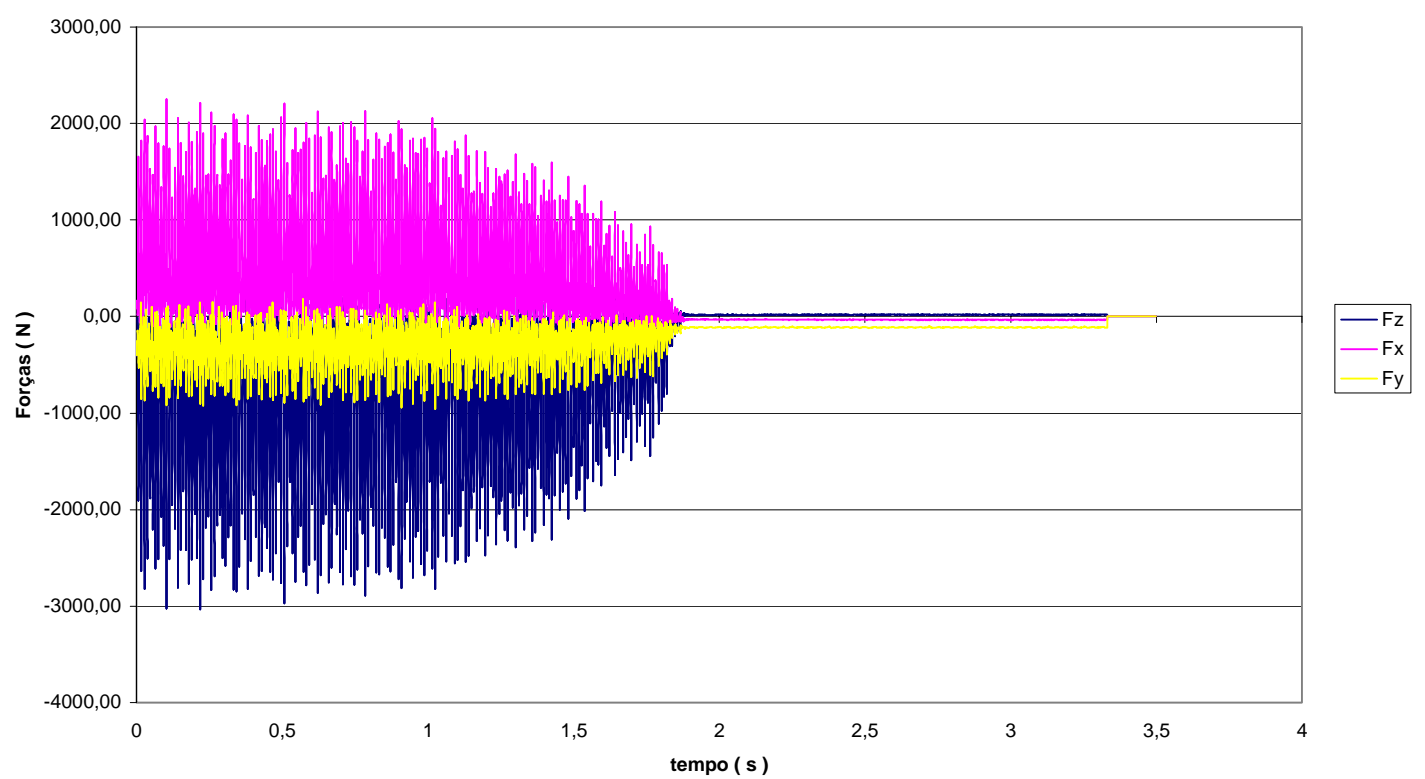

Figura 7.3.15 - Forças de Corte Ensaio fz.ae.vf Replicação 2

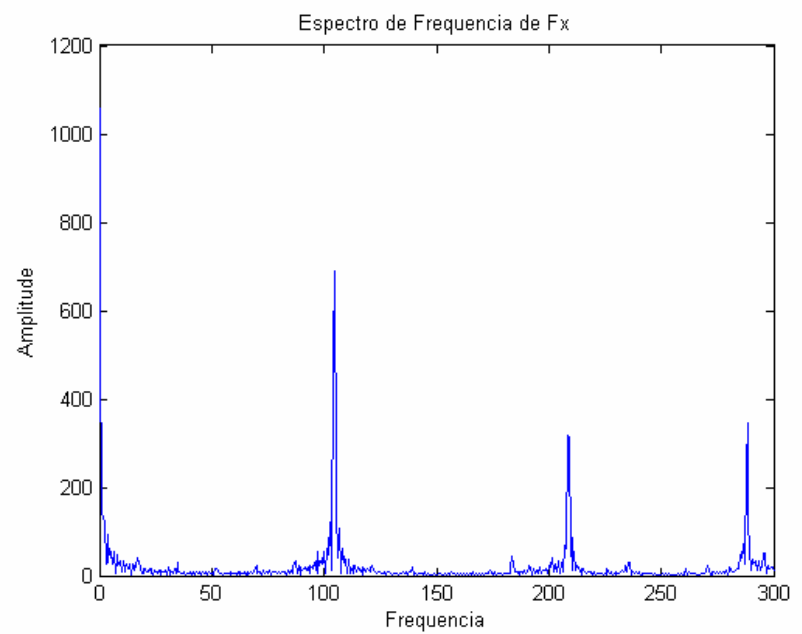

Figura 7.3.16 - Espectro de freqüências ensaio fz.ae.vf Replicação 2 


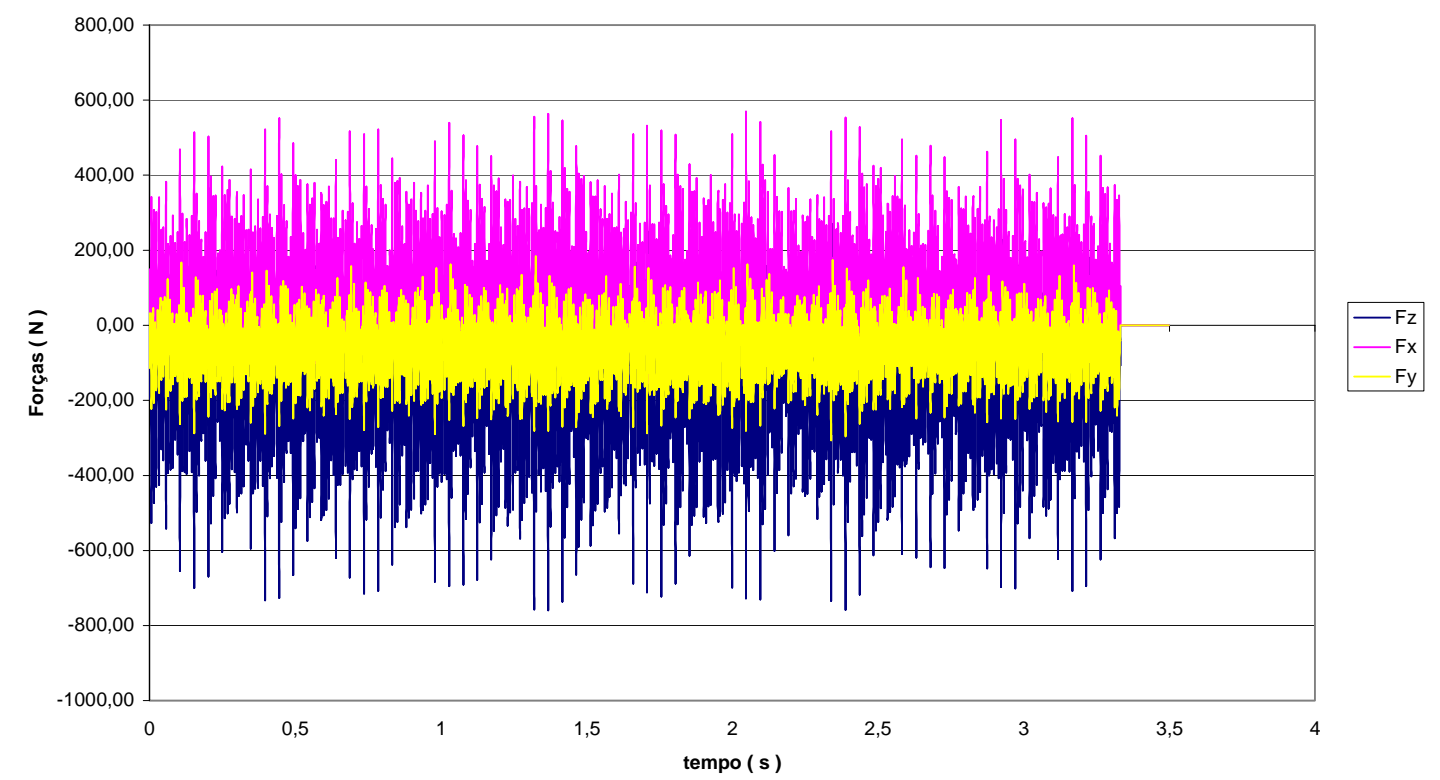

Figura 7.3.17 - Forças de Corte Ensaio (1) Replicação 1

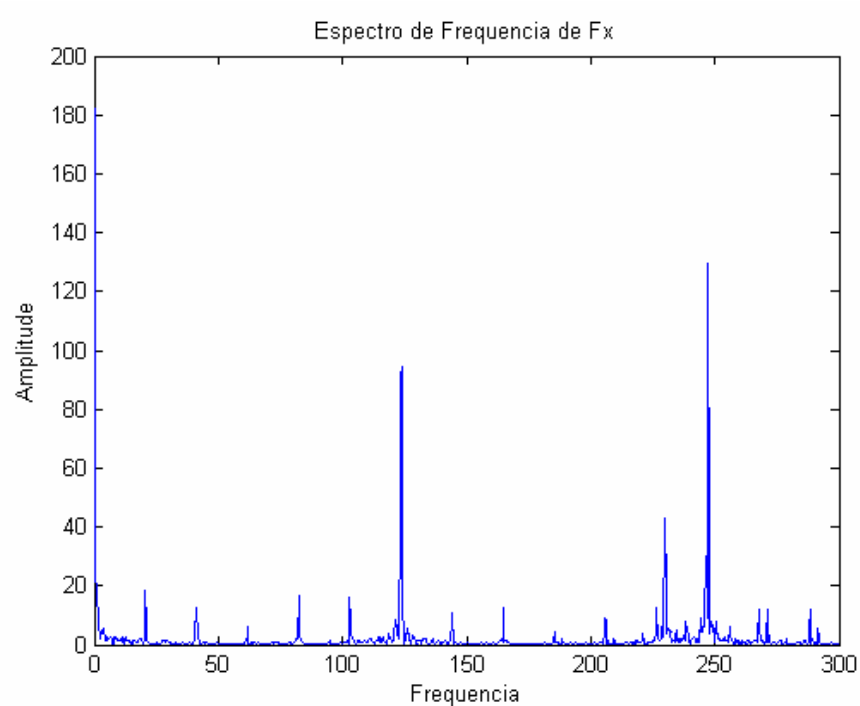

Figura 7.3.18 - Espectro de freqüências ensaio (1) Replicação 1 


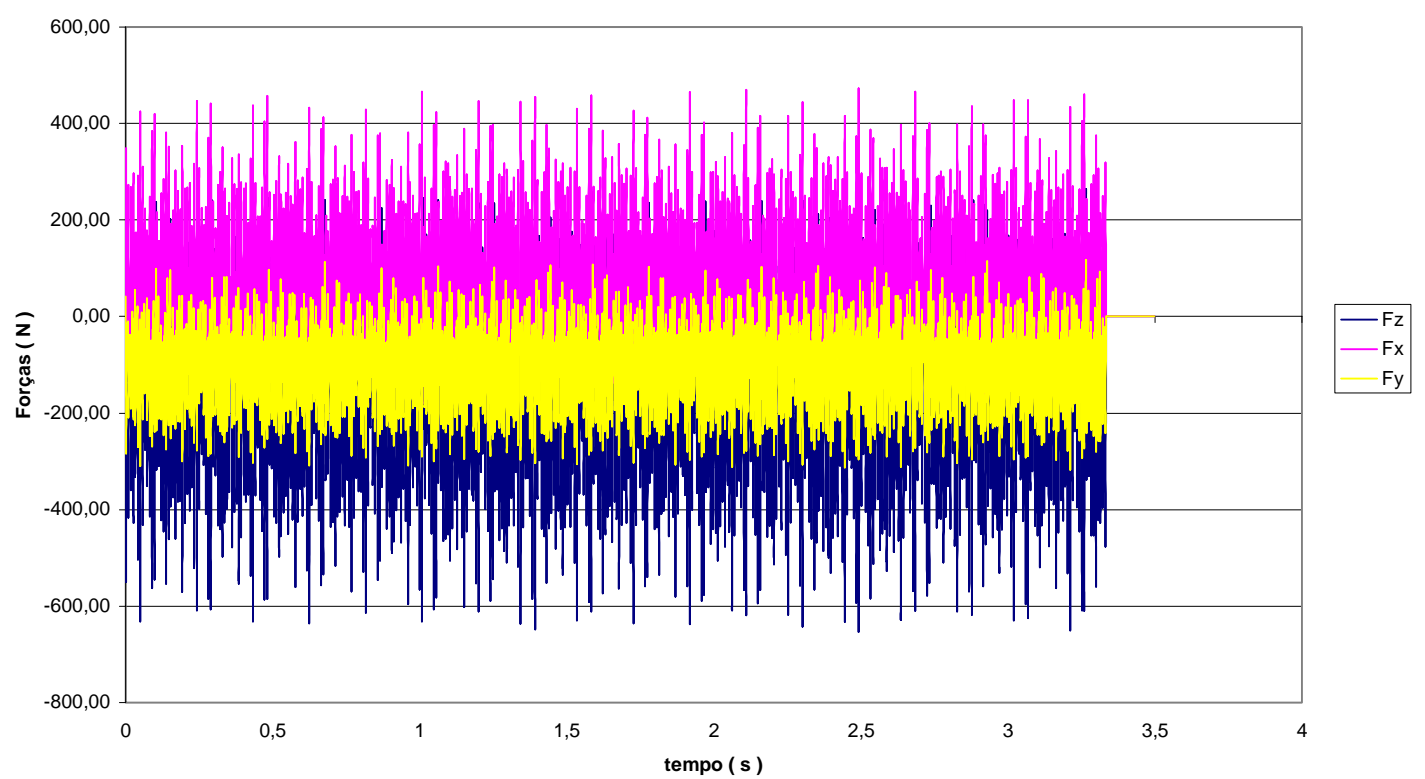

Figura 7.3.19 - Forças de Corte Ensaio (1) Replicação 2

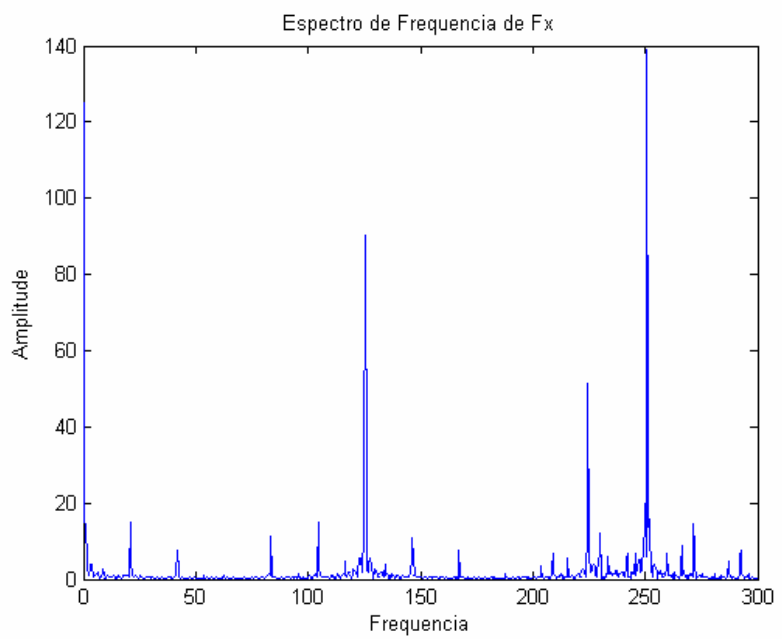

Figura 7.3.20 - Espectro de freqüências ensaio (1) Replicação 2 


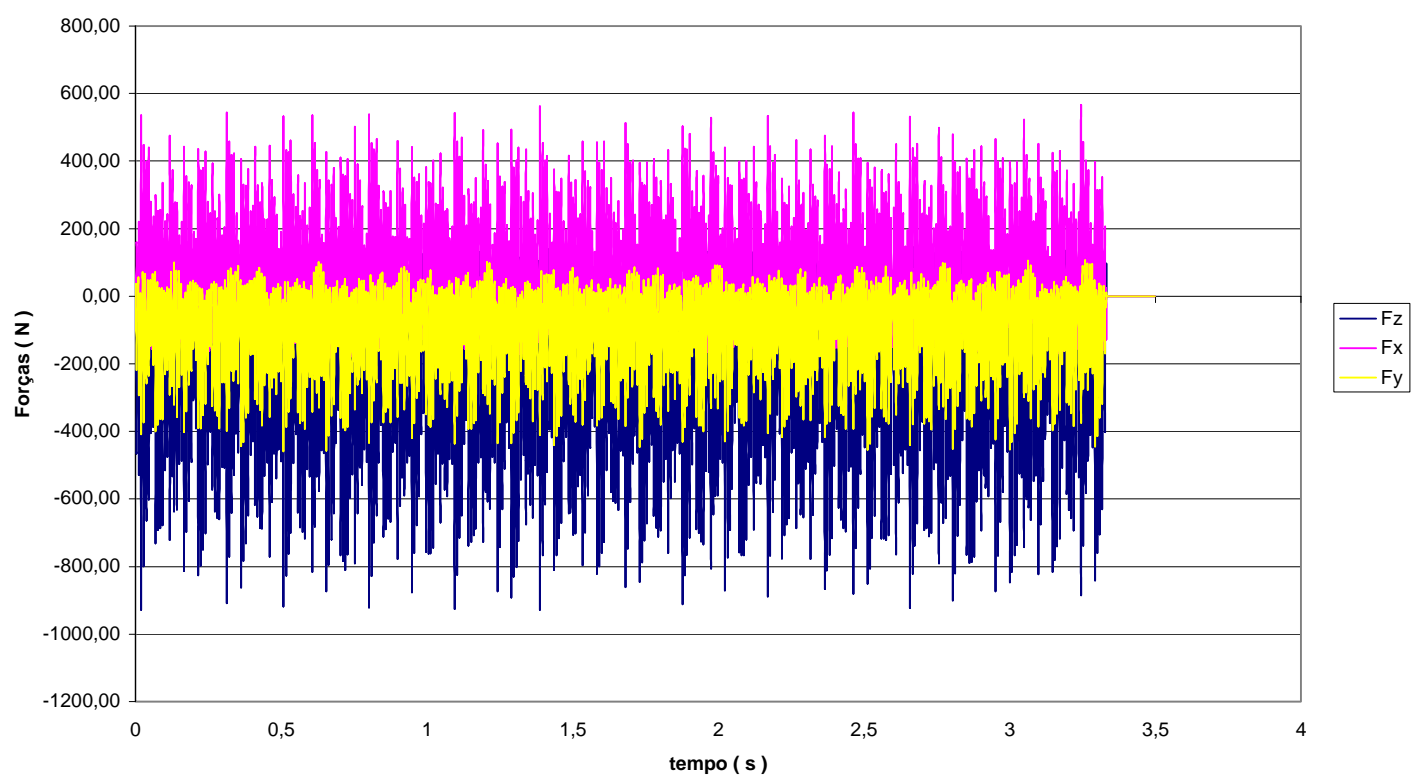

Figura 7.3.21 - Forças de Corte Ensaio ae Replicação 1

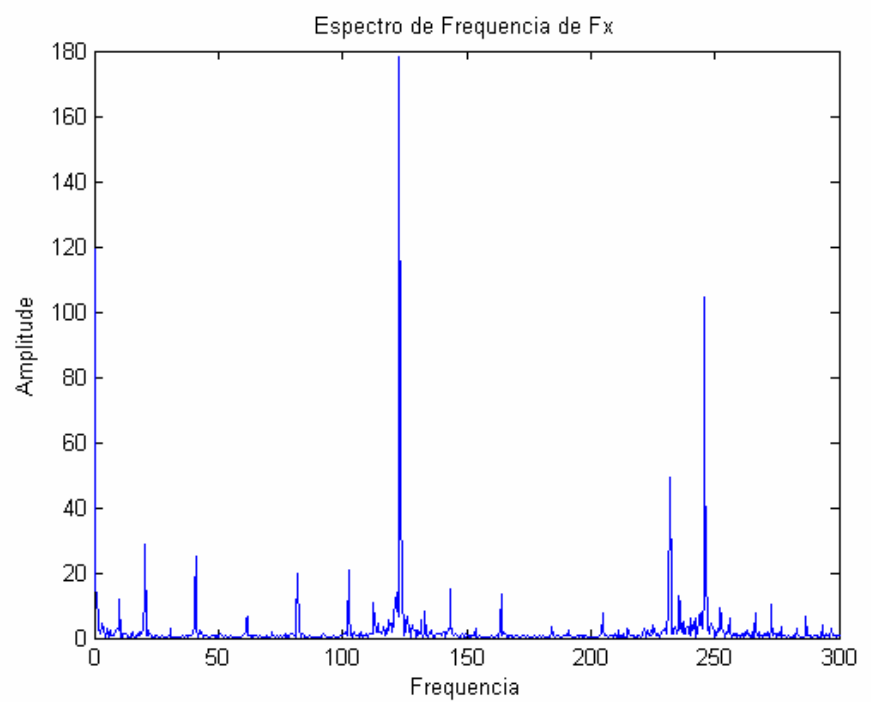

Figura 7.3.22 - Espectro de freqüências ensaio ae Replicação 1 


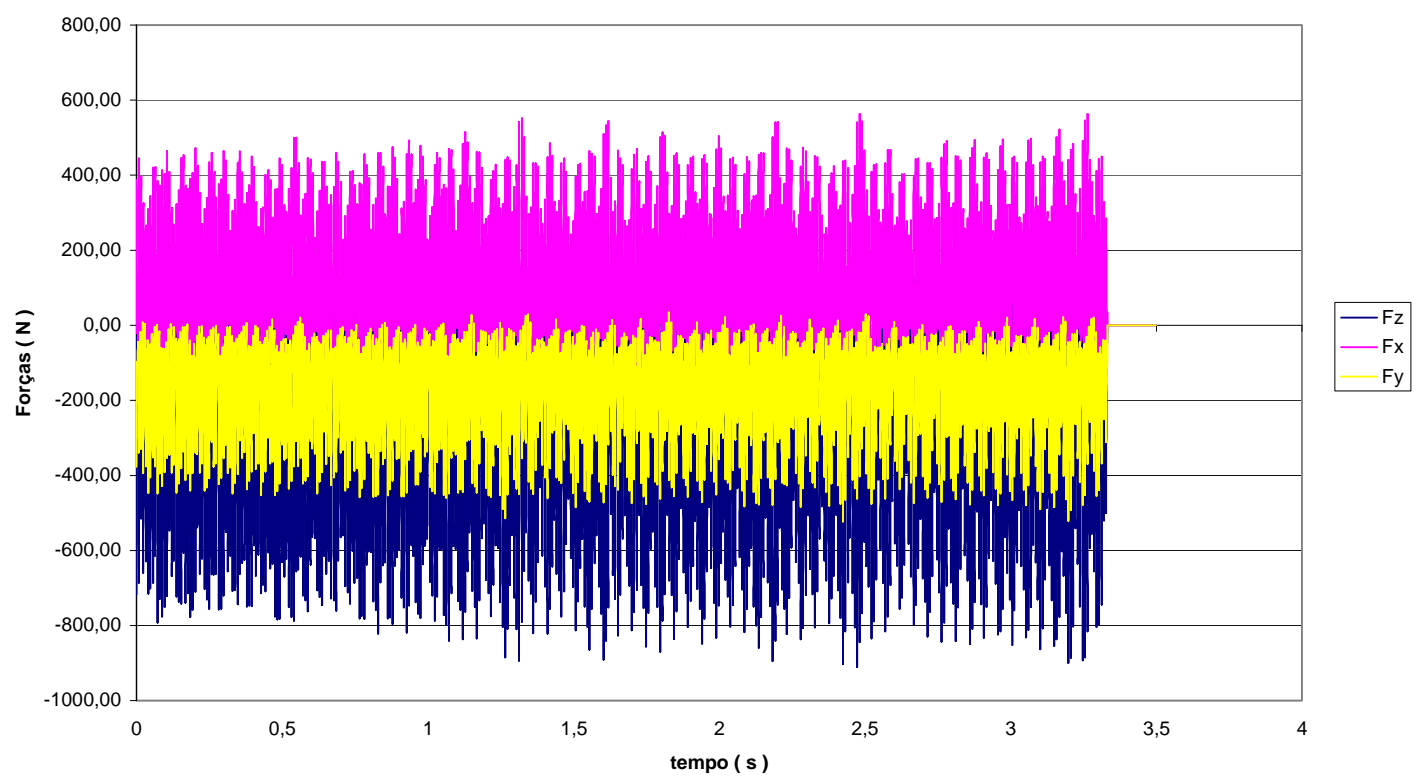

Figura 7.3.23 - Forças de Corte Ensaio ae Replicação 2

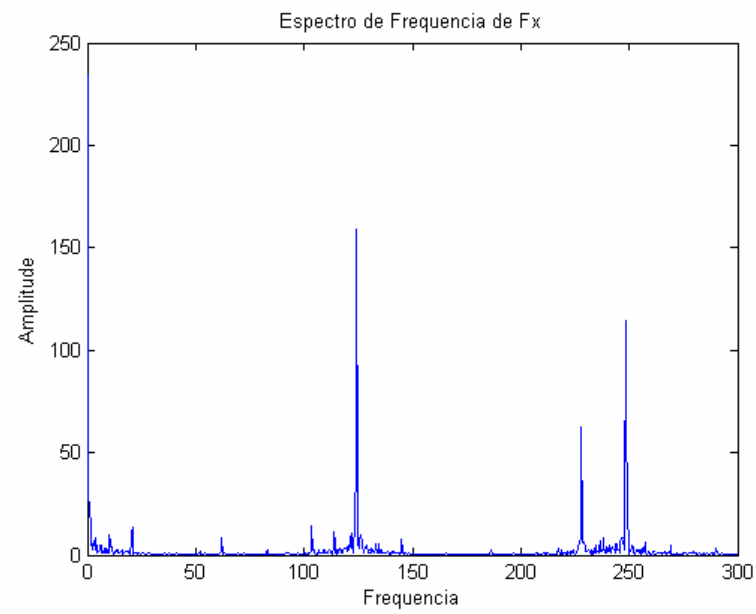

Figura 7.3.24 - Espectro de freqüências ensaio ae Replicação 2 


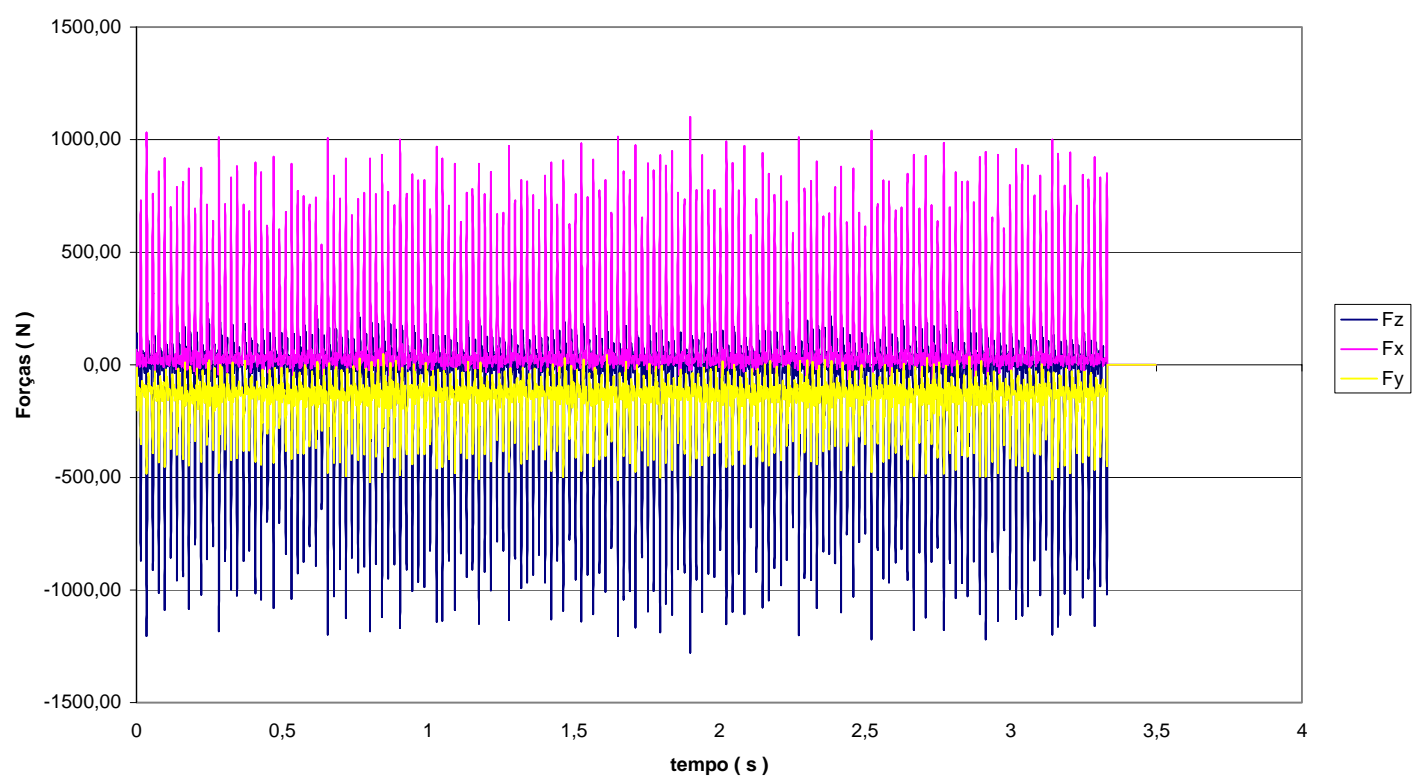

Figura 7.3.25 - Forças de Corte Ensaio fz Replicação 1

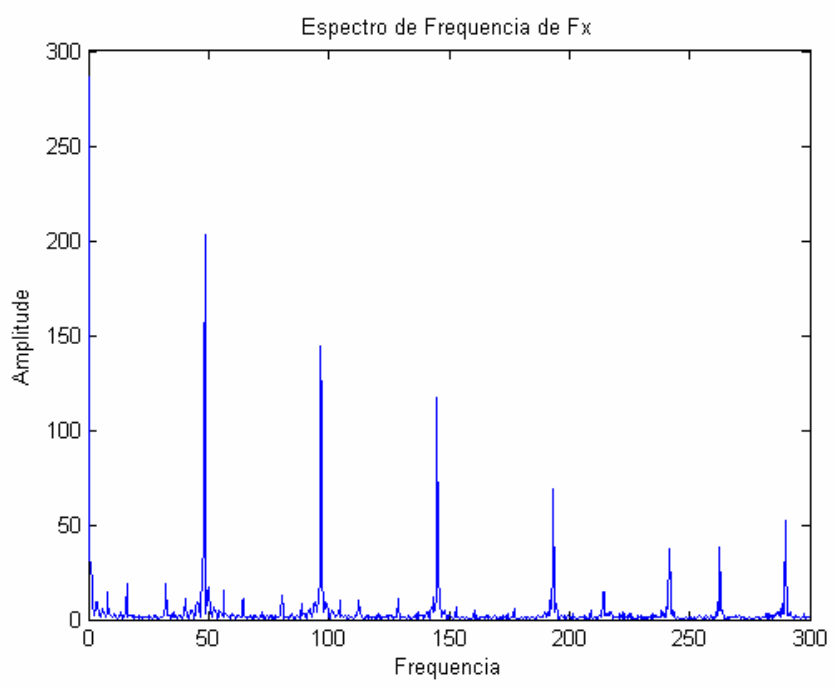

Figura 7.3.26 - Espectro de freqüências ensaio fz Replicação 1 


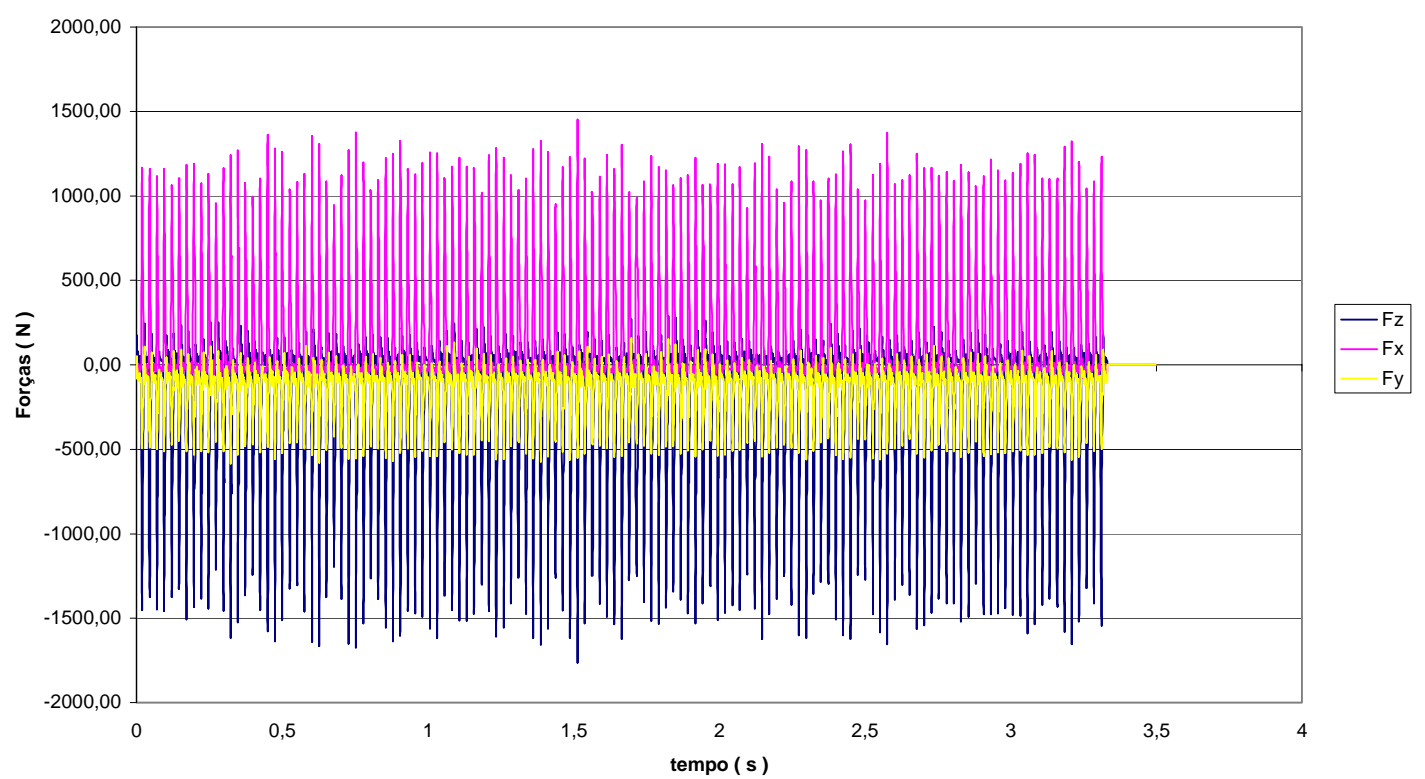

Figura 7.3.27 - Forças de Corte Ensaio fz Replicação 2

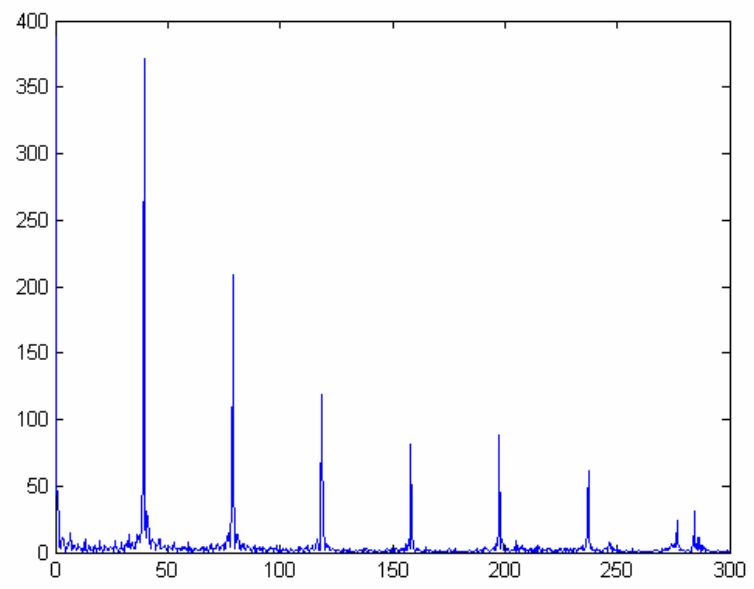

Figura 7.3.28 - Espectro de freqüências ensaio fz Replicação 2 


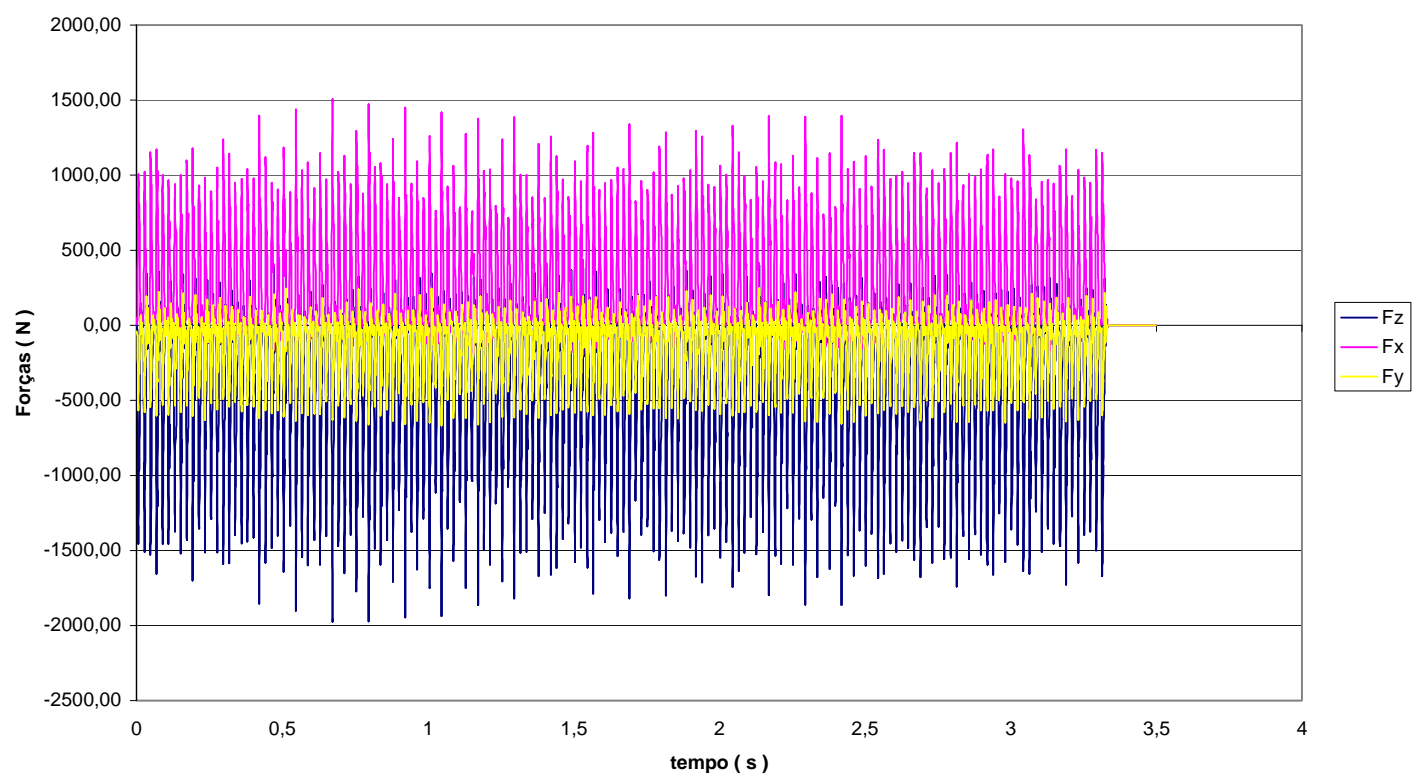

Figura 7.3.29 - Forças de Corte Ensaio fz.ae Replicação 1

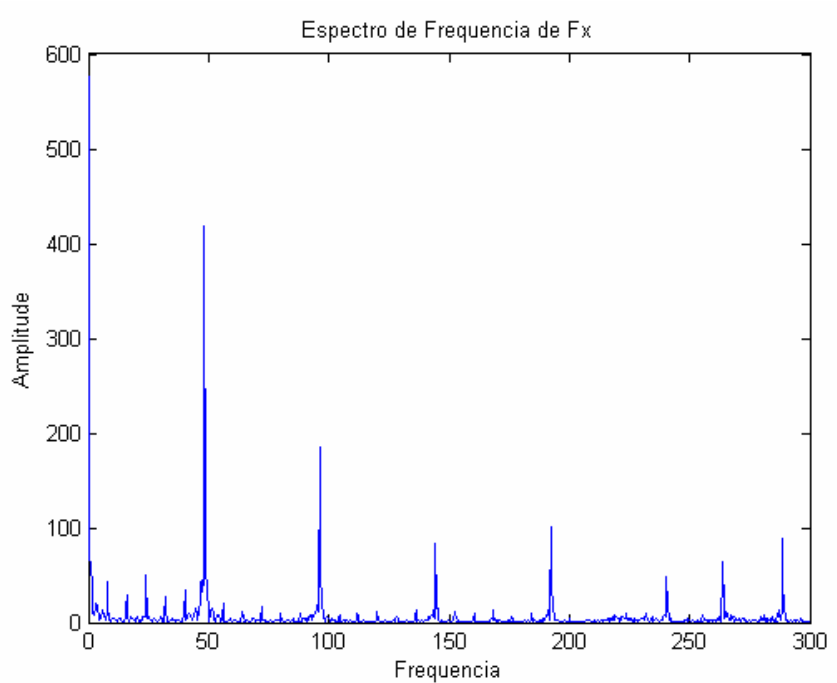

Figura 7.3.30 - Espectro de freqüências ensaio fz.ae Replicação 1 


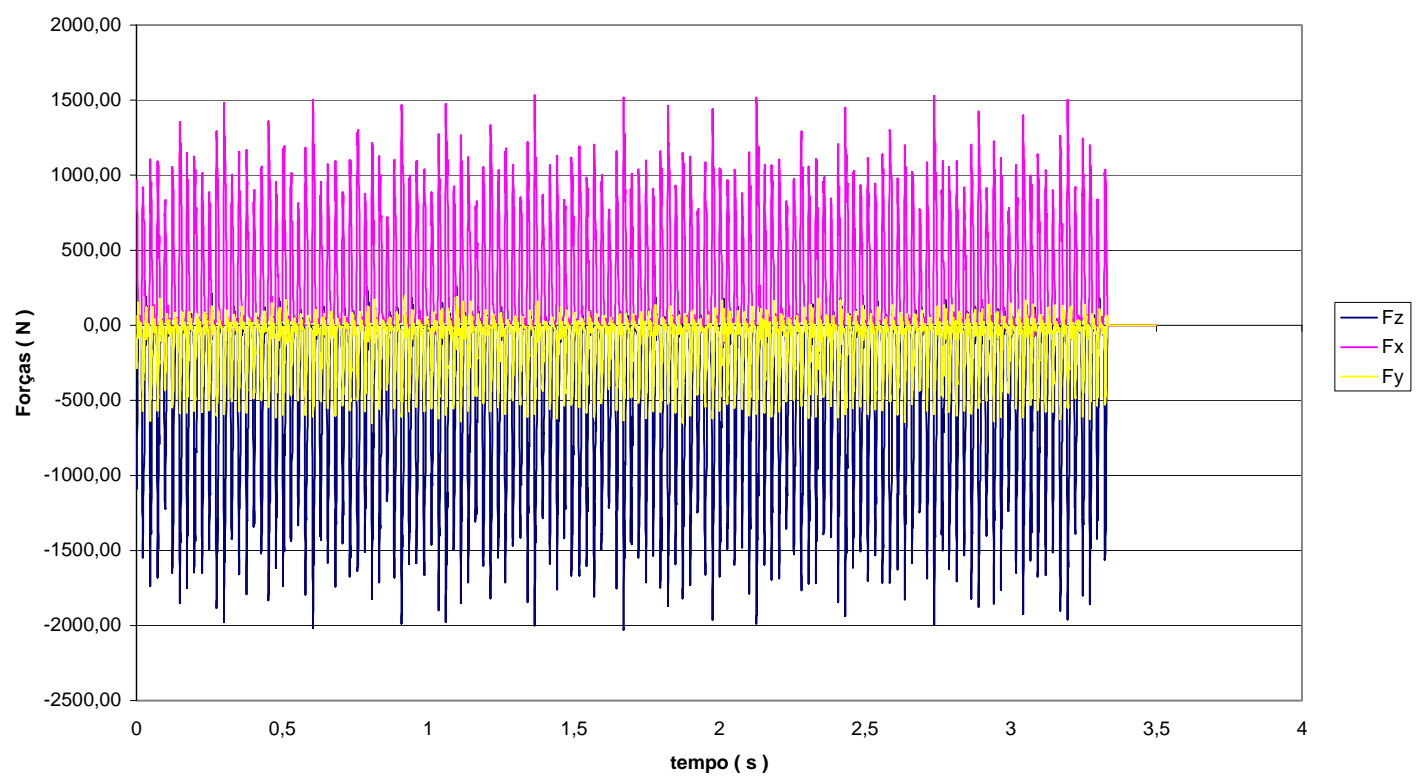

Figura 7.3.31 - Forças de Corte Ensaio fz.ae Replicação 2

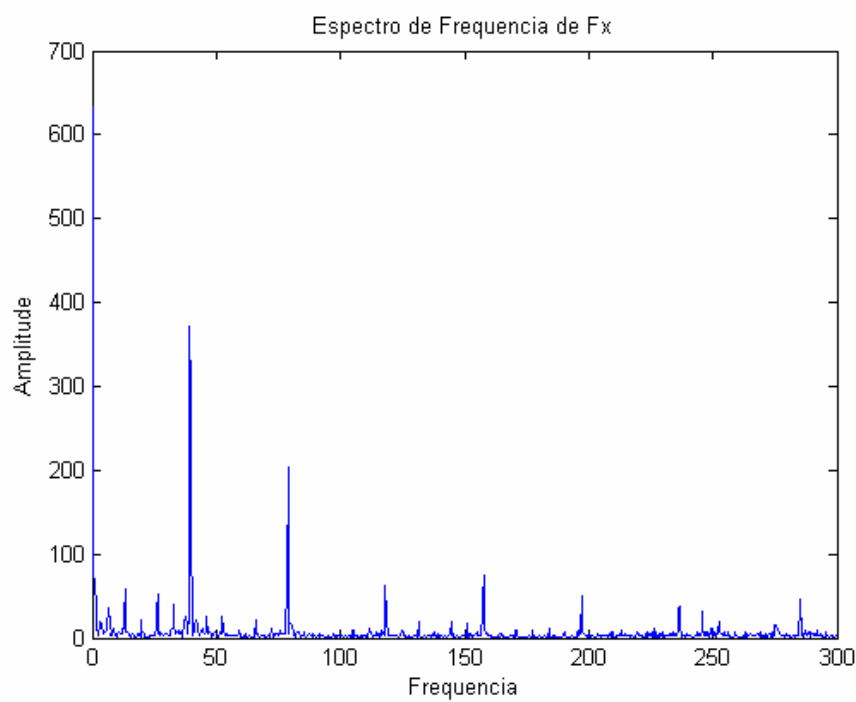

Figura 7.3.32 - Espectro de freqüências ensaio fz.ae Replicação 2 
Para que se pudesse analisar a resposta dinâmica do dinamômetro, foi feita uma análise de um período de 0,3 segundos do ensaio $\mathrm{f}_{\mathrm{z}}$ replicação 2. Este período corresponde a 2 rotações da ferramenta, já que nele a rotação do eixo-árvore é igual a $392 \mathrm{rpm}$, o que corresponde a 6,5 rps. Sendo 6 o número de arestas de corte da ferramenta, a freqüência do sinal de corte é igual a 6 x 6,5, ou seja, $39 \mathrm{~Hz}$. Assim, a figura 7.3.33, representa um intervalo de 0,3 segundos de corte, o que corresponde a 2 rotações da ferramenta. Nela, deve-se observar um número de picos de força igual a 12 .

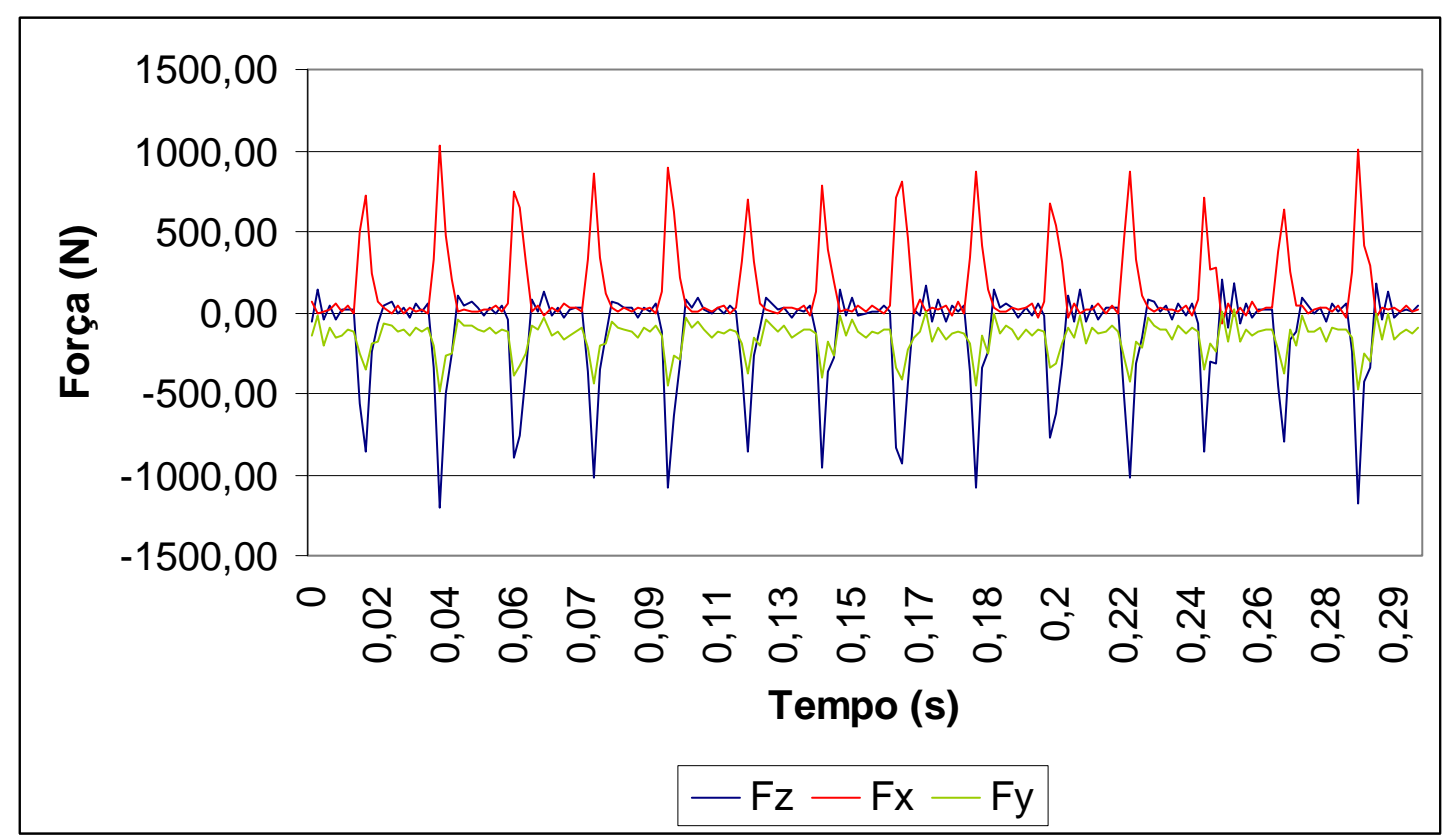

Figura 7.3.33 - Detalhe de 2 rotações da ferramenta no Ensaio $f_{z}$ Replicação 1

Analisando a figura, observa-se um número de picos igual a 14. Isso se deve à imprecisão do $\mathrm{CNC}$ da máquina que estava sendo utilizada, já que a menor escala de ajuste da rotação do fuso é de $50 \mathrm{rpm}$. 
Para cada um destes ensaios, foram medidas as forças de corte nas três direções cartesianas e a rugosidade da superfície usinada. Foi então calculada a força resultante de corte, através da equação 9 , sendo que os resultados podem ser observados nas tabelas a seguir:

Tabela 7.3.2 - Forças de Corte

\begin{tabular}{l|cccccccc}
\hline \multicolumn{1}{c|}{ Ensaio } & vf & ae.vf & fz.vf & fz.ae.vf & (1) & Ae & fz & fz.ae \\
\hline Replicação 1 (N) & 183 & 350 & 785 & 1251 & 318 & 396 & 472 & 810 \\
Replicação 2 (N) & 121 & 413 & 1090 & 1468 & 315 & 459 & 690 & 898 \\
Média (N) & $\mathbf{1 5 2}$ & $\mathbf{3 8 1}$ & $\mathbf{9 3 8}$ & $\mathbf{1 3 5 9}$ & $\mathbf{3 1 7}$ & $\mathbf{4 2 8}$ & $\mathbf{5 8 1}$ & $\mathbf{8 5 4}$ \\
Desvio Padrão (N) & 44 & 45 & 216 & 153 & 2 & 44 & 154 & 62 \\
\hline t-Student (2 caudas, 20\%) (N)* & 84 & 85 & 408 & 289 & 4 & 84 & 291 & 118 \\
\hline * (Blank, 1980) & & & & & & & &
\end{tabular}

Tabela 7.3.3 - Rugosidade da Superfície Usinada $\left(\mathbf{R}_{\mathbf{a}}\right)$

\begin{tabular}{l|cccccccc}
\hline \multicolumn{1}{c|}{ Ensaio } & $v f$ & ae.vf & $f z . v f$ & $f$ z.ae.vf & $(1)$ & Ae & $f z$ & $f$ z.ae \\
\hline Replicação 1 $(\mu \mathrm{m})$ & 1,96 & 2,88 & 4,16 & 8,38 & 1,26 & 1,80 & 4,06 & 3,98 \\
Replicação 2 $(\mu \mathrm{m})$ & 1,82 & 2,70 & 3,82 & 4,96 & 2,30 & 2,20 & 5,16 & 5,06 \\
Média $(\boldsymbol{\mu m})$ & $\mathbf{1 , 8 9}$ & $\mathbf{2 , 7 9}$ & $\mathbf{3 , 9 9}$ & $\mathbf{6 , 6 7}$ & $\mathbf{1 , 7 8}$ & $\mathbf{2 , 0 0}$ & $\mathbf{4 , 6 1}$ & $\mathbf{4 , 5 2}$ \\
Desvio Padrão $(\mu \mathrm{m})$ & 0,10 & 0,13 & 0,24 & 2,42 & 0,74 & 0,28 & 0,78 & 0,76 \\
\hline t-Student (2 caudas, 20\%) $(\boldsymbol{\mu m})$ & 0,19 & 0,24 & 0,45 & 4,56 & 1,39 & 0,53 & 1,47 & 1,44 \\
\hline
\end{tabular}

Tabela 7.3.4 - Rugosidade da Superfície Usinada $\left(\mathbf{R}_{\mathbf{y}}\right)$

\begin{tabular}{l|cccccccc}
\hline \multicolumn{1}{c|}{ Ensaio } & $v f$ & ae.vf & fz.vf & fz.ae.vf & $(1)$ & ae & Fz & $f$ z.ae \\
\hline Replicação 1 $(\mu \mathrm{m})$ & 9,90 & 16,80 & 18,30 & 34,00 & 9,20 & 13,10 & 23,20 & 29,60 \\
Replicação 2 $(\mu \mathrm{m})$ & 12,40 & 17,60 & 20,20 & 31,60 & 17,90 & 17,20 & 34,00 & 37,00 \\
Média $(\boldsymbol{\mu m})$ & $\mathbf{1 1 , 1 5}$ & $\mathbf{1 7 , 2 0}$ & $\mathbf{1 9 , 2 5}$ & $\mathbf{3 2 , 8 0}$ & $\mathbf{1 3 , 5 5}$ & $\mathbf{1 5 , 1 5}$ & $\mathbf{2 8 , 6 0}$ & $\mathbf{3 3 , 3 0}$ \\
Desvio Padrão $(\mu \mathrm{m})$ & 1,77 & 0,57 & 1,34 & 1,70 & $\mathbf{6 , 1 5}$ & 2,90 & $\mathbf{7 , 6 4}$ & 5,23 \\
\hline t-Student (2 caudas, 20\%) $(\boldsymbol{\mu m})$ & 3,33 & 1,07 & 2,53 & 3,20 & 11,60 & 5,47 & 14,40 & 9,87 \\
\hline
\end{tabular}




\section{4 - Análise dos Dados}

A partir dos resultados obtidos e expostos no item anterior, foi aplicado o Método da Regressão Linear Múltipla, tanto para os dados de força (resultante) quanto para os dados de rugosidade. Assim, foi possível estimar os efeitos de cada um dos 3 parâmetros de corte sobre as duas variáveis de saída analisadas. Os efeitos foram normalizados numa escala de 0 a $100 \%$ para facilitar a compreensão. Os resultados podem ser observados abaixo:

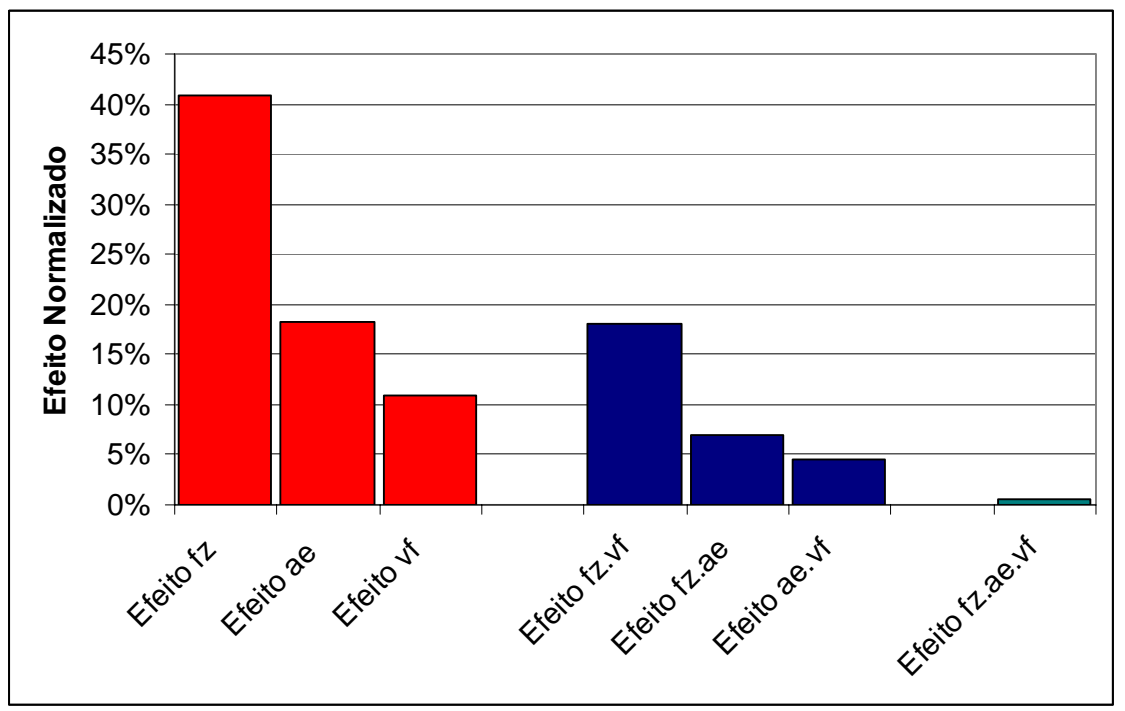

Figura 7.4.1 - Efeito dos Parâmetros sobre a Força de Corte 


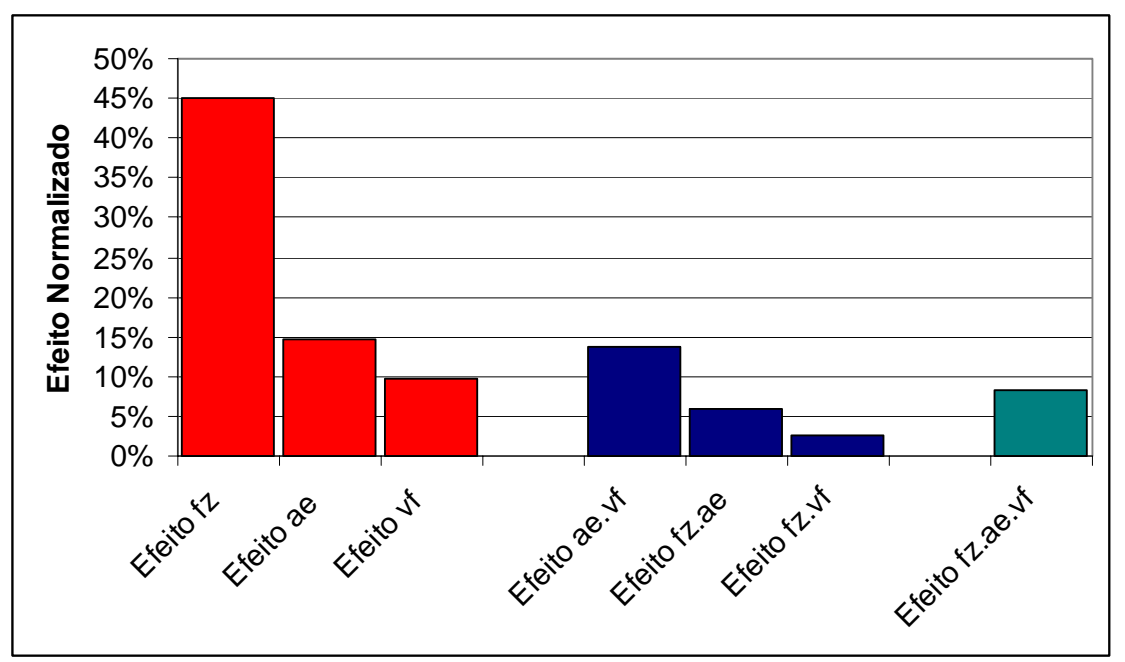

Figura 7.4.2 - Efeito dos Parâmetros sobre a rugosidade $\left(\mathbf{R}_{\mathbf{a}}\right)$

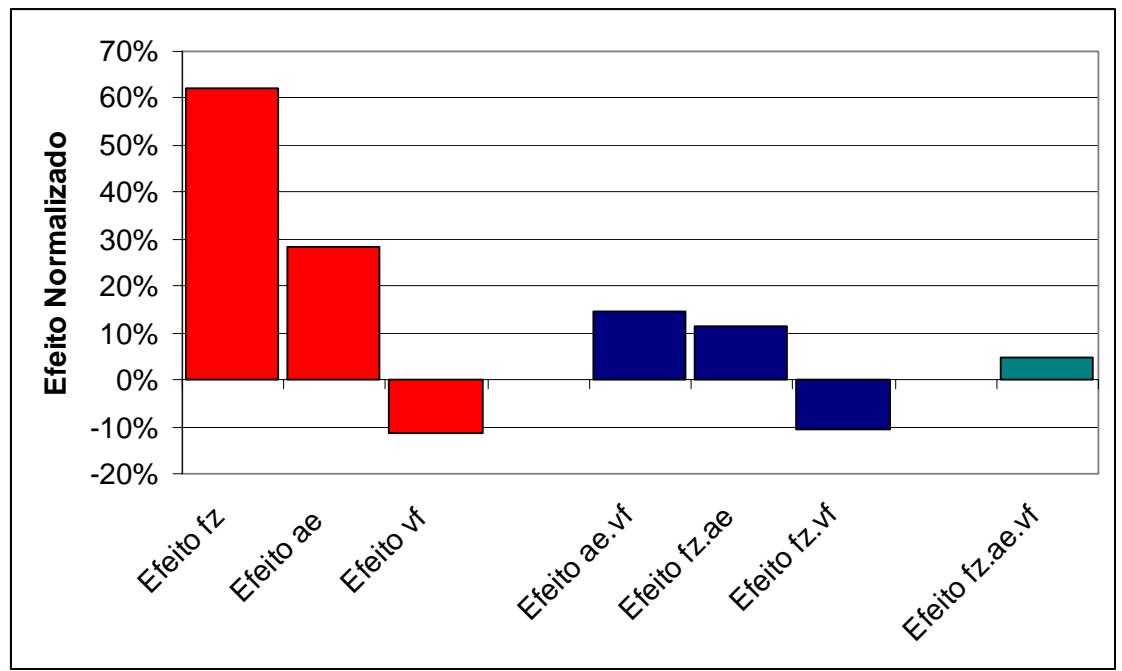

Figura 7.4.3 - Efeito dos Parâmetros sobre a rugosidade $\left(\mathbf{R}_{\mathbf{y}}\right)$

Para determinar quais as variáveis significativas no modelo de forças e de rugosidade, foi aplicado para os dois casos a ANOVA (teste de hipóteses), com o auxílio do software Minitab ${ }^{\circledR}$. Os dados obtidos podem ser observados abaixo: 


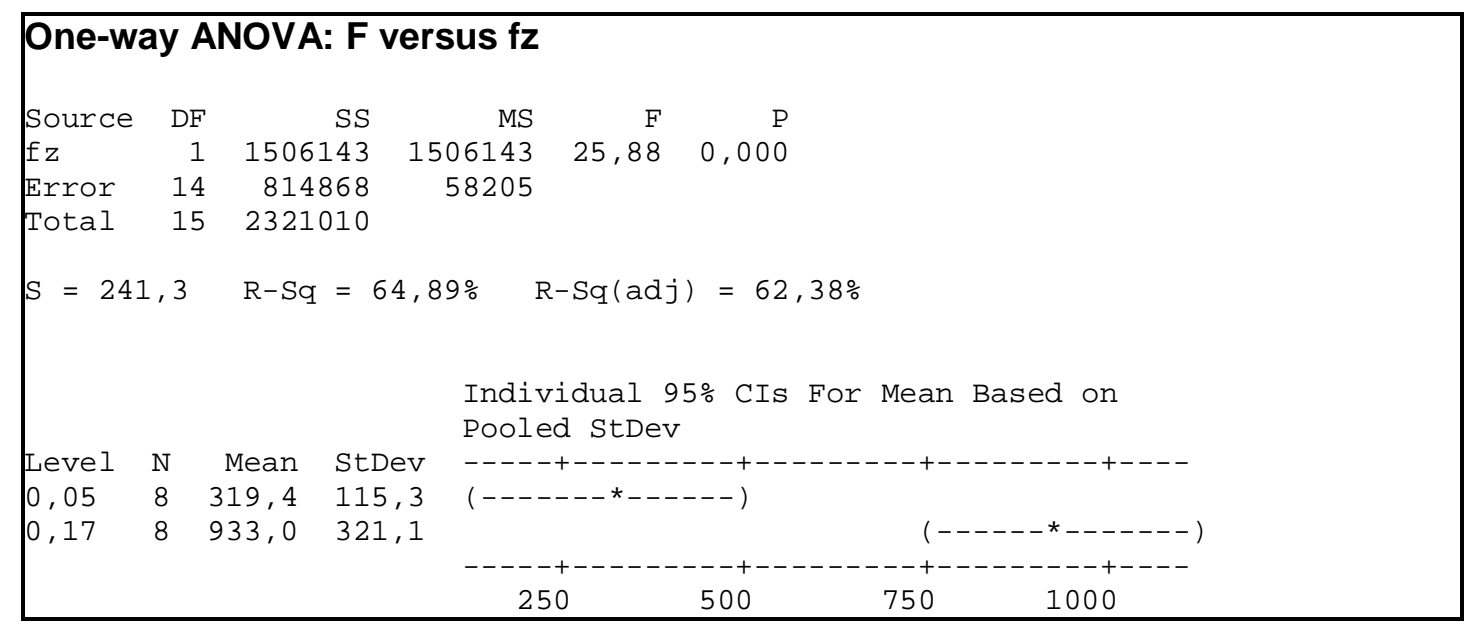

Figura 7.4.4 - ANOVA da Força $x$ avanço por dente

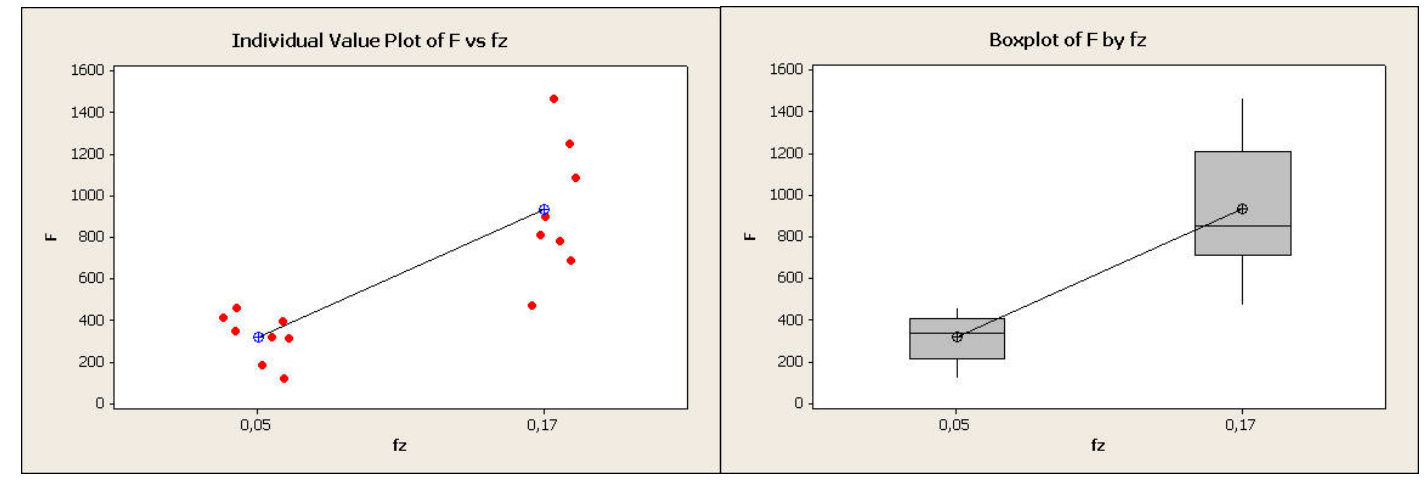

Figura 7.4.5 - Plotagem dos pontos de Força $x$ avanço por dente 


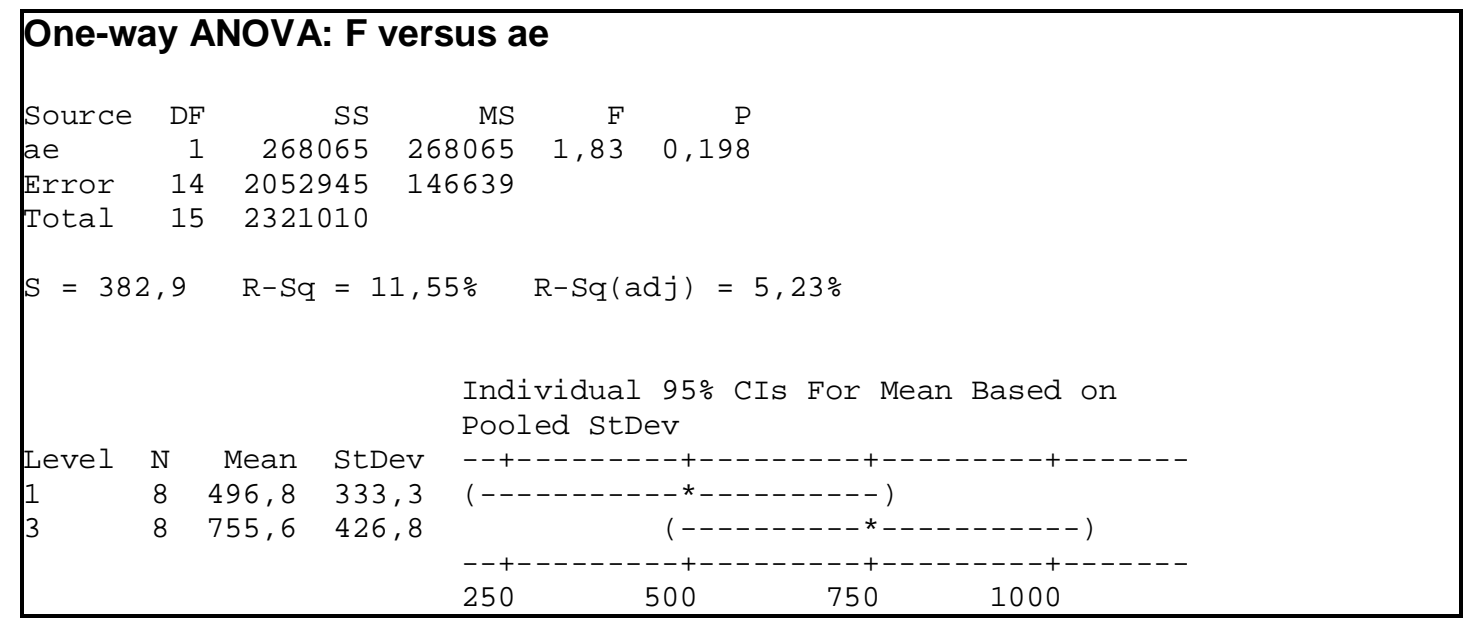

Figura 7.4.6 - ANOVA da Força $x$ largura de corte

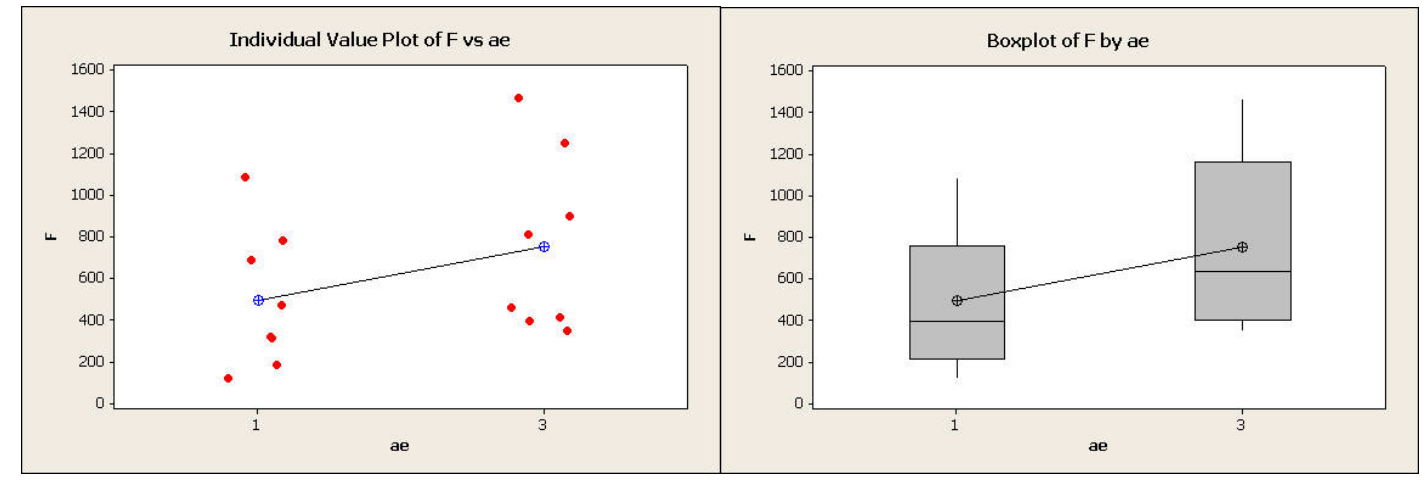

Figura 7.4.7 - Plotagem dos pontos de Força $x$ largura de corte 


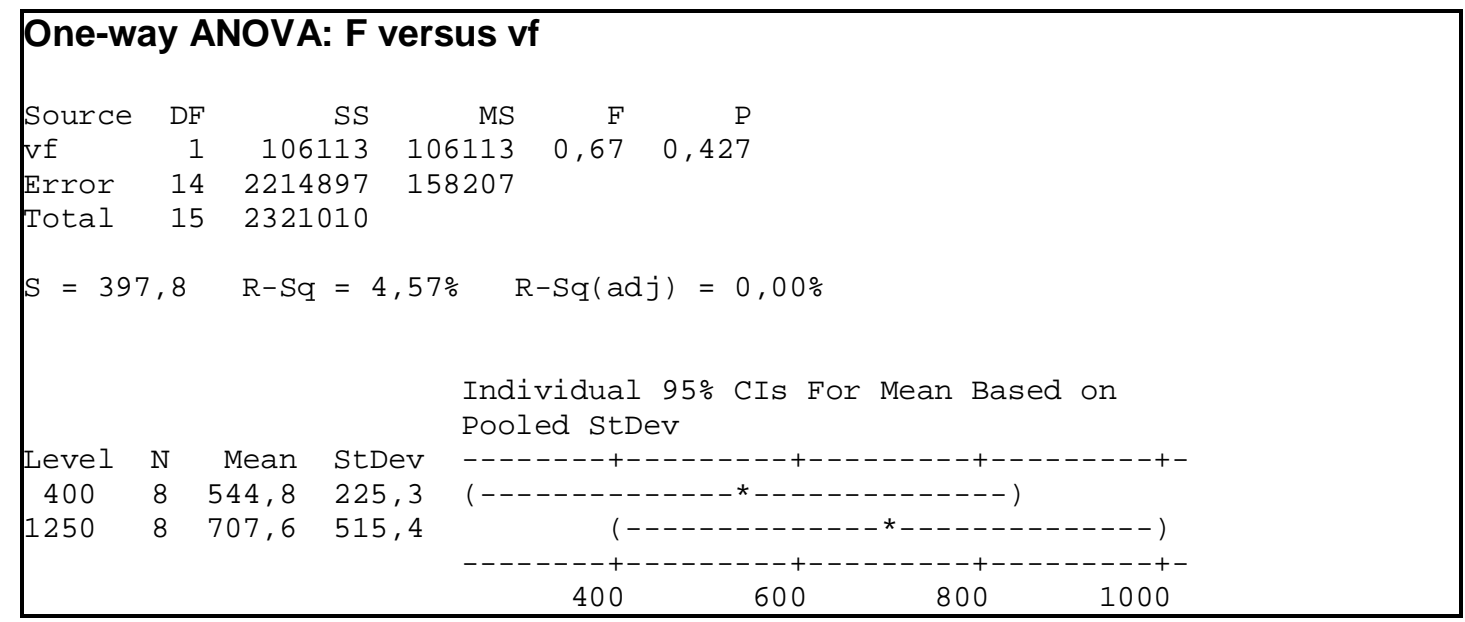

Figura 7.4.8 - ANOVA da Força $x$ velocidade de avanço

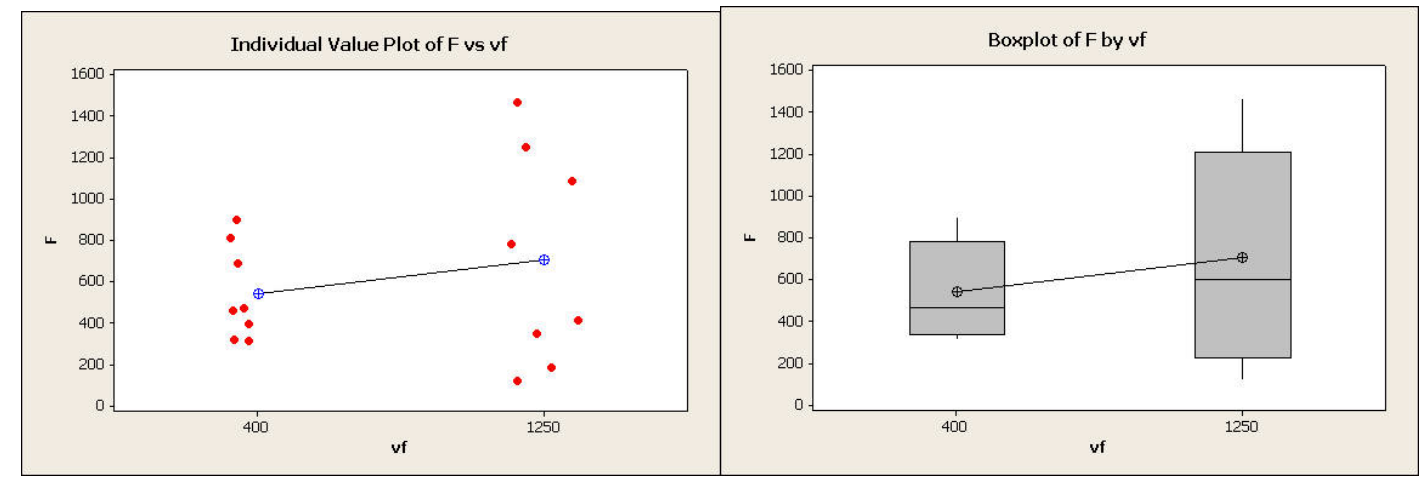

Figura 7.4.9 - Plotagem dos pontos de Força $x$ velocidade de avanço 


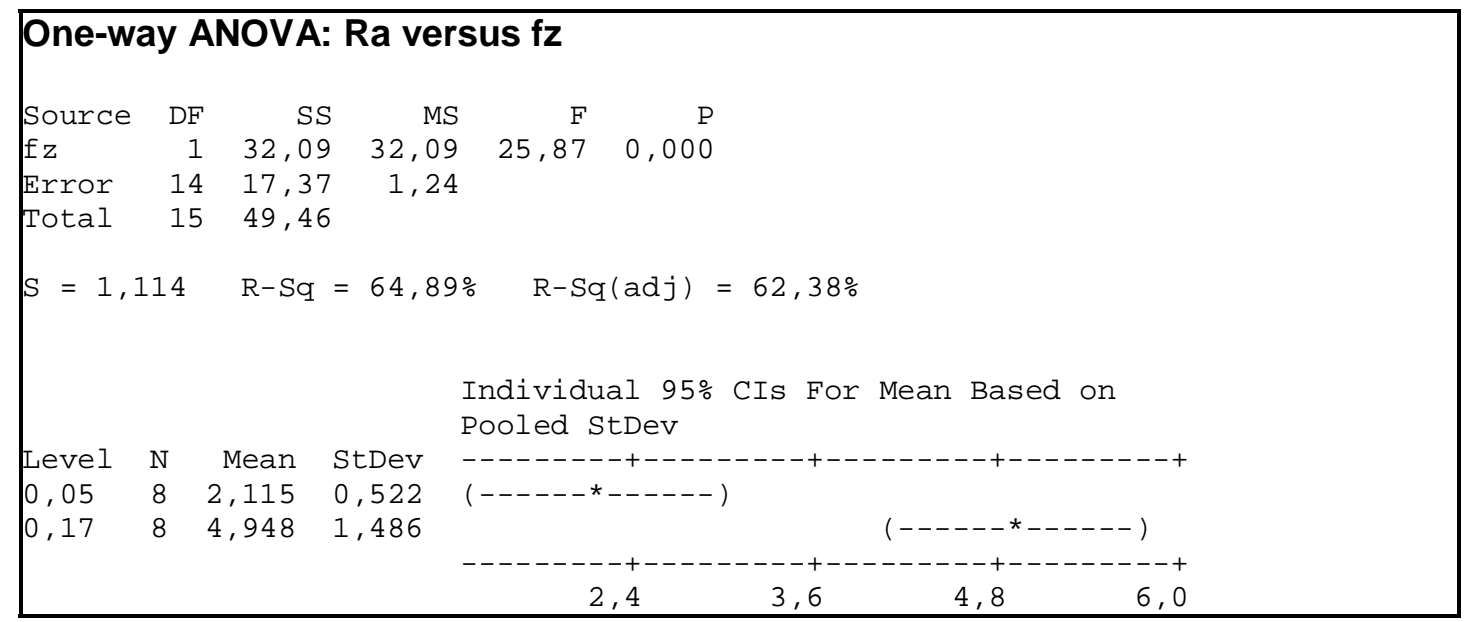

Figura 7.4.10 - ANOVA de Ra $x$ avanço por dente

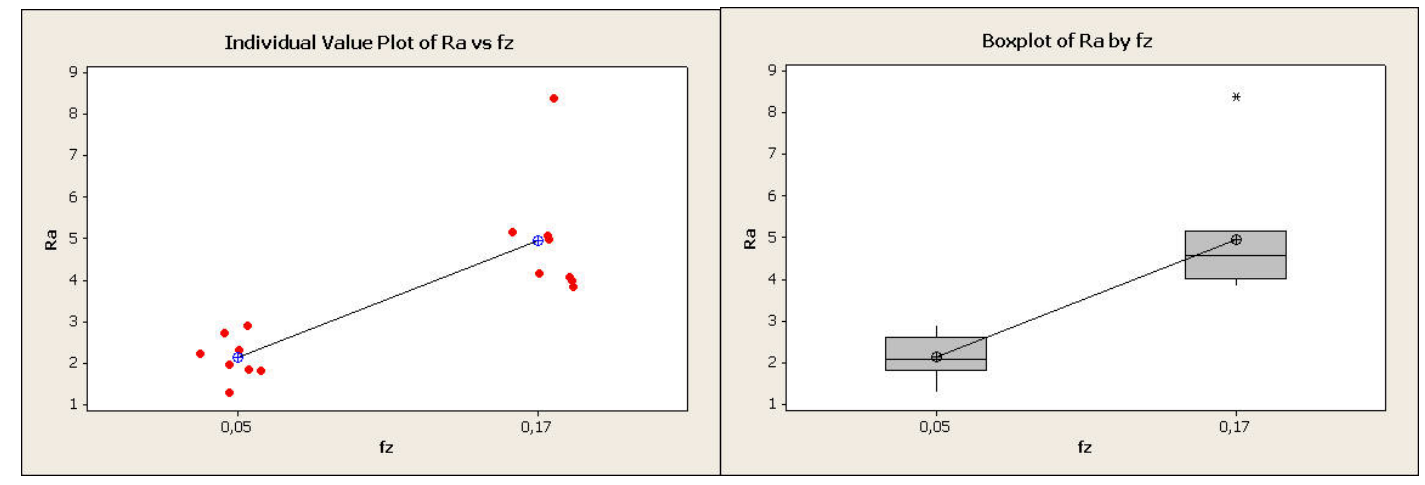

Figura 7.4.11 - Plotagem dos pontos de Ra $x$ avanço por dente 


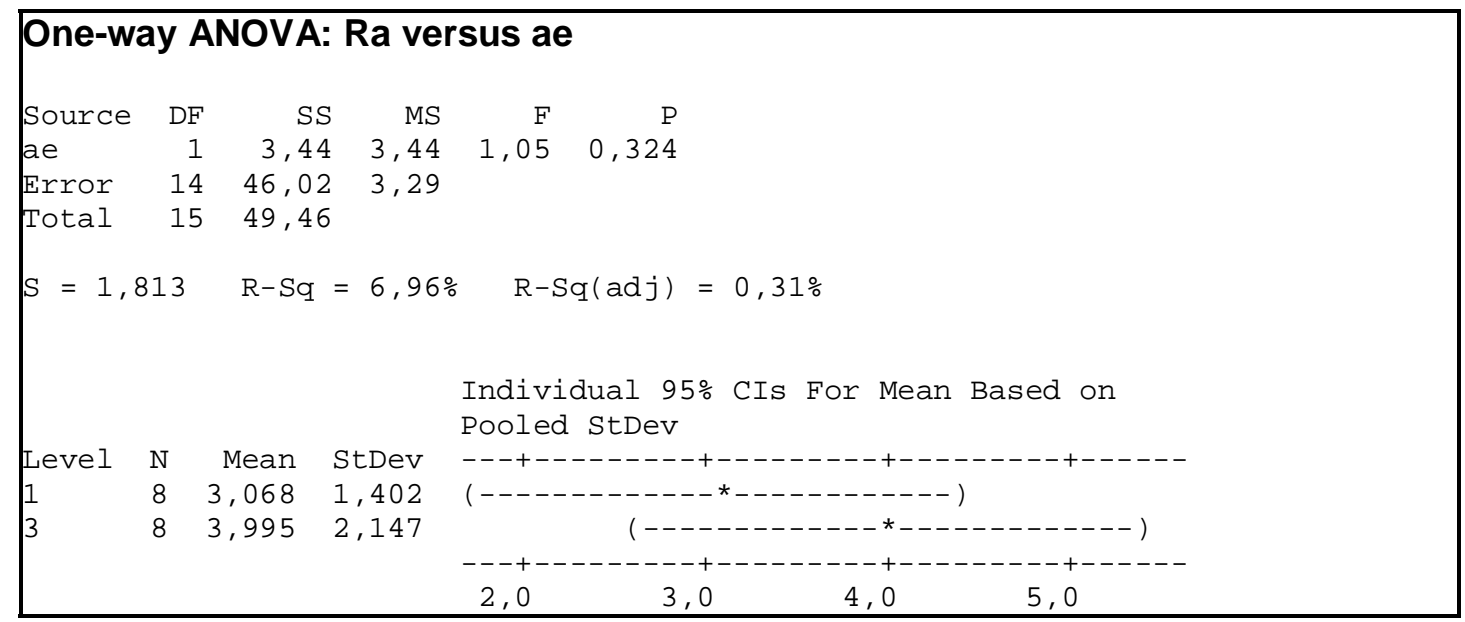

Figura 7.4.12 - ANOVA de Ra $x$ largura de corte

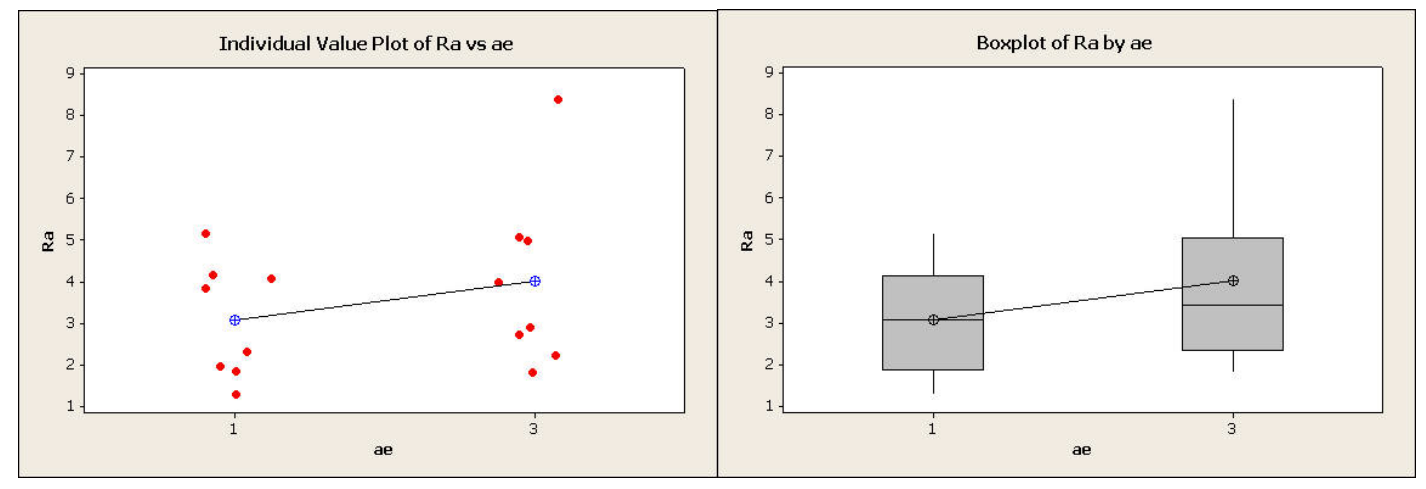

Figura 7.4.13 - Plotagem dos pontos de Ra $x$ largura de corte 


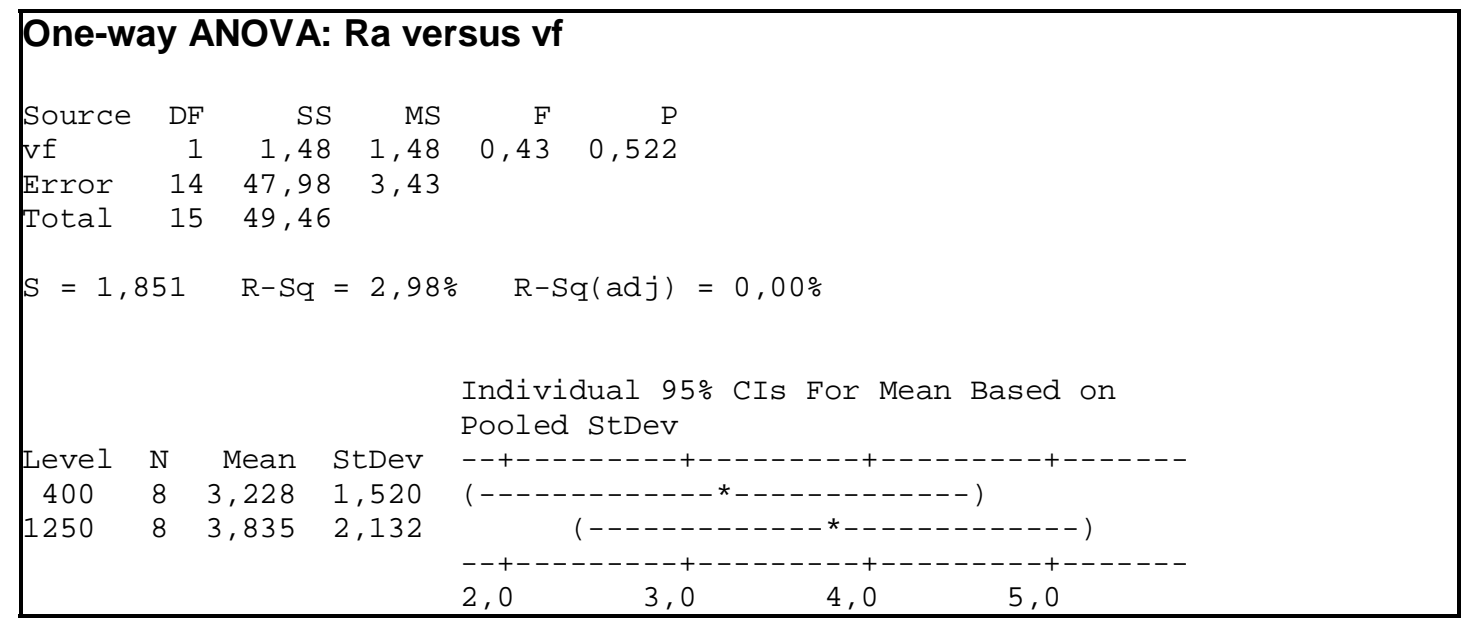

Figura 7.4.14 - ANOVA de Ra $x$ velocidade de avanço

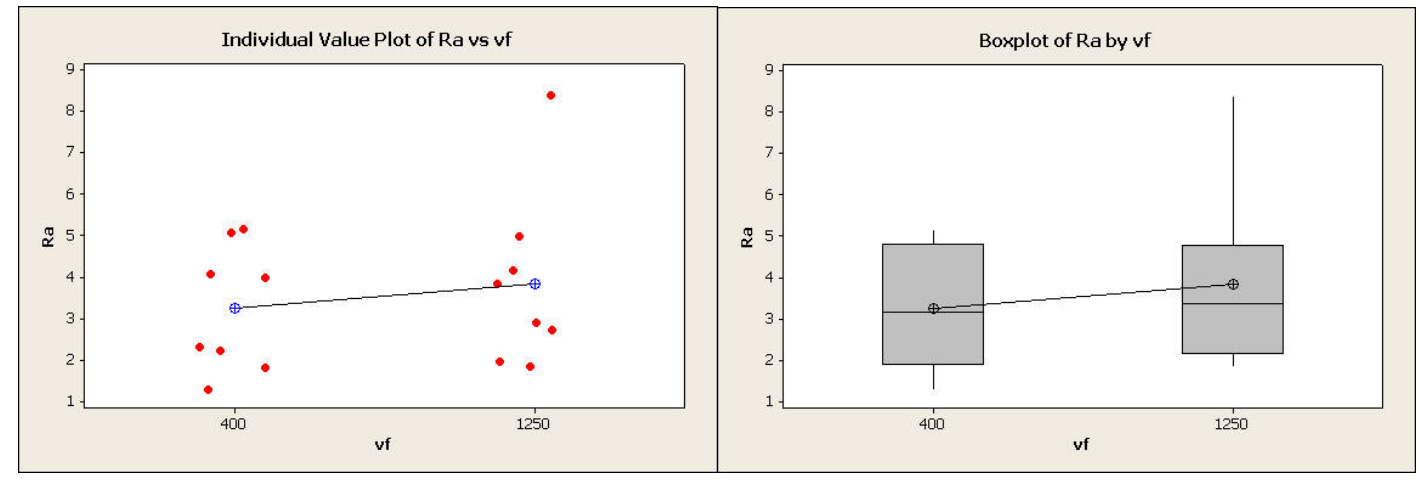

Figura 7.4.15 - Plotagem dos pontos de Ra $\mathrm{x}$ velocidade de avanço 


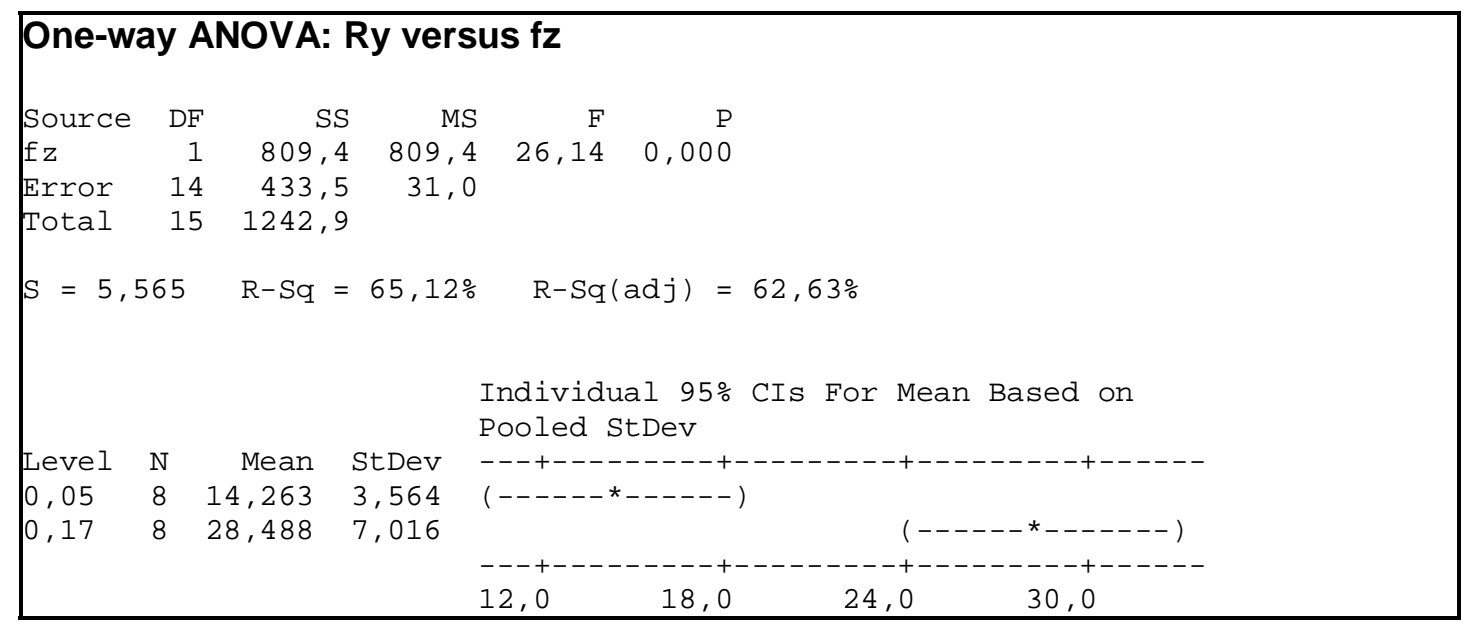

Figura 7.4.16 - ANOVA de Ry $x$ avanço por dente

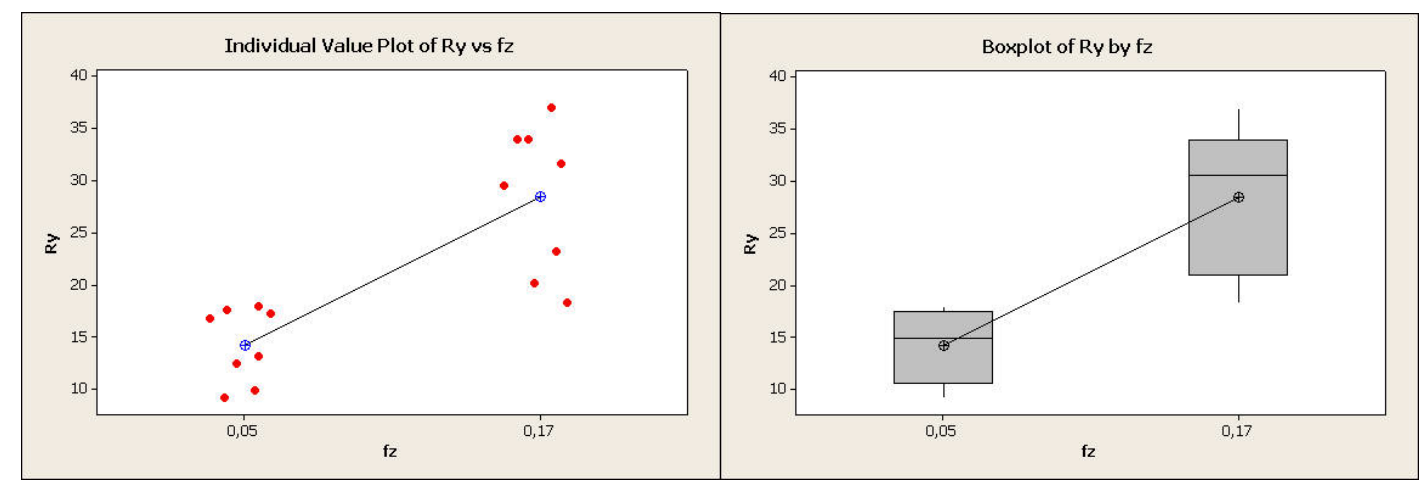

Figura 7.4.17 - Plotagem dos pontos de Ry $x$ avanço por dente 


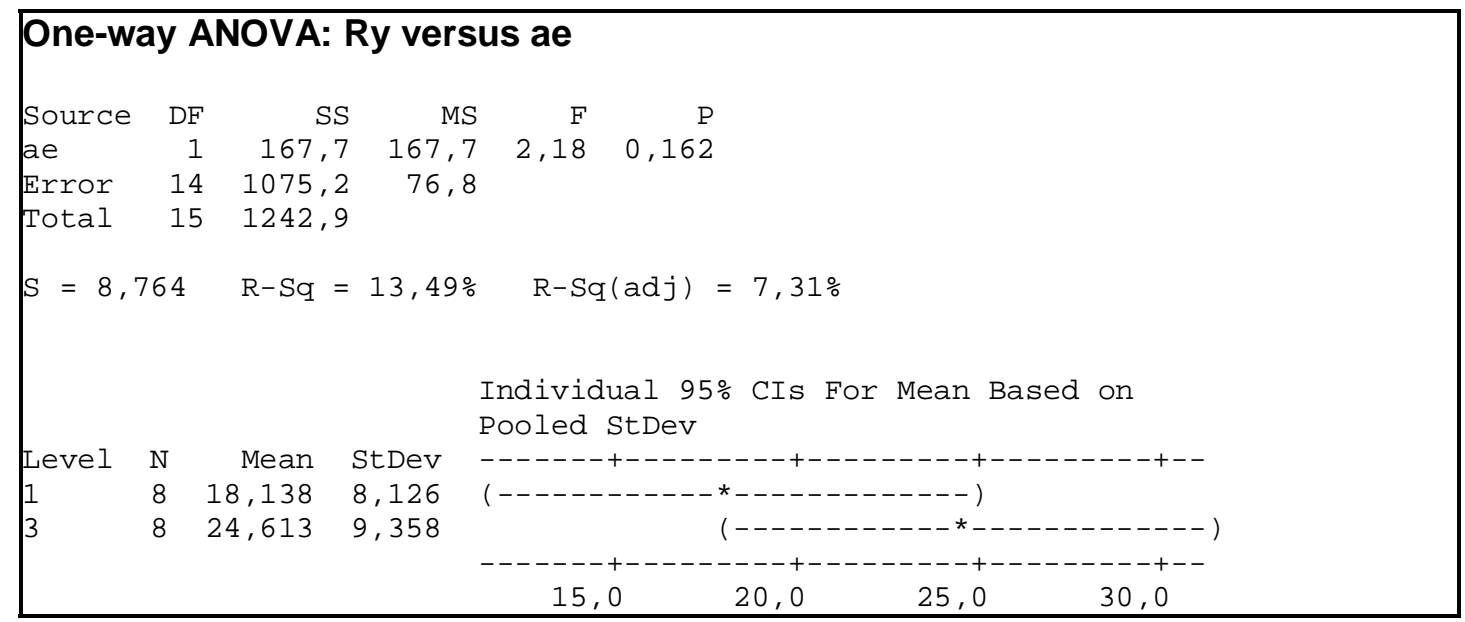

Figura 7.4.18 - ANOVA de Ry $x$ largura de corte

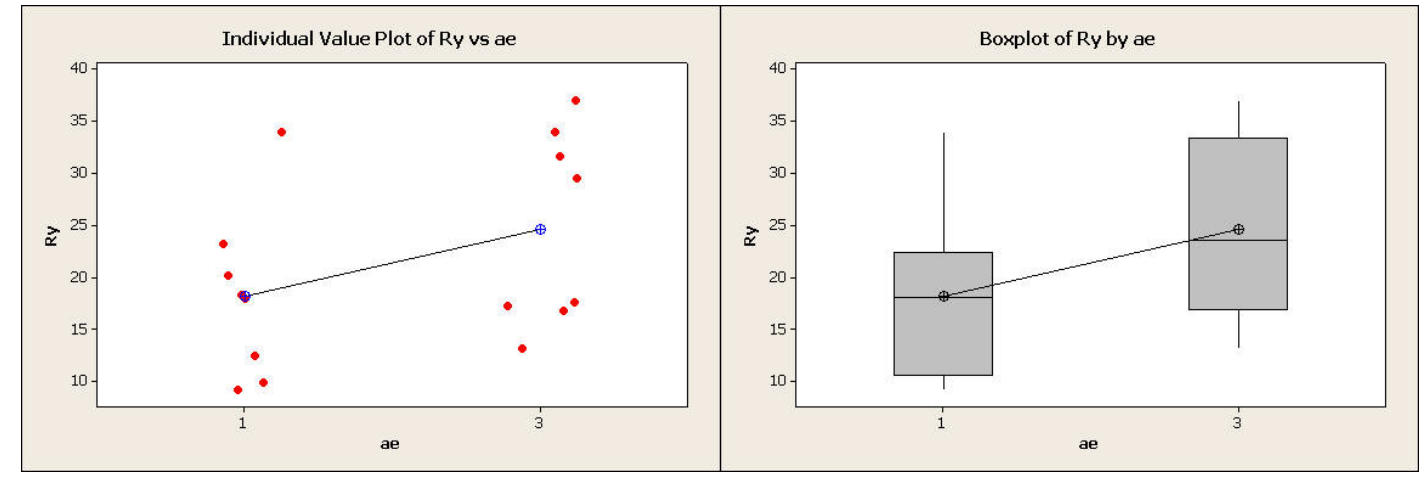

Figura 7.4.19 - Plotagem dos pontos de Ry x largura de corte 


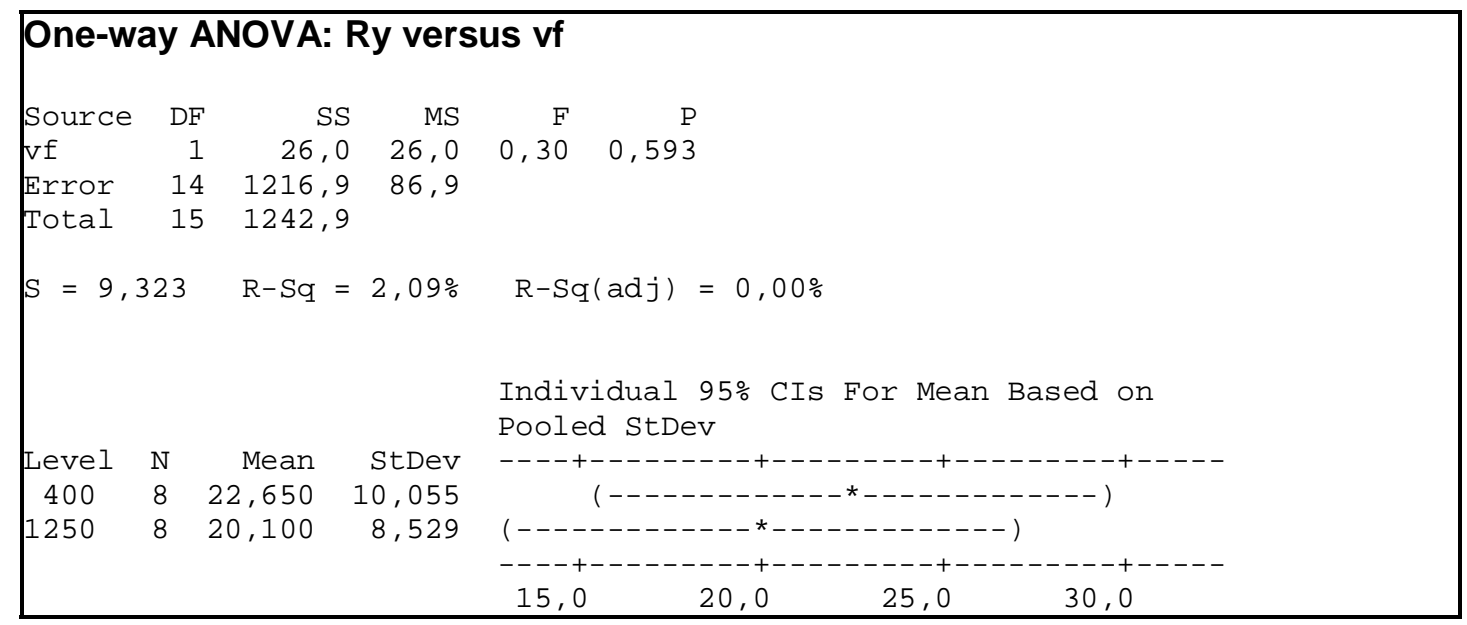

Figura 7.4.20 - ANOVA de Ry $\mathrm{x}$ velocidade de avanço

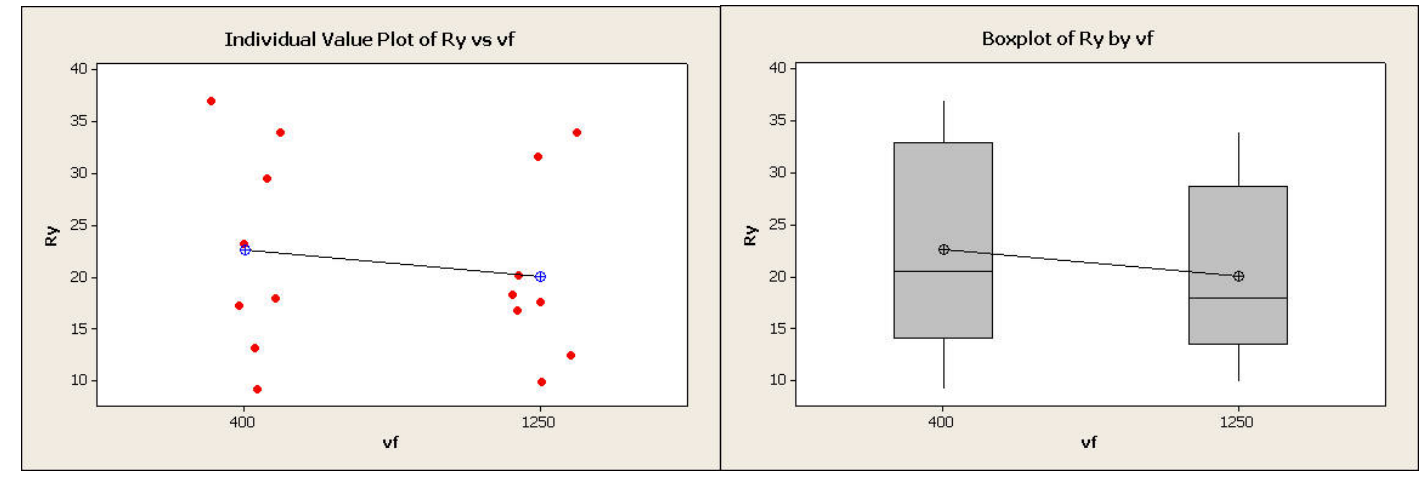

Figura 7.4.5 - Plotagem dos pontos de Ry $x$ velocidade de avanço 


\section{5 - Discussão dos Resultados}

A partir da análise dos resultados obtidos nos ensaios, é possível verificar que a variável que menos influencia na força de corte e na rugosidade da superfície usinada é $\mathrm{V}_{\mathrm{f}}$.

Mesmo sendo a variável de menor influencia, no caso da força de corte, esta variável não deixa de ser significativa, como mostra a ANOVA ( $95 \%$ de confiabilidade). Já no caso da rugosidade, tanto para o parâmetro $R_{a}$ quanto para o $R_{y}$, podemos verificar que $\mathrm{v}_{\mathrm{f}}$ não é significativa, e não há necessidade de levá-la em consideração no caso de uma estimativa da rugosidade em função dos parâmetros de corte.

Para cada um dos ensaios realizados, foi levantado o espectro de freqüência das forças na direção x, através da aplicação da Rápida Transformada de Fourier (FFT). No caso, era de se esperar que a freqüência com maior amplitude fosse a freqüência de entrada de cada um dos dentes da fresa na peça. Esta freqüência pode ser calculada dividindo-se a rotação do cabeçote fresador (em rpm) por 60, e multiplicando-se o resultado pelo número total de dentes da fresa.

Pode-se observar que para todos os ensaios, exceto para as duas replicações dos ensaios 1 e 2, as freqüências obtidas coincidem com as freqüências esperadas. No caso dos ensaios 1 e 2, o que ocorreu foi uma falha na seleção da freqüência de amostragem (de aquisição do sinal).

Esta falha ocorreu, pois havia sido criado um primeiro planejamento experimental, com valores diferentes dos parâmetros de corte, mas que não pôde ser utilizado devido às limitações do conjunto máquina-peça-ferramenta. No primeiro planejamento experimental, não havia nenhuma freqüência de sinal que ultrapassasse os $300 \mathrm{~Hz}$, sendo que foi selecionada então uma freqüência de amostragem de $600 \mathrm{~Hz}$, (de acordo com a teoria de amostragem, que diz que para que se consiga reconstruir o sinal original, a freqüência de amostragem deve ser de pelo menos 2 vezes a freqüência do sinal). O problema é que quando o planejamento experimental foi alterado, os dois 
primeiros ensaios passaram a ter uma freqüência de $416 \mathrm{~Hz}$, devido ao aumento da velocidade de corte, sendo que assim a teoria da amostragem passou a não ser mais obedecida.

Comparando-se os dados de rugosidade $\mathrm{R}_{\mathrm{y}}$ obtidos com a fórmula teórica da equação 15 , podemos observar que para os ensaios nos quais o $\mathrm{f}_{\mathrm{z}}$ estava em seu nível mais baixo, $0,05 \mathrm{~mm}$, a teoria se aplica bem, sendo que os resultados obtidos ficaram em média 50\% maiores do que os teóricos. Isso se deve às interferências do processo, tais como diferença no posicionamento das arestas de corte e excentricidade do eixo árvore.

Porém, para os ensaios em que o $\mathrm{f}_{\mathrm{z}}$ estava em seu nível mais alto, $0,17 \mathrm{~mm}$, pôdese observar que o valor obtido foi de aproximadamente $1 / 3$ do valor teórico, o que pode ter sido causado por alguma interação entre os fatores de interferência.

Pôde-se observar também, que a tendência de variação das forças de corte em relação à variação dos parâmetros de corte é acompanhada pela rugosidade, sendo que assim podemos concluir que estas duas grandezas são diretamente proporcionais, dentro do intervalo do estudo realizado. 


\section{6 - Aplicação Prática dos Resultados}

Para que se fosse possível comprovar na prática os resultados obtidos nos ensaios em laboratório, e confirmar realmente que $\mathrm{v}_{\mathrm{f}}$ é a variável que menos influencia na força de corte, foi desenvolvido um arranjo experimental para a Fresadora de Bordas da TenarisConfab, no qual $\mathrm{v}_{\mathrm{f}}$ foi alterado, mantendo os outros parâmetros constantes, sendo que foram realizadas medidas indiretas da força de corte através da corrente consumida pelos motores dos eixos-árvore. Isso porque não é possível extrapolar os resultados obtidos em laboratório para o caso prático, sem a realização de ensaios nas condições reais. Além disso, foi medida a vibração dos cabeçotes, para identificação de qualquer limitação estrutural do equipamento e seu estado operativo (Montenegro, 2007), e foi realizada inspeção do dimensional e da qualidade dos chanfros, para garantir que não haveria impacto na qualidade do produto.

A proposta foi aumentar a velocidade de avanço da mesa (reduzir o tempo de ciclo) sem aumentar significativamente a força de corte. Para isso, manteve-se o avanço por dente $\left(f_{z}\right)$ constante. Para que o aumento de $v_{f}$ não gerasse um aumento de $f_{z}$, foi também aumentada a rotação dos cabeçotes proporcionalmente à equação abaixo:

$v_{f}=n . Z . f_{z}$

onde:

$\mathrm{n}=$ rotação dos cabeçotes $(\mathrm{RPM})$

$\mathrm{Z}=$ número de dentes do cabeçote

Para manter a largura de corte $\left(\mathrm{a}_{\mathrm{e}}\right)$ constante, a largura real de cada chapa foi medida antes do processo, sendo que a largura de corte foi configurada para que a sobrelargura fosse de $2 \mathrm{~mm}$ de cada lado em todos os ensaios. 
Assim, foram realizados 12 ensaios, com chapas para a fabricação de tubos de 38 " x 0,875 " grau X70, os quais podem ser observados na tabela abaixo:

Tabela 7.6.1 - Arranjo Experimental

\begin{tabular}{|c|c|c|c|c|c|c|}
\hline Ensaio & Tubo & $\begin{array}{c}v_{c} \\
(\mathrm{~m} / \mathrm{min})\end{array}$ & $\begin{array}{c}n \\
(r p m)\end{array}$ & $\begin{array}{c}f_{z} \\
\text { (mm/dente*rotação) }\end{array}$ & $\begin{array}{c}V_{f} \\
(\mathrm{~mm} / \mathrm{min})\end{array}$ & $\begin{array}{c}a_{e} \\
(\mathrm{~mm})\end{array}$ \\
\hline 1 (Controle) & 97107 & 290 & 92 & 5,2 & 12500 & 2 \\
\hline 2 & 97112 & 295 & 94 & 5,2 & 12700 & 2 \\
\hline 3 & 97106 & 299 & 95 & 5,2 & 12900 & 2 \\
\hline 4 & 97102 & 304 & 97 & 5,2 & 13100 & 2 \\
\hline 5 & 97103 & 309 & 98 & 5,2 & 13300 & 2 \\
\hline 6 & 97099 & 313 & 100 & 5,2 & 13500 & 2 \\
\hline 7 & 97098 & 313 & 100 & 5,2 & 13500 & 2 \\
\hline 8 & 97105 & 309 & 98 & 5,2 & 13300 & 2 \\
\hline 9 & 97113 & 304 & 97 & 5,2 & 13100 & 2 \\
\hline 10 & 97101 & 299 & 95 & 5,2 & 12900 & 2 \\
\hline 11 & 97108 & 295 & 94 & 5,2 & 12700 & 2 \\
\hline 12 (Controle) & 97104 & 290 & 92 & 5,2 & 12500 & 2 \\
\hline
\end{tabular}

As medições de corrente dos motores foram feitas através de um registrador gráfico HIOKI 8835, enquanto as medições de vibração foram realizadas por uma empresa terceirizada especializada em Manutenção Preditiva.

Os resultados de cada ensaio podem ser visualizados abaixo:

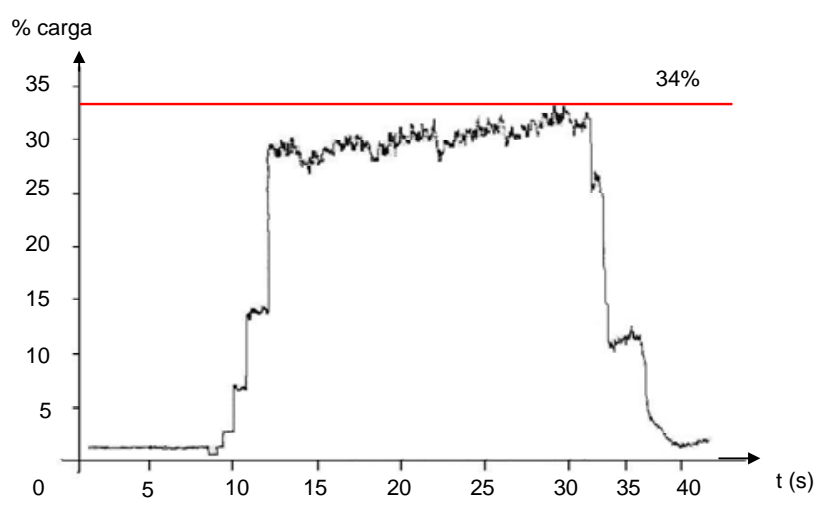

Figura 7.6.1 - Ensaio 1 


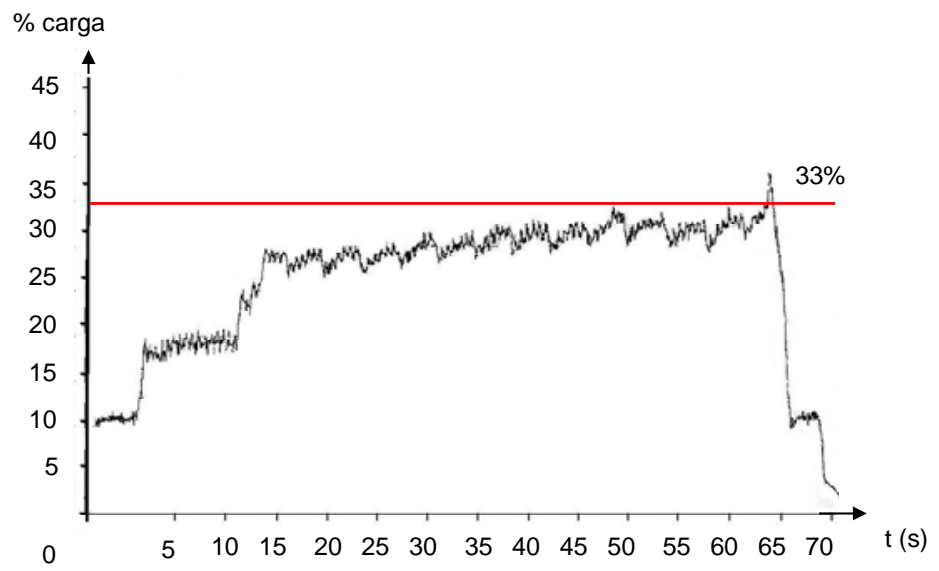

Figura 7.6.2 - Ensaio 2

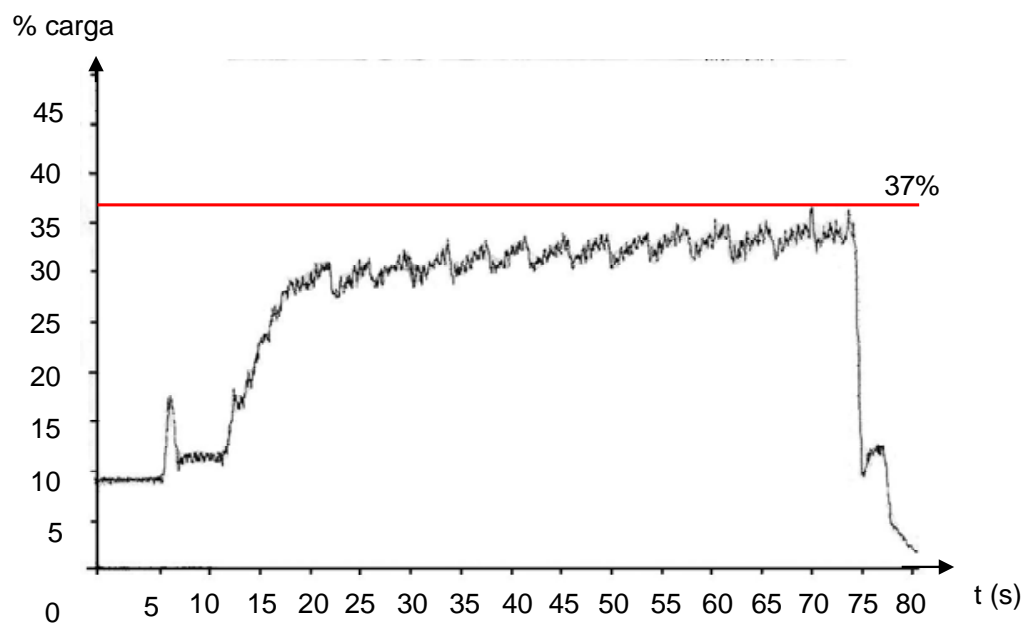

Figura 7.6.3 - Ensaio 3 


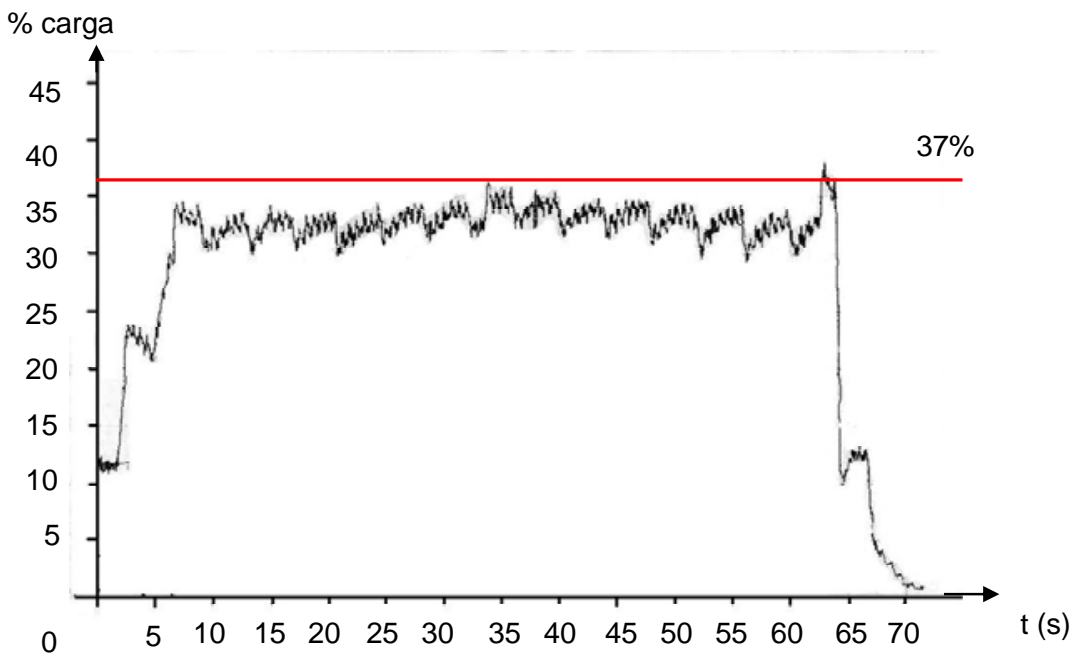

Figura 7.6.4 - Ensaio 4

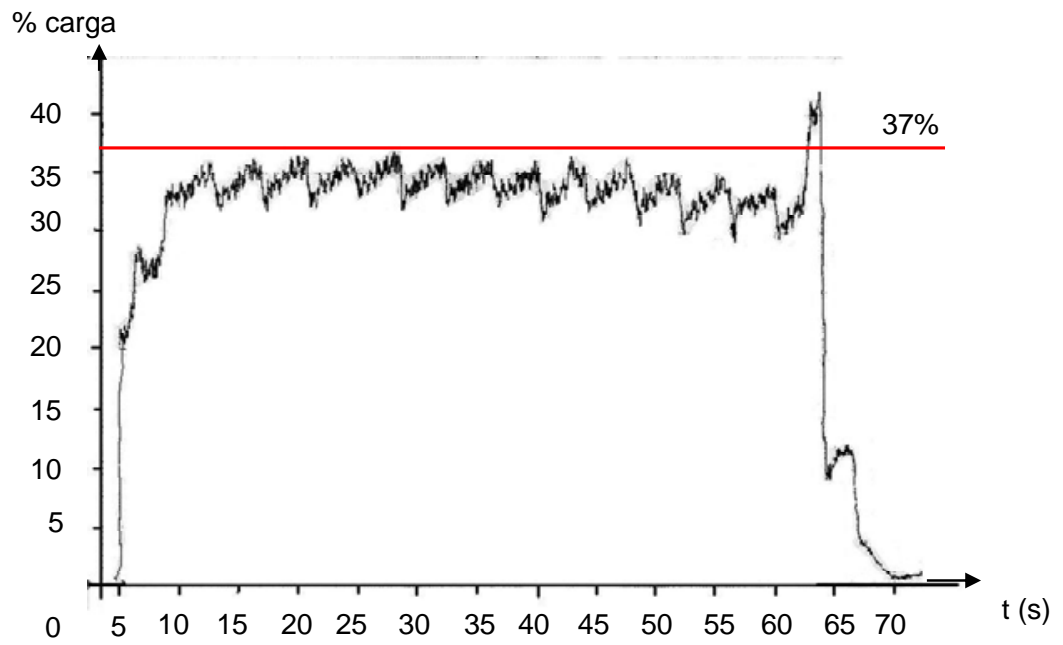

Figura 7.6.5 - Ensaio 5 


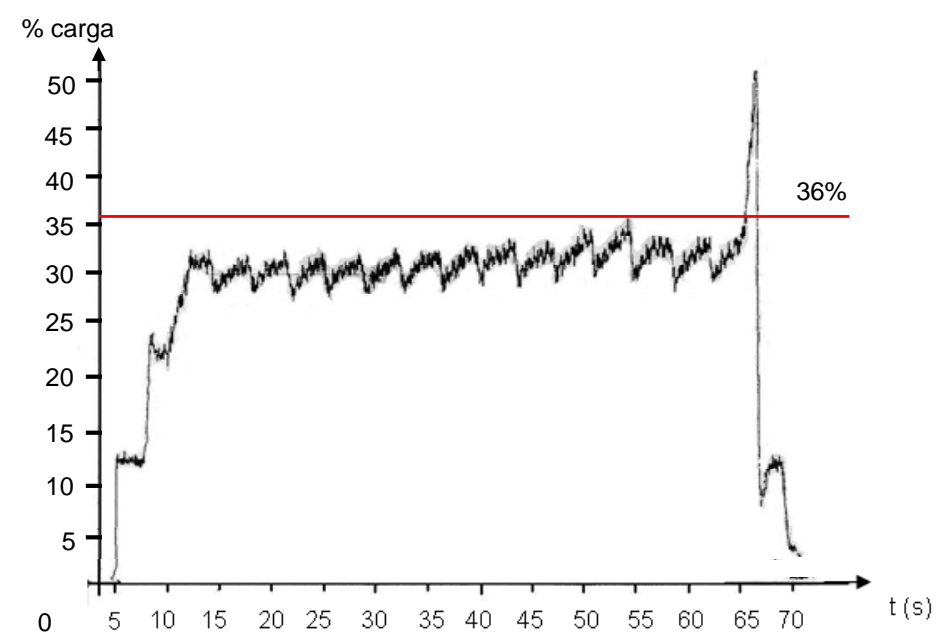

Figura 7.6.6 - Ensaio 6

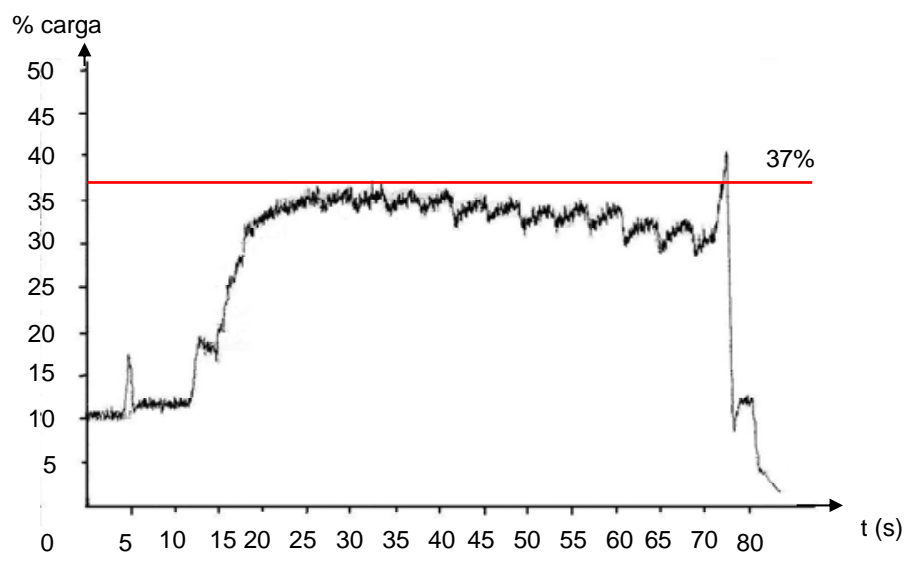

Figura 7.6.7 - Ensaio 7 


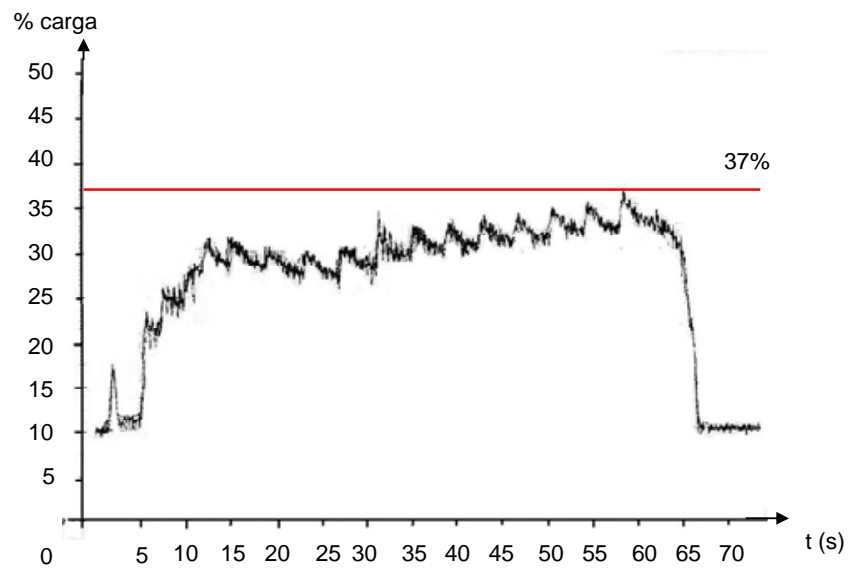

Figura 7.6.8 - Ensaio 8

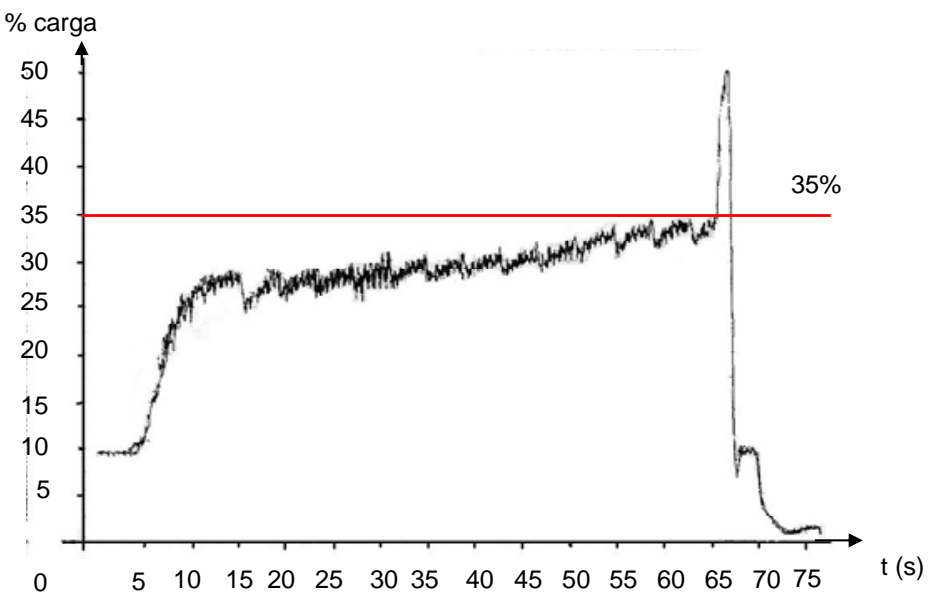

Figura 7.6.9 - Ensaio 9 


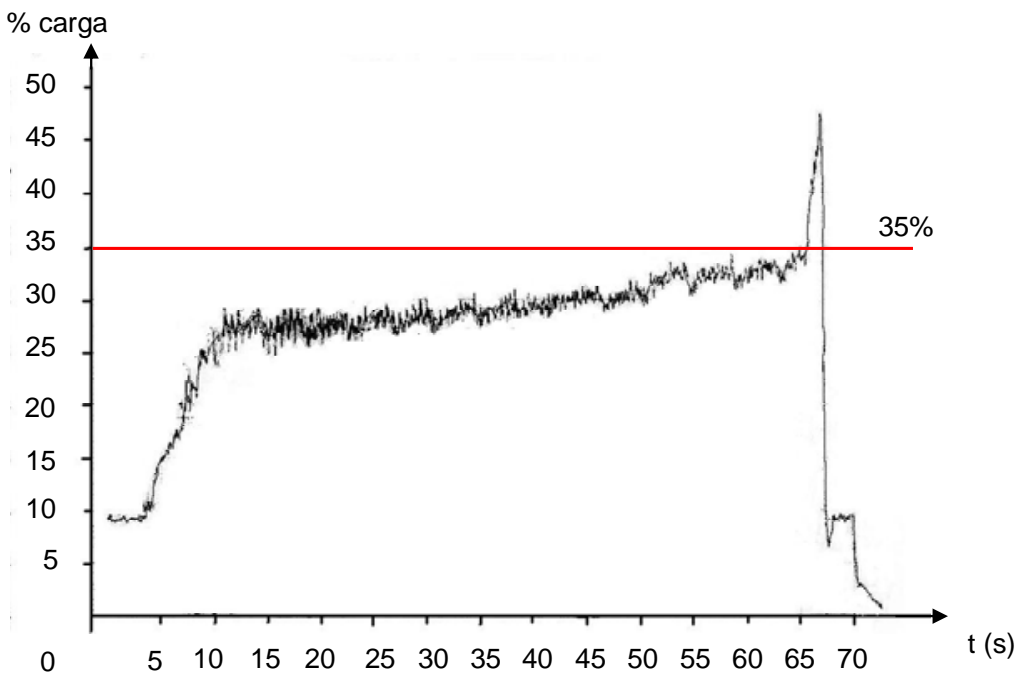

Figura 7.6.10 - Ensaio 10

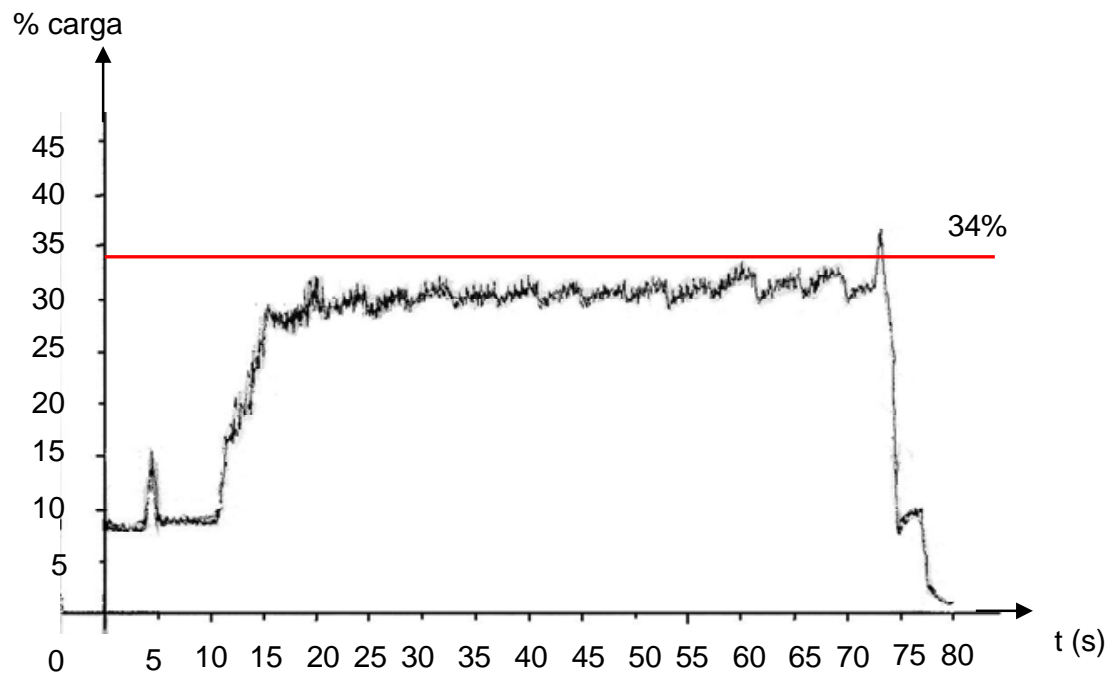

Figura 7.6.11 - Ensaio 11 


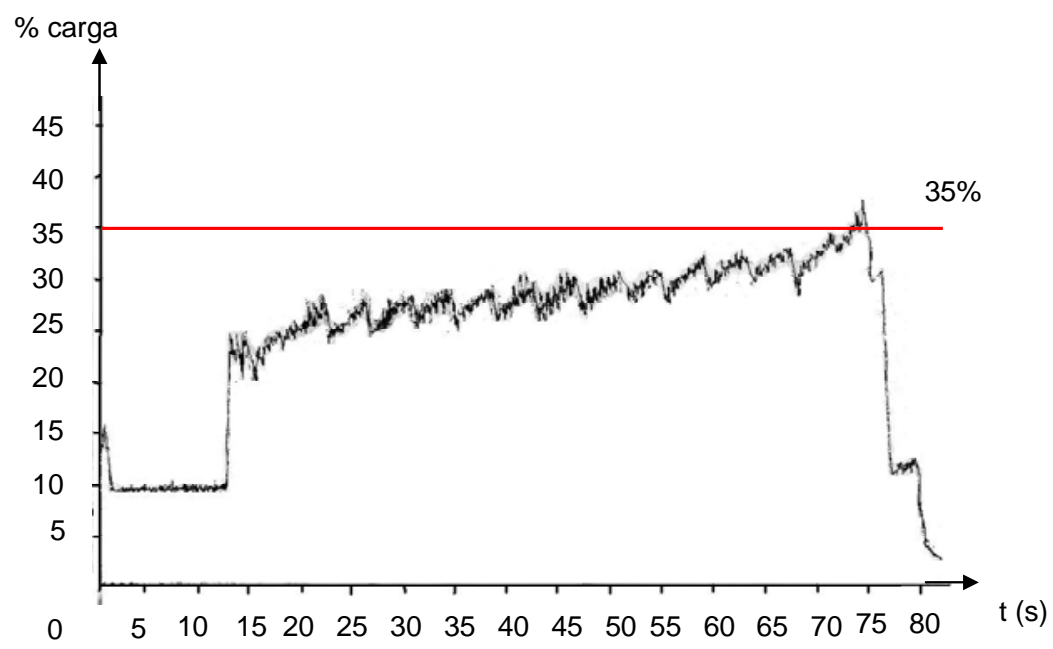

Figura 7.6.12 - Ensaio 12

Para a análise de vibração, foram levantados os valores globais (aceleração) para cada ensaio, sendo que os resultados encontrados se encontram no gráfico abaixo:

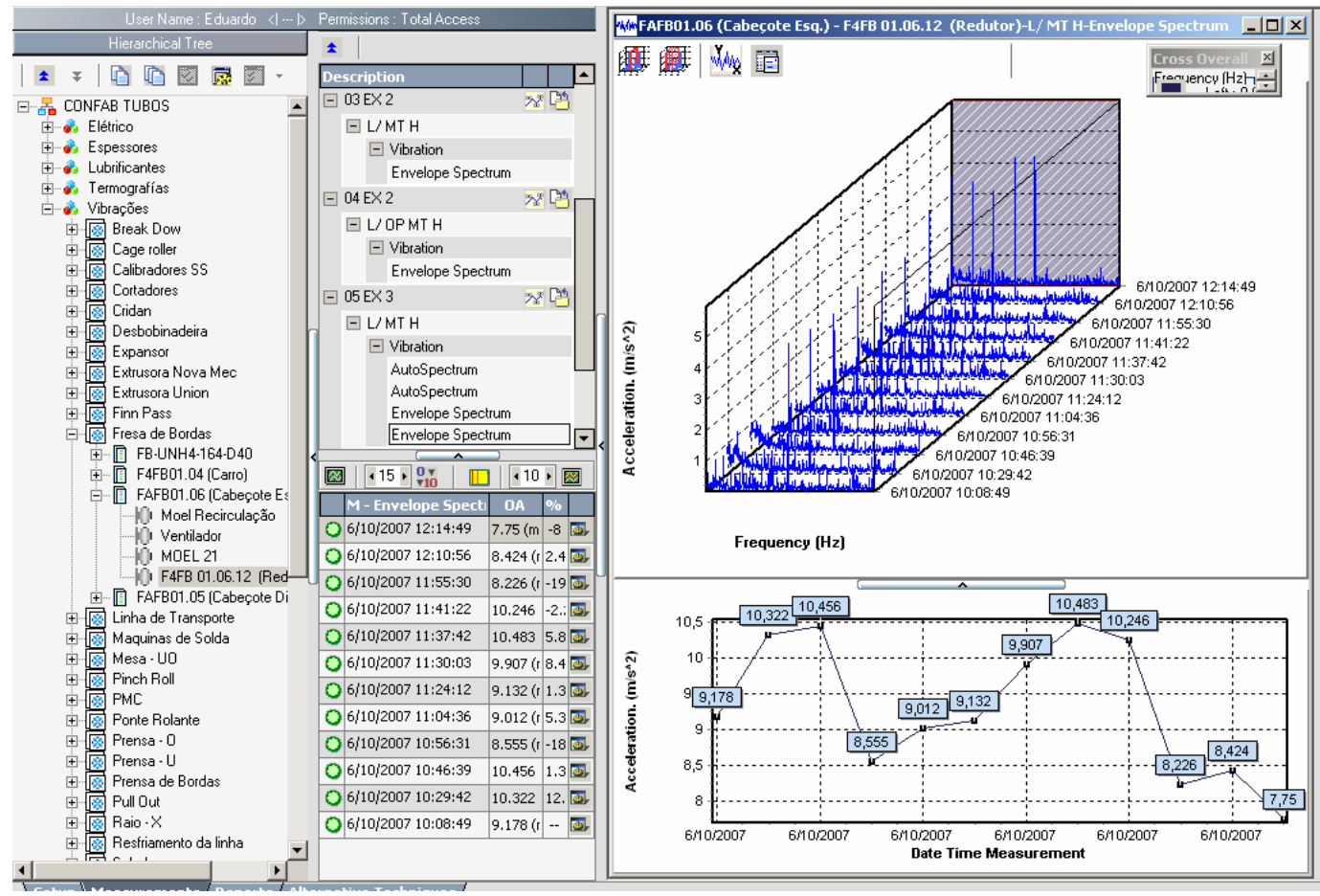

Figura 7.6.13 - Resultados da Análise de Vibração 
Abaixo se encontra uma tabela com o resumo dos resultados dos ensaios:

Tabela 7.6.2 - Resultados dos ensaios de comprovação

\begin{tabular}{c|ccccc}
\hline Ensaio & $\begin{array}{c}\boldsymbol{v}_{\boldsymbol{c}} \\
(\mathbf{m} / \mathbf{m i n})\end{array}$ & $\begin{array}{c}\boldsymbol{v}_{\boldsymbol{f}} \\
(\mathbf{m} \mathbf{m} / \mathbf{m i n})\end{array}$ & $\begin{array}{c}\boldsymbol{a}_{\boldsymbol{e}} \\
(\mathbf{m m})\end{array}$ & $\begin{array}{c}\% \\
\text { Carga }\end{array}$ & $\begin{array}{c}\text { Vibração } \\
\left(\mathbf{m} / \mathbf{s}^{2}\right)\end{array}$ \\
\hline $\mathbf{1}$ (Controle) & 290 & 12500 & 2 & $\mathbf{3 4}$ & $\mathbf{9 , 1 7 8}$ \\
$\mathbf{2}$ & 295 & 12700 & 2 & $\mathbf{3 3}$ & $\mathbf{1 0 , 3 2 2}$ \\
$\mathbf{3}$ & 299 & 12900 & 2 & $\mathbf{3 7}$ & $\mathbf{1 0 , 4 5 6}$ \\
$\mathbf{4}$ & 304 & 13100 & 2 & $\mathbf{3 7}$ & $\mathbf{8 , 5 5 5}$ \\
$\mathbf{5}$ & 309 & 13300 & 2 & $\mathbf{3 7}$ & $\mathbf{9 , 0 1 2}$ \\
$\mathbf{6}$ & 313 & 13500 & 2 & $\mathbf{3 6}$ & $\mathbf{9 , 1 3 2}$ \\
$\mathbf{7}$ & 313 & 13500 & 2 & $\mathbf{3 7}$ & $\mathbf{9 , 9 0 7}$ \\
$\mathbf{8}$ & 309 & 13300 & 2 & $\mathbf{3 7}$ & $\mathbf{1 0 , 4 8 3}$ \\
$\mathbf{9}$ & 304 & 13100 & 2 & $\mathbf{3 5}$ & $\mathbf{1 0 , 2 4 6}$ \\
$\mathbf{1 0}$ & 299 & 12900 & 2 & $\mathbf{3 5}$ & $\mathbf{8 , 2 2 6}$ \\
$\mathbf{1 1}$ & 295 & 12700 & 2 & $\mathbf{3 4}$ & $\mathbf{8 , 4 2 4}$ \\
$\mathbf{1 2}$ (Controle) & 290 & 12500 & 2 & $\mathbf{3 5}$ & $\mathbf{7 , 7 5 0}$ \\
\hline
\end{tabular}

Tabela 7.6.3 - \% Carga dos Motores dos Cabeçotes

\begin{tabular}{c|ccccc}
\hline $\begin{array}{c}V_{f} \\
(\mathrm{~mm} / \mathrm{min})\end{array}$ & $\begin{array}{c}\text { Replicação } \\
1\end{array}$ & $\begin{array}{c}\text { Replicação } \\
\text { 12500 }\end{array}$ & Média & $\begin{array}{c}\text { Desvio } \\
\text { Padrão }\end{array}$ & $\begin{array}{c}\text { T-student } \\
\text { (20\%, 2 caudas) }\end{array}$ \\
\hline 12700 & 33 & 35 & $\mathbf{3 4 , 5}$ & 0,7 & $\mathbf{1 , 3}$ \\
12900 & 37 & 34 & $\mathbf{3 3 , 5}$ & 0,7 & $\mathbf{1 , 3}$ \\
13100 & 37 & 35 & $\mathbf{3 6}$ & 1,4 & $\mathbf{2 , 6}$ \\
13300 & 37 & 35 & $\mathbf{3 6}$ & 1,4 & $\mathbf{2 , 6}$ \\
13500 & 36 & 37 & $\mathbf{3 7}$ & 0,0 & $\mathbf{0 , 0}$ \\
\hline
\end{tabular}

Tabela 7.6.4 - Vibração dos Cabeçotes

\begin{tabular}{c|ccccc}
\hline $\begin{array}{c}V_{f} \\
(\mathrm{~mm} / \text { min })\end{array}$ & $\begin{array}{c}\text { Replicação } \\
1\end{array}$ & $\begin{array}{c}\text { Replicação } \\
\mathbf{2}\end{array}$ & Média & $\begin{array}{c}\text { Desvio } \\
\text { Padrão }\end{array}$ & $\begin{array}{c}\text { T-student } \\
\text { (20\%, 2 caudas) }\end{array}$ \\
\hline 12500 & 9,178 & 7,75 & $\mathbf{8 , 4 6 4}$ & 1,0 & $\mathbf{1 , 9}$ \\
12700 & 10,322 & 8,424 & $\mathbf{9 , 3 7 3}$ & 1,3 & $\mathbf{2 , 5}$ \\
12900 & 10,456 & 8,226 & $\mathbf{9 , 3 4 1}$ & 1,6 & $\mathbf{2 , 9}$ \\
13100 & 8,555 & 10,246 & $\mathbf{9 , 4 0 0 5}$ & 1,2 & $\mathbf{2 , 2}$ \\
13300 & 9,012 & 10,483 & $\mathbf{9 , 7 4 7 5}$ & 1,0 & $\mathbf{1 , 9}$ \\
13500 & 9,132 & 9,907 & $\mathbf{9 , 5 1 9 5}$ & 0,5 & $\mathbf{1 , 0}$ \\
\hline
\end{tabular}


Foi realizada uma análise da variação percentual da porcentagem de carga nos motores dos cabeçotes e dos valores globais de vibração, entre os ensaios com $\mathrm{v}_{\mathrm{f}}=$ 12500 e $\mathrm{v}_{\mathrm{f}}=13500 \mathrm{~mm} / \mathrm{min}$ (os dois extremos), sendo que os resultados podem ser vistos na tabela abaixo:

Tabela 7.6.5 - Variabilidade dos resultados

\begin{tabular}{c|ccc}
\hline Parâmetro & Min & Med & Max \\
\hline \% Carga & $0 \%$ & $\mathbf{6 \%}$ & $14 \%$ \\
Vibração & $0 \%$ & $\mathbf{1 2 \%}$ & $60 \%$ \\
\hline
\end{tabular}

No caso da porcentagem de carga dos motores, podemos perceber que a variação média é bem pequena, e considerando o desvio padrão dos ensaios, pode ser até nula.

No caso da análise de vibração, que foi obtida no ponto de acoplamento do motor com o redutor do cabeçote fresador, segundo laudo fornecido para empresa especializada em Manutenção Preditiva, “o mesmo não apresentou níveis considerados de grande incremento ou fora da faixa admissível de seu funcionamento. De acordo com os resultados obtidos durante as medições ficou confirmado que o projeto de aumento da produção não oferecerá influência negativa nas condições de trabalho do equipamento.” 


\section{8 - CONCLUSÕES}

O dinamômetro foi projetado utilizando-se as restrições impostas pela sua aplicação, sendo que desta forma foram encontradas as dimensões ideais para as células de carga. A construção do dinamômetro seguiu as recomendações dos procedimentos de instrumentação das células de carga para que se pudesse garantir a sua precisão. Os resultados obtidos nos ensaios demonstraram que o dinamômetro possui precisão suficiente para que estudos sobre as forças de corte envolvidas no processo de fresamento sejam realizados.

Os ensaios foram realizados, sendo que, com os mesmos foi possível determinar que o parâmetro que mais influencia, tanto na força de corte quanto na rugosidade da superfície usinada é o avanço por dente, seguido pela largura de corte, sendo que a velocidade de avanço é o parâmetro que menos influencia estas duas grandezas.

O método de regressão linear múltipla se mostrou uma ferramenta muito útil na análise dos dados obtidos, aliando simplicidade de aplicação e coerência com os dados reais, o que pôde ser observado através da aplicação dos resultados obtidos no processo real, sendo que o comportamento previsto pelo modelo foi reproduzido.

A partir dos resultados dos ensaios no equipamento real, conclui-se que o aumento da velocidade de avanço da mesa não influencia significativamente a força de corte exigida dos cabeçotes fresadores.

Além disso, a condição de trabalho do equipamento com velocidades mais altas se encontra dentro de padrões aceitáveis de vibração, o que pode ser confirmado pelos dados de vibração coletados durante os ensaios.

Assim, conclui-se que é possível trabalhar com uma velocidade de avanço de $13.500 \mathrm{~mm} / \mathrm{min}$, sendo que desta forma o tempo de ciclo é diminuído em 4 segundos.

Portanto, conclui-se que o trabalho obteve êxito no propósito de aumentar a produtividade da Fresadora de Bordas através da otimização dos parâmetros de corte. 


\section{9 - SUGESTÕES PARA TRABALHOS FUTUROS}

- Correlacionar o desgaste da ferramenta com as forças de corte e com a rugosidade da superfície usinada;

- Otimização dos parâmetros de corte objetivando o aumento da vida da ferramenta, sem comprometer a produtividade;

- Determinar parâmetros objetivos como critério de fim de vida da ferramenta, a ser utilizado pelos operadores no ambiente fabril;

- Medir as tensões residuais da superfície usinada e correlacioná-la com os parâmetros de corte;

- Comparar as respostas dinâmicas do dinamômetro construído com um dinamômetro comercial. 
10 - REFERÊNCIAS BIBLIOGRÁFICAS

(Almeida, 1996) - ALMEIDA, P. A. O - Extensometria Elétrica 1 - Notas de Aula - EPUSP - São Paulo, 1996

(Altintas, 2000) - ALTINTAS, Y. - Manufacturing Automation - Metal Cutting Mechanics, Machine Tool Vibrations and CNC Design, Cambridge University Press, Cambridge, United Kingdom, 2000.

(Araújo e Silveira, 2001) - Araújo, A. C., Silveira, J. L. - The Influence of Specific Cutting Force on End Milling Models, COBEM, 2001.

(Blank, 1980) - Blank, L. - Statistical Procedures for Engineering, Management and Science, McGraw-Hill Book Company, New York, 1980.

(Cook e Rabinowicz, 1963) - Cook, N. H., Rabinowicz, E. - PHYSICAL MEASUREMENT AND ANALYSIS - Addison-Wesley, Chapter Five, 1963.

(Dally, 1978) - Dally, J. W. - Experimental Stress Analysis - McGrw-Hill, 1978.

(Diniz, 2006) - DINIZ, A.E.; MARCONDES, F.C.; COPPINI, N.L. - Tecnologia da Usinagem dos Materiais, Artliber editora, São Paulo, Brasil, 2006. 
(Excelsensor, 2005) - www.excelsensor.com.br

(FEM.UNICAMP, 2005) - http://www.fem.unicamp.br/instmedCGI.htm

(Jennrich, 1995) - JENRICH, R. I. - “An Introduction to Computational Statistics - Regression Analysis” - Englewood Cliffs, NJ. Prentice Hall, 1995.

(Montenegro, 2007) - Montenegro, L. - Manutenção e Análise Vibratória, Centro de Capacitación e Investigacón em Vibraciones, segunda edição, La Plata, 2007.

(Montgomery, 2001) - MONTGOMERY, D. C - "Introduction to Statistical Quality Control”, New York : Wiley, Fourth Edition, p. 572-615, c 2001.

(Saglam e Unuvar, 2001) - Saglam, H., Unuvar, A. - THREECOMPONENT, STRAIN GAGE BASED MILLING DYNAMOMETER DESIGN AND MANUFACTURING - Journal of Integrated Design and Process Science, Vol. 5, No 2, pp 95-109, 2001.

(Sandvik, 2005) - Sandvik Coromant - Manual Técnico de Usinagem, Elanders, Suécia, 2005.

(Shaw, 2005) - Shaw, M. C. - Metal Cutting Principles - Oxford University Press, Inc., $2^{\text {nd }}$ ed., 2005. 
(Stemmer, 1989) - STEMMER, C. E. - Ferramentas de Corte, Editora da UFSC, Florianópolis, Brasil, 2001.

(Tenaris, 2007) - http://www.tenaris.com/TenarisConfab/pt

(Teses.USP, 2005) - http://www.teses.usp.br/tesesdisponiveis/33132_tde_ 23072003_135507publico09_Capitulo_3__Rugosidade 


\section{1 - ANEXOS}

\section{Anexo 1 - Memorial de Cálculo Células de Carga}

As células de carga foram dimensionadas de acordo com a metodologia descrita no Capítulo 4. Os dados de partida para o dimensionamento foram os seguintes:

- Tensão de fundo de escala: $2 \mathrm{mV} / \mathrm{V}$

- Força axial máxima: $3000 \mathrm{~N}$

O esquema de instrumentação dos strain gages de medição das forças axiais está mostrado na figura a seguir:

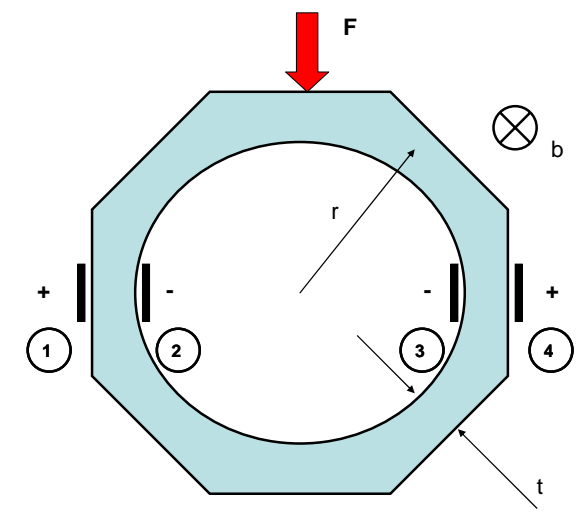

Figura 11.1.1 - Esquema Célula de Carga

Os sinais destes strain gages estão ligados em Ponte de Wheatstone, sendo que este esquema pode ser visto na figura abaixo:

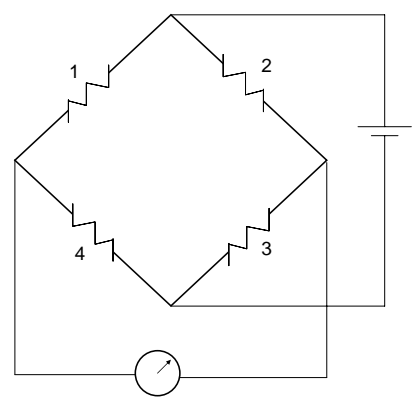

Figura 11.1.2 - Ligação em Ponte 
Assim, utilizando a equação da Ponte de Wheatstone, temos que:

$$
\frac{\Delta V}{V}=\frac{K}{4}\left[\varepsilon_{1}-\varepsilon_{2}+\varepsilon_{3}-\varepsilon_{4}\right]
$$

Assumindo que o $\mathrm{K}$ do strain gage utilizado é igual a 2 , e que $\Delta \mathrm{V} / \mathrm{V}$ é igual a 2 $\mathrm{mV} / \mathrm{V}$, temos que:

$$
2 \times 10^{-3}=\frac{2}{4} 4 \varepsilon \longrightarrow \varepsilon=1000 \times 10^{-6} \mu d \text { (micro-deformações) }
$$

Como pela equação 53 temos que:

$$
\varepsilon_{90^{\circ}}=1,09 \frac{F r}{E b t^{2}}
$$

E para o aço utilizado na fabricação das células de carga $\mathrm{E}=210 \mathrm{GPa}$, então:

$$
1000 \times 10^{-6}=1,09 \cdot \frac{3000 \cdot r}{210000 \cdot b \cdot t^{2}}
$$

Assim, foram selecionados valores que satisfizessem à equação acima, que com seus devidos arredondamentos, foram:

- $\quad$ Raio $(\mathrm{r})=40 \mathrm{~mm}$

- $\quad$ Largura $(b)=25 \mathrm{~mm}$

- $\quad$ Espessura $(\mathrm{t})=5 \mathrm{~mm}$ 


\section{Anexo 2 - Desenhos de Fabricação do Dinamômetro}

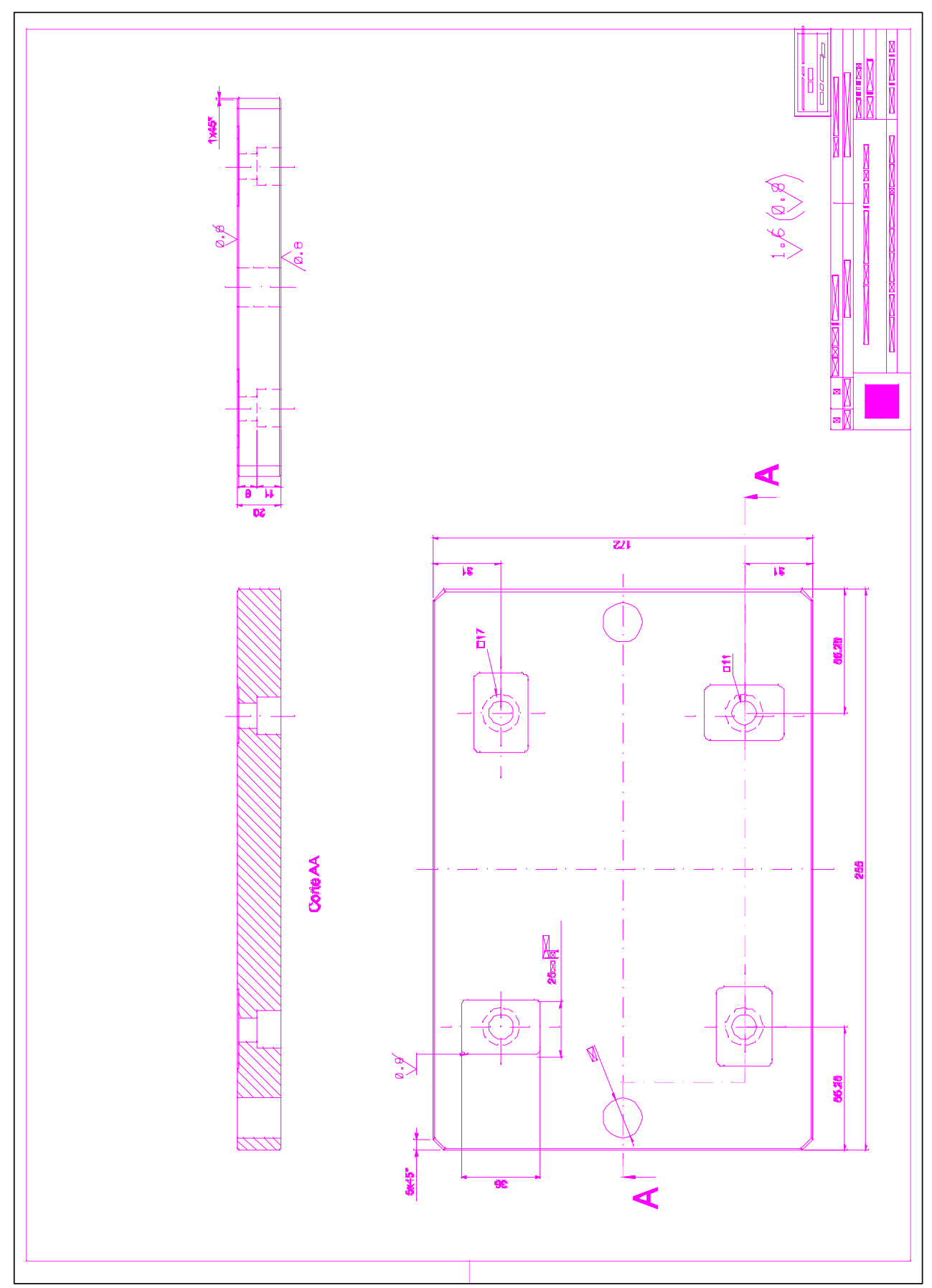

Figura 11.2.1 - Desenho de Fabricação da Base de Apoio 


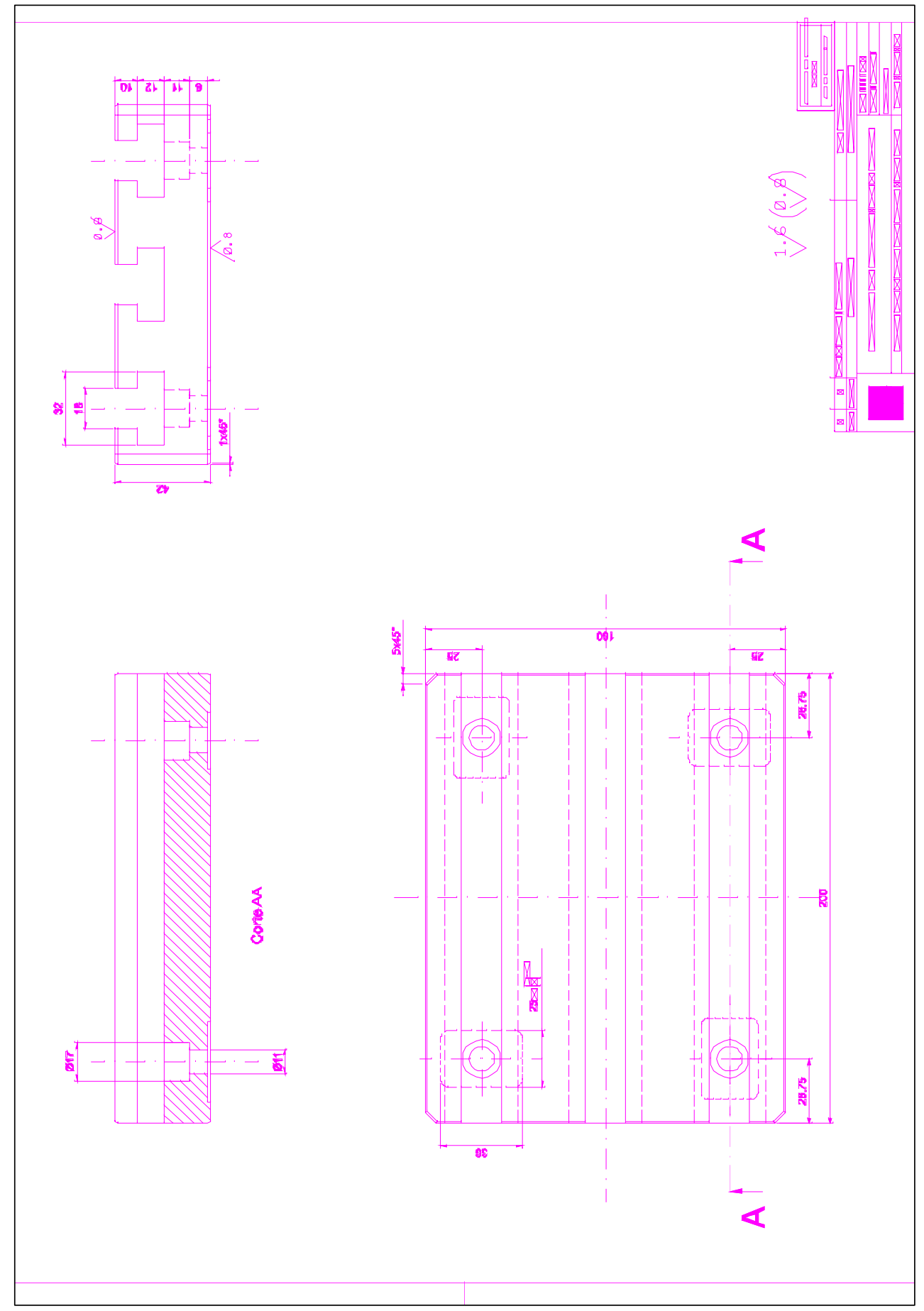

Figura 11.2.2 - Desenho de Fabricação da Mesa de Trabalho 


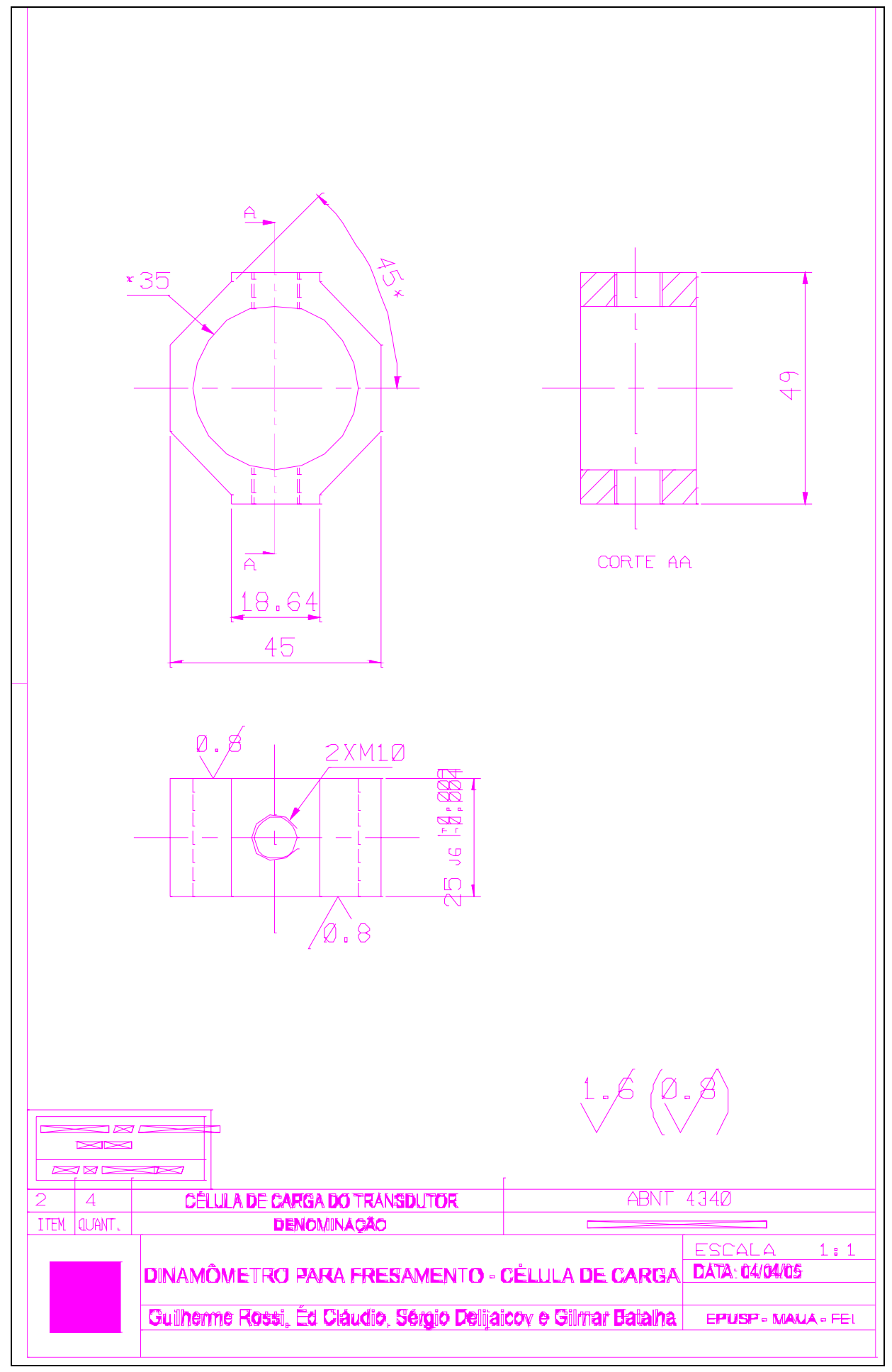

Figura 11.2.3 - Desenho de Fabricação das Células de Carga 